Supporting Information

\title{
Chemoenzymatic synthesis of sialyl sulfo-oligosaccharides as potent Siglec-8 ligands via the transglycosylation catalyzed by keratanase II
}

Shiori Yuge, Ayaka Tateishi, Keiji Numata, Masashi Ohmae*

Department of Material Chemistry, Graduate School of Engineering, Kyoto University, Kyoto 615-8510, Japan

\section{Experimental procedures and physical data for the new compounds}

\section{Materials and Methods}

Commercially available starting materials were used without further purification unless otherwise stated. Anhydrous solvents were purchased from Fujifilm Wako Pure Chemical Co. and stored under Ar before use. Sulfur trioxide trimethylamine complex $\left(\mathrm{SO}_{3} \cdot \mathrm{NMe}_{3}\right)$ was purchased from Merck. 2-chloro-1,3dimethyl-1H-benzimidazol-3-ium chloride (CDMBI) was purchased from Fushimi Pharmaceutical Co., Ltd. Molecular sieves 4A (MS4A) was powdered and activated over $100{ }^{\circ} \mathrm{C}$ under reduced pressure with $\mathrm{P}_{2} \mathrm{O}_{5}$ as desiccant before use. Silica gel column chromatography was carried out on Silica Gel 60, spherical, neutrality (Nacalai Tesque), or with a CombiFlash Rf 75 Var (Teledyne Isco) on RediSep Rf Gold Normal Phase Silica columns. The reactions were monitored by TLC (silica gel 60 F254, Merck) visualized by spraying a mixture of conc. $\mathrm{H}_{2} \mathrm{SO}_{4}(5 \mathrm{~mL})$ in $p$-anisaldehyde $(10 \mathrm{~mL})$ and $\mathrm{MeOH}(85 \mathrm{~mL})$ and heated at $140{ }^{\circ} \mathrm{C}$, or $0.7 \%$ ninhydrin in $\mathrm{EtOH}$ and heated at $140{ }^{\circ} \mathrm{C}$. Optical rotations were measured with a P-1010 polarimeter (Jasco). ${ }^{1} \mathrm{H}$ and ${ }^{13} \mathrm{C}$ NMR were recorded on a DPX-400 spectrometer equipped with a $5 \mathrm{~mm}$ QNP probe (Bruker). The NMR samples were dissolved in appropriate deuterated solvents $\left(\mathrm{CDCl}_{3}\right.$, $\mathrm{CD}_{3} \mathrm{OD}$, or $\mathrm{D}_{2} \mathrm{O}$ ) and measured in a standard $5 \mathrm{~mm}$ diameter borosilicate tube in about 5 (for ${ }^{1} \mathrm{H}$ ) to 30

$\mathrm{mg} \cdot \mathrm{mL}^{-1}$ (for $\mathrm{C}-\mathrm{H} \mathrm{COSY}$ ) concentration. Assignments were based on homo- and heteronuclear 
correlation measurements, and DEPT measurements. High resolution ESI mass spectrometry (HRMS) was carried out with the Exactive Plus spectrometer (Thermo Fisher Scientific). The QCM measurements were carried out on the AFFINIX Q4 analyzer (Initium) by using the sensors immobilizing Siglec-8 Fc chimera.

\section{Synthesis}

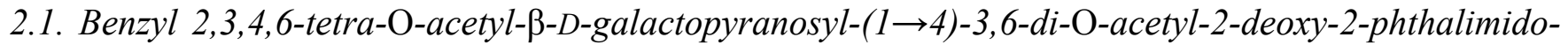
$\beta$-D-glucopyranoside (11).

Synthesis of compound $\mathbf{1 1}$ has already been reported; ${ }^{[1]}$ however, the method was slightly different. Thus, the procedures for the synthesis of $\mathbf{1 1}$ in this study are described briefly. $\mathrm{BnOH}(0.53 \mathrm{~mL}, 5.0 \mathrm{mmol})$ and MS4A (0.8 g) were added to a solution of $\mathbf{1 0}(2.2 \mathrm{~g}, 2.5 \mathrm{mmol})$ in dry $\mathrm{CH}_{2} \mathrm{Cl}_{2}(8.0 \mathrm{~mL})$. The mixture was stirred at $-20^{\circ} \mathrm{C}$ under Ar for $1 \mathrm{~h}$, followed by the addition of TMSOTf (92 $\left.\mu \mathrm{L}, 0.50 \mathrm{mmol}\right)$ in $\operatorname{dry} \mathrm{CH}_{2} \mathrm{Cl}_{2}$ $(1.0 \mathrm{~mL})$. After completion of the reaction, $\mathrm{Et}_{3} \mathrm{~N}(1.0 \mathrm{~mL}, 7.2 \mathrm{mmol})$ was added to the mixture, followed by stirring at $-20{ }^{\circ} \mathrm{C}$ for $15 \mathrm{~min}$. The mixture was filtered through a bed of diatomaceous earth (Celite ${ }^{\circledR}$ No. 545), diluted in $\mathrm{CHCl}_{3}$, washed successively with satd. aq. $\mathrm{NaHCO}_{3}$ and brine. The organic layer was dried over $\mathrm{MgSO}_{4}$, filtered through filter paper, and concentrated under reduced pressure. The residue was subjected to silica gel column chromatography ( $n$-hexane/EtOAc 1:0 to $0: 1, \mathrm{v} / \mathrm{v}$, linear gradient, CombiFlash Rf75 Var), providing 11 (1.7 g, 2.1 mmol, 81\%). Physical data of $11\left[{ }^{1} \mathrm{H}\right.$ and H-H COSY NMR spectra, and HRMS (ESI)] was consistent with that reported previously. ${ }^{[1]}$

\subsection{Benzyl 2,3,4,6-tetra-O-acetyl- $\beta$-D-galactopyranosyl-(1 $\rightarrow 4)$-2-acetamido-3,6-di-O-acetyl-2-deoxy- $\beta$ -} D-glucopyranoside (12).

Compound 12 synthesized previously by us was prepared again from 11. Briefly, ethylenediamine (10 $\mathrm{mL}, 150 \mathrm{mmol})$ was added to a solution of $11(1.1 \mathrm{~g}, 1.3 \mathrm{mmol})$ in EtOH $(100 \mathrm{~mL})$, followed by stirring 
under reflux conditions for $21 \mathrm{~h}$. After completion of the reaction, the mixture was concentrated under diminished pressure. $\mathrm{Ac}_{2} \mathrm{O}(40 \mathrm{~mL}, 420 \mathrm{mmol})$ was added to the residue dissolved in dry pyridine (100 $\mathrm{mL}$ ) with catalytic amounts of 4-dimethylaminopyridine (DMAP; $15 \mathrm{mg}, 0.12 \mathrm{mmol}$ ), followed by stirring at $\mathrm{rt}$ under dry atmosphere for $24 \mathrm{~h}$. The mixture was concentrated, dissolved in $\mathrm{CHCl}_{3}$, washed successively with $4 \%$ aq. $\mathrm{KHSO}_{4}$, satd. aq. $\mathrm{NaHCO}_{3}$ and brine. The organic layer was dried over $\mathrm{MgSO}_{4}$, filtered through filter paper, and concentrated under reduced pressure. The residue was subjected to silica gel column chromatography ( $n$-hexane/EtOAc 1:0 to 0:1, v/v, linear gradient, Rf75 system) to give pure 12 (740 mg, $1.0 \mathrm{mmol}, 78 \%)$ as a white solid. Physical data of $12\left[{ }^{1} \mathrm{H}\right.$ and H-H COSY NMR spectra, and HRMS (ESI)] was consistent with that confirmed by us previously. ${ }^{[2]}$

\subsection{Benzyl 2,3-di-O-acetyl-4,6-O-(4-mthoxybenzylidene)- $\beta$-D-galactopyranosyl-(1 $\rightarrow 4)$-2-acetamido-3-} O-acetyl-6-O-tert-butyldimethylsilyl-2-deoxy- $\beta$-D-glucopyranoside (13).

All $O$-acetyl groups in $12(680 \mathrm{mg}, 0.94 \mathrm{mmol})$ were removed by $\mathrm{MeONa}$ in $\mathrm{MeOH}$. A white precipitate formed was collected by filtration through filter paper, washed three times with $\mathrm{MeOH}(2.0 \mathrm{~mL})$, and dried under diminished pressure overnight. The filtrate was neutralized by Dowex $50 \mathrm{~W}-\mathrm{X} 8\left(\mathrm{H}^{+}\right.$form $)$, filtered through cotton, and concentrated to dryness. A white solid formed (460 mg, $0.98 \mathrm{mmol})$ was combined with the precipitate $(300 \mathrm{mg}, 0.62 \mathrm{mmol})$, and dissolved in dry DMF $(4.0 \mathrm{~mL})$, followed by the addition of $p$-anisaldehyde dimethylacetal $(280 \mu \mathrm{L}, 1.6 \mathrm{mmol}) .( \pm)$-10-Camphorsulfonic acid (100 mg, $0.44 \mathrm{mmol}$ ) was added to a solution of the mixture to acidify the reaction system, followed by stirring at $50{ }^{\circ} \mathrm{C}$ under Ar. $p$-Anisaldehyde dimethyl acetal $(210 \mu \mathrm{L}, 1.2 \mathrm{mmol})$ was further added starting after 23 , 46, $69 \mathrm{~h}$ until the reaction was completed. After $73 \mathrm{~h}, \mathrm{Et}_{3} \mathrm{~N}(260 \mu \mathrm{L}, 1.8 \mathrm{mmol})$ was added to the reaction mixture at $0{ }^{\circ} \mathrm{C}$ for neutralization. The mixture was concentrated under reduced pressure and diluted with pyridine (1.5 mL). tert-Butyldimethylchlorosilane (TBDMS-Cl; $140 \mathrm{mg}, 0.93 \mathrm{mmol}$ ) was added to the mixture at $\mathrm{rt}$ under dry atm. After completion of the reaction $(23 \mathrm{~h}), \mathrm{Ac}_{2} \mathrm{O}(710 \mu \mathrm{L}, 7.5 \mathrm{mmol})$ was added 
to the reaction mixture. After stirring overnight, $\mathrm{MeOH}(2.0 \mathrm{~mL})$ was added to the mixture to quench excess reagents, followed by concentration under reduced pressure. The residue was dissolved in $\mathrm{CHCl}_{3}$, washed successively with satd. aq. $\mathrm{NaHCO}_{3}$ and brine. The organic layer was dried over $\mathrm{MgSO}_{4}$, filtered through filter paper, and concentrated in vacuo. The residue was subjected to silica gel column chromatography $\left(\mathrm{CHCl}_{3} / \mathrm{EtOAc} 1: 0\right.$ to $0: 1, \mathrm{v} / \mathrm{v}$, containing $0.5 \% \mathrm{Et}_{3} \mathrm{~N}$, linear gradient, $\mathrm{Rf} 75$ system) to obtain 13 (290 mg, $0.35 \mathrm{~mol}, 57 \%$, 4 steps) as amorphous. $[\alpha]_{\mathrm{D}}^{23}-36.8\left(c \quad 0.5, \mathrm{CHCl}_{3}\right) ; R_{\mathrm{f}} 0.61$ $\left(\mathrm{CHCl}_{3} / \mathrm{EtOAc} \mathrm{1:2);}{ }^{1} \mathrm{H} \mathrm{NMR}\left(400 \mathrm{MHz}, \mathrm{CDCl}_{3}, \mathrm{TMS}\right): \delta\right.$ (ppm) 7.37-6.89 (m, 9H, aromatic), 5.46-5.43 $\left(\mathrm{d}, J_{2, \mathrm{NH}}=9.6 \mathrm{~Hz}, 1 \mathrm{H}, \mathrm{NH}\right), 5,42\left(\mathrm{~s}, 1 \mathrm{H}, \mathrm{CH}\right.$ of $p$-methoxybenzylidene), 5.24 (dd, $J_{1^{\prime}, 2^{\prime}}=8.0 \mathrm{~Hz}, J_{2^{\prime}, 3^{\prime}}=10.4$ $\left.\mathrm{Hz}, 1 \mathrm{H}, \mathrm{H}-2^{\prime}\right), 4.95\left(\mathrm{dd}, J_{2,3}=10.0 \mathrm{~Hz}, J_{3.4}=9.1 \mathrm{~Hz}, 1 \mathrm{H}, \mathrm{H}-3\right), 4.86-3.83\left(\mathrm{~m}, 2 \mathrm{H}, \mathrm{H}-3^{\prime}, \mathrm{CH}_{2} \mathrm{Ph}\right), 4.65$ (d, $\left.J_{1^{\prime}, 2^{\prime}}=8.0 \mathrm{~Hz}, 1 \mathrm{H}, \mathrm{H}_{-1}^{\prime}\right), 4.57\left(\mathrm{~d}, J=12.4 \mathrm{~Hz}, 1 \mathrm{H}, \mathrm{CH}_{2} \mathrm{Ph}\right), 4.36\left(\mathrm{~d}, J_{1,2}=8.0 \mathrm{~Hz}, 1 \mathrm{H}, \mathrm{H}-1\right), 4.32-4.28(\mathrm{~m}, 2 \mathrm{H}$, H-4', H-6'a), $4.13(\mathrm{~m}, 1 \mathrm{H}, \mathrm{H}-2), 4.02\left(\mathrm{dd}, J_{5^{\prime}, 6^{\prime} \mathrm{b}}=1.5 \mathrm{~Hz}, J_{6^{\prime} \mathrm{a}, 6^{\prime} \mathrm{b}}=12.7 \mathrm{~Hz}, 1 \mathrm{H}, \mathrm{H}-6^{\prime} \mathrm{b}\right), 3.94-3.83$ (m, 3H, H-4, H-6a, H-6b), 3.81 (s, 3H, OMe), 3.40 (s, 1H, H-5'), 3.31 (m, 1H, H-5), 2.06-1.93 (m, 12H, 4×CH $3 \mathrm{CO}$ ), $0.93\left(\mathrm{~s}, 9 \mathrm{H}, \mathrm{C}\left(\mathrm{CH}_{3}\right)_{3}\right.$ of TBDMS), $0,11\left(\mathrm{~s}, 6 \mathrm{H}, 2 \times \mathrm{CH}_{3}\right.$ of TBDMS); ${ }^{13} \mathrm{C} \mathrm{NMR}\left(100 \mathrm{MHz}, \mathrm{CDCl}_{3}\right): \delta$ 171.58, 170.69, 170.09, $168.83(\mathrm{C}=\mathrm{O}), 160.12,137.33,130.07,128.29,127,79,127.68,113.52$ (aromatic), 101.09 (CH of 4-methoxybenzylidene), 100.35 (C1'), 99.83 (C1), 75.55 (C5), 74.20 (C4), 73.13 (C4'), $72.55(\mathrm{C} 3), 72.16\left(\mathrm{C}^{\prime}\right), 69.79\left(\mathrm{CH}_{2} \mathrm{Ph}\right), 69.05\left(\mathrm{C}^{\prime}\right), 68.52\left(\mathrm{C6}^{\prime}\right), 66.19\left(\mathrm{C}^{\prime}\right), 61.10(\mathrm{C} 6), 55.22(\mathrm{OMe})$

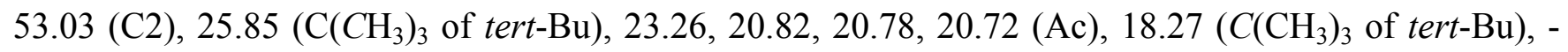
5.04, -5.36 $\left(2 \times \mathrm{CH}_{3}\right.$ of TBDMS); HRMS (ESI) calcd for $\mathrm{C}_{41} \mathrm{H}_{57} \mathrm{NO}_{15} \mathrm{SiNa}[\mathrm{M}+\mathrm{Na}]^{+} 854.3395$, found 854.3379.

2.4. Benzyl 2,3-di-O-acetyl- $\beta$-D-galactopyranosyl-(1 $\rightarrow 4)$-2-acetamido-3-O-acetyl-2-deoxy- $\beta$ - $D$ glucopyranoside (14).

$n$-Bu ${ }_{4} \mathrm{NF}$ in THF $\left(c a .1 \mathrm{~mol} \cdot \mathrm{L}^{-1}\right.$ solution, $\left.690 \mu \mathrm{L}\right)$ and $\mathrm{AcOH}(39 \mu \mathrm{L})$ was added to a solution of $13(290$ $\mathrm{mg}, 0.34 \mathrm{mmol})$ in THF $(10 \mathrm{~mL})$ at $\mathrm{rt}$ under Ar. After starting the reaction, $n-\mathrm{Bu}_{4} \mathrm{NF}$ in $\mathrm{THF}\left(c a .1 \mathrm{~mol} \cdot \mathrm{L}^{-1}\right.$ 
solution, $340 \mu \mathrm{L})$ and $\mathrm{AcOH}(20 \mu \mathrm{L})$ were further added after 4 and $27 \mathrm{~h}$ until the reaction was completed (46 h). The mixture was concentrated under diminished pressure, and subjected to silica gel column chromatography $\left(\mathrm{CHCl}_{3} /\right.$ EtOAc 1:0 to $0: 1, \mathrm{v} / \mathrm{v}$, containing $0.5 \% \mathrm{Et}_{3} \mathrm{~N}$, linear gradient, $\mathrm{Rf} 75$ system $)$. The fractions containing the product were collected, combined and concentrated. The residue was dissolved in $80 \%$ aq. $\mathrm{AcOH}(4.0 \mathrm{~mL})$, followed by stirring at $50{ }^{\circ} \mathrm{C}$ for $2 \mathrm{~h}$. The mixture was concentrated in vacuo, and the residue was subjected to silica gel column chromatography $\left(\mathrm{CHCl}_{3} / \mathrm{MeOH}\right.$ 1:0 to 10:1, v/v, linear gradient, Rf75 system) to obtain $14(110 \mathrm{mg}, 0.18 \mathrm{~mol}, 50 \%, 2$ steps $)$ as white amorphous. $[\alpha]_{\mathrm{D}}^{23}-351.2$ $\left(c\right.$ 0.5, $\left.\mathrm{CHCl}_{3}\right) ; R_{\mathrm{f}} 0.19\left(\mathrm{CHCl}_{3} / \mathrm{MeOH} 10: 1\right) ;{ }^{1} \mathrm{H} \mathrm{NMR}\left(400 \mathrm{MHz}, \mathrm{MeOH}-d_{4}\right): \delta(\mathrm{ppm})$ 7.34-7.29 $(\mathrm{m}, 5 \mathrm{H}$, aromatic), 5.28-5.16 (dd $\left.J_{1^{\prime}, 2^{\prime}}=8.0 \mathrm{~Hz}, J_{2^{\prime}, 3^{\prime}}=10.4 \mathrm{~Hz}, 1 \mathrm{H}, \mathrm{H}-2^{\prime}\right), 5.12-5.07\left(\mathrm{dd}, J_{2,3}=10.4 \mathrm{~Hz}, J_{3.4}=9.2 \mathrm{~Hz}\right.$, 1H, H-3), 4.92-4.90 (m, 2H, H-3', $\left.\mathrm{CH}_{2} \mathrm{Ph}\right), 4.68$ (d, $\left.J_{1^{\prime}, 2^{\prime}}=8.0 \mathrm{~Hz}, 1 \mathrm{H}, \mathrm{H}-1^{\prime}\right), 4.64-4.61$ (m, 2H, H-1, $\left.\mathrm{CH}_{2} \mathrm{Ph}\right)$, $4.10\left(\mathrm{~d}, J_{3^{\prime}, 4^{\prime}}=2.8 \mathrm{~Hz}, 1 \mathrm{H}, \mathrm{H}-4^{\prime}\right), 3.97-3.89$ (m, 3H, H-2, H-4, H-6a), 3.83-3.72 (m, 3H, H-6b, H-6'a, H6'b), $3.63\left(\mathrm{~m}, 1 \mathrm{H}, \mathrm{H}-5^{\prime}\right), 3.44-3.41(\mathrm{~m}, 1 \mathrm{H}, \mathrm{H}-5), 2.09-1.91\left(\mathrm{~m}, 12 \mathrm{H}, 4 \times \mathrm{CH}_{3} \mathrm{CO}\right) ;{ }^{13} \mathrm{C} \mathrm{NMR}(100 \mathrm{MHz}$ $\left.\mathrm{CDCl}_{3}\right): \delta(\mathrm{ppm}) 173.40,172.52,171.95,171.33(C=\mathrm{O}), 138.91,129.35,128.78,128.75$ (aromatic), 102.28 (C1'), 101.35 (C1), 76.89 (C5), 76.82 (C4), 76.25 (C5'), 75.45 (C3'), 74.80 (C3), $71.82\left(\mathrm{CH}_{2} \mathrm{Ph}\right), 71.26$ (C2'), $67.47\left(\mathrm{C} 4^{\prime}\right), 61.54\left(\mathrm{C}^{\prime}\right), 61.16$ (C6), 55.43 (C2), 22.75, 21.18, 20.85, 20.75 (Ac); HRMS (ESI) calcd for $\mathrm{C}_{27} \mathrm{H}_{37} \mathrm{NO}_{14} \mathrm{Na}[\mathrm{M}+\mathrm{Na}]^{+}$622.2112, found 622.2113 .

\subsection{Di-sodium 6-O-sulfonato- $\beta$-D-galactopyranosyl-(1 $\rightarrow 4)$-2-acetamido-2-deoxy-6-O-sulfonato-D-} glucopyranose (8).

Compound 14 (97 mg, $0.16 \mathrm{mmol})$ was dissolved in dry DMF $(3.0 \mathrm{~mL})$ and stirred at $0{ }^{\circ} \mathrm{C}$ under Ar. Sulfur trioxide trimethylamine complex $\left(\mathrm{SO}_{3} \cdot \mathrm{NMe}_{3} ; 90 \mathrm{mg}, 0.65 \mathrm{mmol}\right)$ was added to the mixture at $0{ }^{\circ} \mathrm{C}$ under $\mathrm{Ar}$ and stirred at $50{ }^{\circ} \mathrm{C}$ under $\mathrm{Ar} . \mathrm{SO}_{3} \cdot \mathrm{NMe}_{3}(45 \mathrm{mg}, 0.32 \mathrm{mmol})$ was further added to a solution of the mixture starting after 24 and $48 \mathrm{~h}$ until the reaction was completed. After $51 \mathrm{~h}, \mathrm{MeOH}(1.5 \mathrm{~mL})$ were added to the reaction mixture at $0{ }^{\circ} \mathrm{C}$ to quench excess reagents. The mixture was concentrated in vacuo, 
and the residue was subjected to silica gel column chromatography $\left(\mathrm{CHCl}_{3} / \mathrm{MeOH}\right.$ 1:0: to 10:1, v/v, containing $0.5 \% \mathrm{Et}_{3} \mathrm{~N}$, linear gradient, $\mathrm{Rf} 75$ system $) . \mathrm{Ac}_{2} \mathrm{O}(200 \mu \mathrm{L}, 2.1 \mathrm{mmol})$ was added to the residue dissolved in dry pyridine $(2.0 \mathrm{~mL})$, followed by stirring at $\mathrm{rt}$ under dry atmosphere for $20 \mathrm{~h}$. The mixture was concentrated in vacuo, and the residue was subjected to silica gel column chromatography $\left(\mathrm{CHCl}_{3} / \mathrm{MeOH}\right.$ 1:0: to 10:1, v/v, containing $0.5 \% \mathrm{Et}_{3} \mathrm{~N}$, linear gradient, $\mathrm{Rf} 75$ system) to obtain benzyl (triethylammonium 2,3,4-tri- $O$-acetyl-6- $O$-sulfo- $\beta$-D-galactopyranosyl)-(1 $\rightarrow 4$ )-(triethylammonium $\quad 2$ acetamido-3- $O$-acetyl-2-deoxy-6- $O$-sulfo- $\beta$-D-glucopyranoside) (99 mg, 0.099 mmol, 61\%, 2 steps) as amorphous. This compound (99 $\mathrm{mg}, 0.099 \mathrm{mmol})$ was hydrogenated by $20 \% \mathrm{Pd}(\mathrm{OH})_{2}-\mathrm{C}(45 \mathrm{mg})$ under $\mathrm{H}_{2}$ atmosphere in $\mathrm{MeOH}(5.0 \mathrm{~mL})$ at $\mathrm{rt}$ for $2 \mathrm{~h}$. After filtration by filter paper, $1.0 \mathrm{~mol} \cdot \mathrm{L}^{-1} \mathrm{aq} \mathrm{NaOH}(1.5$ $\mathrm{mL}$ ) was added to the mixture, followed by stirring under dry atm. at $0{ }^{\circ} \mathrm{C}$ for $3 \mathrm{~h}$. The reaction mixture was concentrated until the volume was $1 / 3$ under diminished pressure. The residue was subjected to BioGel P2 column chromatography eluting with distilled water to obtain pure 8 (55 mg, $0.094 \mathrm{mmol}$, $95 \%, 2$ steps) as amorphous. HRMS (ESI) calcd for $\mathrm{C}_{14} \mathrm{H}_{23} \mathrm{NO}_{17} \mathrm{~S}_{2}{ }^{2-} 270.5209$, found 270.5209 .

2.6. Tri-sodium (5-acetamido-3,5-dideoxy-D-glycero- $\alpha$-D-galacto-non-2-uropyranosyl)onate-(2 $\rightarrow 3)-6-$

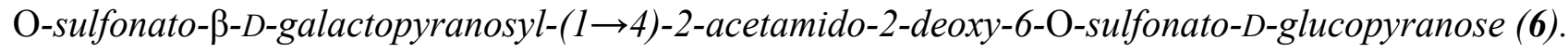
Compounds $7(11 \mathrm{mg}, 18.6 \mu \mathrm{mol})$ and $8(20 \mathrm{mg}, 31.4 \mu \mathrm{mol})$ were dissolved in Tris-HCl buffer $(500 \mu \mathrm{L}$, $\left.100 \mathrm{mmol} \cdot \mathrm{L}^{-1}, \mathrm{pH} 8.5\right)$ containing $\mathrm{MgCl}_{2}\left(20 \mathrm{mmol} \cdot \mathrm{L}^{-1}\right)$. PmST1 (83 $\left.\mathrm{mU}\right)$ and alkaline phosphatase from calf intestine $(9 \mathrm{U})$ were added to the mixture, and incubated at $37^{\circ} \mathrm{C}$ for $19 \mathrm{~h}$. The reaction mixture was heated at $90^{\circ} \mathrm{C}$ for $5 \mathrm{~min}$, then centrifuged to remove insoluble precipitates, and the supernatant was subjected to BioGel P-4 size exclusion chromatography eluting with distilled water. The product fractions were collected and combined, followed by lyophilization to give 6 (3.9 mg, $4.33 \mathrm{mmol}, 23 \%$ ). HRMS (ESI) calcd for $\mathrm{C}_{25} \mathrm{H}_{39} \mathrm{~N}_{2} \mathrm{O}_{25} \mathrm{~S}_{2}{ }^{3-} 277.0433$, found 277.0429 . 


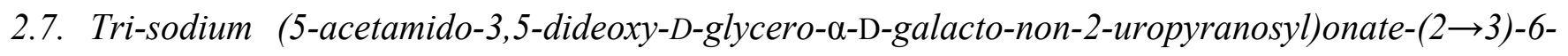
O-sulfonato- $\beta$-D-galactopyranosyl-(1 $\rightarrow 4)$-[2-methyl-4,5-dihydro-6-O-sulfonato- $\alpha$-D-glucopyranoso][2,1-d]-1,3-oxazole (3).

Compound $6(14 \mathrm{mg}, 15.5 \mu \mathrm{mol})$ and $\mathrm{K}_{3} \mathrm{PO}_{4}(66 \mathrm{mg}, 156 \mu \mathrm{mol})$ were dissolved in $\mathrm{D}_{2} \mathrm{O}(310 \mu \mathrm{L})$, and the mixture was cooled to $0{ }^{\circ} \mathrm{C}$. CDMBI $(34 \mathrm{mg}, 151 \mu \mathrm{mol})$ in $\mathrm{D}_{2} \mathrm{O}(155 \mu \mathrm{L})$ was added to the solution, and kept standing at $0{ }^{\circ} \mathrm{C}$ for $6 \mathrm{~h}$. The reaction mixture was centrifuged to remove insoluble precipitates, and the supernatant was subjected to $\mathrm{C} 18$ reversed-phase column chromatography $\left(\mathrm{H}_{2} \mathrm{O} / \mathrm{MeOH}\right.$ 1:0 to $0: 1$, $\mathrm{v} / \mathrm{v}$, containing $0.5 \% \mathrm{Et}_{3} \mathrm{~N}$, linear gradient, Rf75 system). The product fractions were collected and combined, followed by lyophilization. The mixture of $\mathbf{3}, \mathbf{6}$ and $\mathrm{K}_{3} \mathrm{PO}_{4}$ (showing the $\mathrm{pH}$ value near 10 in distilled water) was obtained (61 mg as the total weight). The purity of 3 was $48 \%$, which was calculated by measuring the integration of $\mathrm{H}-1$ of the oxazoline donor and of the total $\mathrm{CH}_{3}$ of the acetamido groups on the ${ }^{1} \mathrm{H}$ NMR spectrum. The mixture containing $\mathbf{3}$ was used for the enzymatic transglycosylation without further purification in order to avoid decomposition of the activated oxazoline donor $\mathbf{3}$.

${ }^{1} \mathrm{H}$ NMR (400 MHz, $\left.\mathrm{D}_{2} \mathrm{O}\right): \delta(\mathrm{ppm}) 6.05(\mathrm{~d}, 0.62 \mathrm{H}, J=6.8 \mathrm{~Hz}, \mathrm{H}-1), 4.53(\mathrm{~d}, 1 \mathrm{H}), 4,46(\mathrm{~s}, 1 \mathrm{H}), 4.25-$ $4.06(\mathrm{~m}, 5 \mathrm{H}), 3.97-3.79(\mathrm{~m}, 7 \mathrm{H}), 3.62-3,45(\mathrm{~m}, 7 \mathrm{H}), 2.72-2.67$ (m, 1H, H-3"-eq), 2.03, 1.99 (ss, 6H, $\mathrm{CH}_{3}$ of oxazoline ring, NHAc), 1.77 (t, $1 \mathrm{H}, J=12.0 \mathrm{~Hz}, \mathrm{H}-3$ "-ax). HRMS (ESI) calcd for $\mathrm{C}_{25} \mathrm{H}_{37} \mathrm{KN}_{2} \mathrm{O}_{24} \mathrm{~S}_{2}{ }^{2-}$ $[\mathrm{M}+\mathrm{K}]^{2-}$ 426.0407, found 426.0407, calcd for $\mathrm{C}_{25} \mathrm{H}_{37} \mathrm{~K}_{2} \mathrm{~N}_{2} \mathrm{O}_{24} \mathrm{~S}_{2}{ }^{-}[\mathrm{M}+2 \mathrm{~K}]^{-}$891.0452, found 891.0460.

\subsection{1-Azido-3,6,9-trioxaundecanyl 2,3,4,6-tetra-O-acetyl- $\beta$-D-galactopyranosyl-(1 $\rightarrow 4)$-3,6-di-O-acetyl-} 2-deoxy-2-phthalimido- $\beta$-D-glucopyranoside (15).

Compound 10 (1.00 g, $1.15 \mathrm{mmol})$ and 1-azido-3,6,9-trioxaundecane-11-ol (210 mg, $0.96 \mathrm{mmol})$ were dissolved in anhydrous $\mathrm{CH}_{2} \mathrm{Cl}_{2}(10 \mathrm{~mL})$, and then activated MS4A $(1.00 \mathrm{~g})$ was added to the mixture. The mixture was stirred at $-20^{\circ} \mathrm{C}$ for $0.5 \mathrm{~h}$ under $\mathrm{Ar}$ atmosphere, followed by addition of TMSOTf $(19 \mu \mathrm{L}$, $0.096 \mathrm{mmol})$. The mixture was stirred at $-20{ }^{\circ} \mathrm{C}$ for $1 \mathrm{~h}$ under $\mathrm{Ar}$ atmosphere. And then triethylamine 
$(100 \mu \mathrm{L}, 0.72 \mathrm{mmol})$ was added to the reaction mixture, followed by stirring at $-20{ }^{\circ} \mathrm{C}$ for 15 min under Ar atmosphere. The mixture was filtered through filter paper, and the filtrate was concentrated under diminished pressure. The residue was immediately subjected to silica gel column chromatography $(n-$ hexane-EtOAc, linear gradient from 0 to $100 \%$ of EtOAc) to give pure $\mathbf{1 5}(0.798 \mathrm{~g}, 0.863 \mathrm{mmol}, 90 \%)$ as amorphous.

$[\alpha]_{\mathrm{D}}^{23}+10.1\left(c\right.$ 1.0, $\left.\mathrm{CHCl}_{3}\right) ; R_{\mathrm{f}} 0.36$ (n-hexan:EtOAc 1:3); ${ }^{1} \mathrm{H}$ NMR $\left(\mathrm{CDCl}_{3}, 400 \mathrm{MHz}, \mathrm{TMS}\right): \delta(\mathrm{ppm})$ $7.90-7.70\left(\mathrm{~m}, 4 \mathrm{H}\right.$, aromatic), $5.76\left(\mathrm{dd}, 1 \mathrm{H}, J_{2,3}=10.8 \mathrm{~Hz}, J_{3,4}=8.5 \mathrm{~Hz}, \mathrm{H}-3\right), 5.42\left(\mathrm{~d}, 1 \mathrm{H}, J_{1,2}=8.4 \mathrm{~Hz}\right.$, $\mathrm{H}-1), 5.34\left(\mathrm{bd}, 1 \mathrm{H}, J_{3^{\prime} 4^{\prime}}=2.8 \mathrm{~Hz}, \mathrm{H}-4^{\prime}\right), 5.13\left(\mathrm{dd}, 1 \mathrm{H}, J_{1^{\prime}, 2^{\prime}}=8.0 \mathrm{~Hz}, J_{2^{\prime}, 3^{\prime}}=10.4 \mathrm{~Hz}, \mathrm{H}-2^{\prime}\right), 4.96(\mathrm{dd}, 1 \mathrm{H}$, $\left.J_{2^{\prime}, 3^{\prime}}=10.4 \mathrm{~Hz}, J_{3^{\prime}, 4^{\prime}}=3.4 \mathrm{~Hz}\right), 4.55\left(\mathrm{~d}, 1 \mathrm{H}, J_{1^{\prime}, 2^{\prime}}=8.0 \mathrm{~Hz}, \mathrm{H}-1^{\prime}\right), 4.53\left(\mathrm{dd}, 1 \mathrm{H}, J_{5,6 \mathrm{~b}}=1.8 \mathrm{~Hz}, J_{6 \mathrm{a}, 6 \mathrm{~b}}=12.0\right.$ Hz, H-6b), $4.20\left(\mathrm{dd}, 1 \mathrm{H}, J_{1,2}=8.4 \mathrm{~Hz}, J_{2,3}=10.8 \mathrm{~Hz}, \mathrm{H}-2\right), 4.15\left(\mathrm{dd}, 1 \mathrm{H}, J_{5,6 \mathrm{a}}=5.0 \mathrm{~Hz}, J_{6 \mathrm{a}, 6 \mathrm{~b}}=12.0 \mathrm{~Hz}\right.$, H-6a), 4.12-4.00 (m, 2H, H-6'a, H-6'b), 3.90-3.85 (m, 3H, H-4, H-5', PEG), 3.82-3.78 (m, 1H, H-5), 3.74-3.34 (m, 15H, PEG), 2.15, 2.14, 2.07, 2.04, 1.97, $1.91(3 \mathrm{H} \times 6, \mathrm{~s} \times 6, \mathrm{Ac} \times 6) ;{ }^{13} \mathrm{C} \mathrm{NMR}\left(\mathrm{CDCl}_{3}, 100\right.$ MHz): $\delta(\mathrm{ppm}) 170.47,170.36,170.19,170.11,169.78,169.14$ ( $C=\mathrm{O}$ of $\mathrm{Ac}), 134.62$ ( $C=\mathrm{O}$ of phthaloyl), 123.87 (aromatic), $101.44\left(\mathrm{C} 1^{\prime}\right), 98.35$ (C1), 77.37 (C4), 72.91 (C5), $71.54(\mathrm{C} 3), 71.34\left(\mathrm{C}^{\prime}\right), 70.94\left(\mathrm{C5}^{\prime}\right)$, 70.88, 70.79, 70.78, 70.37, 70.27, 69.46 (CH2 of PEG), $69.44\left(\mathrm{C}^{\prime}\right.$ ) $, 66.90\left(\mathrm{C}^{\prime}{ }^{\prime}\right), 62.56(\mathrm{C} 6), 62.10\left(\mathrm{C}^{\prime}\right)$ 55.27 (C2) $51.01\left(\mathrm{CH}_{2}\right.$ of PEG), 21.30, 21.01, 21.00×2, 20.95, $20.89\left(\mathrm{CH}_{3}\right.$ of Ac) ; HRMS (ESI) $m / z$ : $\left[\mathrm{M}+\mathrm{NH}_{4}\right]^{+}$calcd for $\mathrm{C}_{40} \mathrm{H}_{56} \mathrm{~N}_{5} \mathrm{O}_{21}, 942.3462$; found, 942.3445; $[\mathrm{M}+\mathrm{Na}]^{+}$calcd for $\mathrm{C}_{40} \mathrm{H}_{52} \mathrm{~N}_{4} \mathrm{O}_{21} \mathrm{Na}$, 947.3016; found, 947.2997.

2.9. 1-Azido-3,6,9-trioxaundecanyl 2,3,4,6-tetra-O-acetyl- $\beta$-D-galactopyranosyl-(1 $\rightarrow 4)$-2-acetamido3,6-di-O-acetyl-2-deoxy- $\beta$-D-glucopyranoside (16).

Compound 15 (2.34 g, $2.53 \mathrm{mmol})$ was dissolved in anhydrous $\mathrm{MeOH}(30 \mathrm{~mL}) . \mathrm{MeONa}(\mathrm{ca} .28 \mathrm{wt} \%$; $267 \mu \mathrm{L}$ ) was added to the mixture under dry atmosphere, followed by stirring for $4 \mathrm{~h}$. Dowex $50 \mathrm{~W}-\mathrm{X} 8$ $\left(\mathrm{H}^{+}\right.$form) was added to the reaction mixture to neutralize the system, and filtered through cotton. The 
filtrate was concentrated under diminished pressure. Hydrazine monohydrate (490 $\mu \mathrm{L}, 10.1 \mathrm{mmol})$ was added to a solution of the residue in $\mathrm{EtOH}(45 \mathrm{~mL})$, followed by stirring under reflux conditions for $5 \mathrm{~h}$. The resulting precipitate was filtered off through a filter paper, and the filtrate was concentrated under reduced pressure. The residue was completely dried up under vacuum overnight. The residue was dissolved in dry pyridine $(10 \mathrm{~mL})$, followed by addition of acetic anhydride $(10.6 \mathrm{~mL}, 76 \mathrm{mmol})$. The reaction mixture was stirred under dry atmosphere overnight. $\mathrm{MeOH}(10 \mathrm{~mL})$ was added to the mixture to quench excess reagents, followed by concentration under diminished pressure. The residue was extracted with $\mathrm{CHCl}_{3}$, washed successively with aq $4 \% \mathrm{KHSO}_{4}$, satd aq $\mathrm{NaHCO}_{3}$ and brine. The organic layer was dried over $\mathrm{MgSO}_{4}$, followed by filtration through filter paper. The filtrate was concentrated under reduced pressure, and the residue was subjected to silica gel column chromatography by Rf-75 system eluting with $\mathrm{CHCl}_{3}-\mathrm{MeOH}(0-16 \%$ linear gradient) to provide pure $16(1.85 \mathrm{~g}, 2.21 \mathrm{mmol}, 87 \%)$ as amorphous.

$[\alpha]_{\mathrm{D}}^{23}+18.4\left(c 1.0, \mathrm{CHCl}_{3}\right) ; R_{\mathrm{f}} 0.59\left(\mathrm{CHCl}_{3}: \mathrm{MeOH} 10: 1\right) ;{ }^{1} \mathrm{H} \mathrm{NMR}\left(\mathrm{CDCl}_{3}, 400 \mathrm{MHz}, \mathrm{TMS}\right): \delta(\mathrm{ppm})$ $6.62\left(\mathrm{~d}, 1 \mathrm{H}, J_{2, \mathrm{NH}}=9.5 \mathrm{~Hz}, \mathrm{~N} H\right), 5.35\left(\mathrm{bd}, 1 \mathrm{H}, J_{3^{\prime}, 4^{\prime}}=2.5 \mathrm{~Hz}, \mathrm{H}-4^{\prime}\right), 5.10\left(\mathrm{dd}, 1 \mathrm{H}, J_{1^{\prime}, 2^{\prime}}=8.0 \mathrm{~Hz}, J_{2^{\prime}, 3^{\prime}}=\right.$ $\left.10.5 \mathrm{~Hz}, \mathrm{H}-2^{\prime}\right), 4.99\left(\mathrm{dd}, 1 \mathrm{H}, J_{2,3}=10.0 \mathrm{~Hz}, J_{3,4}=8.5 \mathrm{~Hz}, \mathrm{H}-3\right), 4.95\left(\mathrm{dd}, 1 \mathrm{H}, J_{2^{\prime}, 3^{\prime}}=10.0 \mathrm{~Hz}, J_{3^{\prime}, 4^{\prime}}=3.5\right.$ Hz, H-3'), 4.69 (d, 1H, $\left.J_{1,2}=8.5 \mathrm{~Hz}, \mathrm{H}-1\right), 4.48\left(\mathrm{~d}, 1 \mathrm{H}, J_{1^{\prime}, 2^{\prime}}=8.0 \mathrm{~Hz}, \mathrm{H}-1^{\prime}\right), 4.47\left(\mathrm{dd}, 1 \mathrm{H}, J_{5,6 \mathrm{~b}}=2.0 \mathrm{~Hz}\right.$, $\left.J_{6 \mathrm{a}, 6 \mathrm{~b}}=12.1 \mathrm{~Hz}, \mathrm{H}-6 \mathrm{~b}\right), 4.15-4.08$ (m, 4H, H-2, H-6a, H-6'b, $\mathrm{CH}_{2}$ of PEG×1), 3.88-3.57 (m, 17H, H-4, H-5, H-5', H-6'a, $\mathrm{CH}_{2}$ of $\left.\mathrm{PEG} \times 13\right), 3.40$ (t, 2H, $J=5 \mathrm{~Hz}, \mathrm{CH}_{2}$ of $\left.\mathrm{PEG} \times 2\right), 2.14,2.12,2.06 \times 2,2.05,1.97$, $1.96(\mathrm{~s} \times 7,3 \mathrm{H} \times 7, \mathrm{Ac} \times 7) ;{ }^{13} \mathrm{C} \mathrm{NMR}\left(\mathrm{CDCl}_{3}, 100 \mathrm{MHz}\right): \delta(\mathrm{ppm}) 170.68,170.62,170.52,170.47,170.26$ $170.16(C=\mathrm{O}$ of $\mathrm{Ac}), 102.19(\mathrm{C} 1), 101.36\left(\mathrm{C} 1^{\prime}\right), 76.57(\mathrm{C} 4), 73.92(\mathrm{C} 3), 72.60(\mathrm{C} 5), 71.93\left(\mathrm{CH}_{2}\right.$ of PEG), $71.11\left(\mathrm{C}^{\prime}\right)$, , 70.95, 70.90, 70.76, 70.71, 70.53, $70.0\left(\mathrm{CH}_{2}\right.$ of $\left.\mathrm{PEG} \times 6\right), 69.22\left(\mathrm{C}^{\prime}\right), 68.73\left(\mathrm{C6}^{\prime}\right), 66.71\left(\mathrm{C4}^{\prime}\right)$ $62.52\left(\mathrm{C}^{\prime}\right), 60.84(\mathrm{C} 6), 53.65(\mathrm{C} 2), 50.79\left(\mathrm{CH}_{2}\right.$ of PEG), 23.07×2, 21.04×2, 20.77×2, $20.64\left(\mathrm{CH}_{3}\right.$ of $\left.\mathrm{Ac}\right)$; HRMS (ESI) $m / z$ : [M+Na $]^{+}$calcd for $\mathrm{C}_{34} \mathrm{H}_{52} \mathrm{~N}_{4} \mathrm{O}_{20} \mathrm{Na}$, 859.3067; found, 859.3052. 


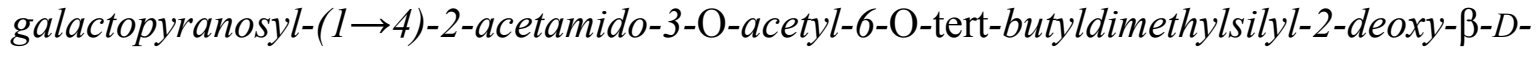
glucopyranoside (17).

$\mathrm{MeONa}(\mathrm{ca} .28 \mathrm{wt} \%$ in $\mathrm{MeOH} ; 170 \mu \mathrm{L})$ was added to a solution of compound 16 (1.02 $\mathrm{g}, 1.22 \mathrm{mmol})$ in dry $\mathrm{MeOH}(20 \mathrm{~mL})$ under dry atmosphere. The reaction mixture was stirred at $\mathrm{rt}$ under dry atmosphere for $1 \mathrm{~h}$, followed by addition of Dowx $50 \mathrm{~W}-\mathrm{X} 8\left(\mathrm{H}^{+}\right.$form $)$to neutralize the system, and then filtered through cotton. The filtrate was concentrated under reduced pressure, and the residue was completely dried up under vacuum. The residue was dissolved in dry DMF $(12 \mathrm{~mL})$, followed by addition of $p$ anisaldehyde dimethylacetal $(312 \mu \mathrm{L}, 1.83 \mathrm{mmol})$ and $( \pm)$-10-coamphorsulfonic acid to acidify the reaction system. The reaction mixture was stirred at $\mathrm{rt}$ under dry atmosphere. After $5.5 \mathrm{~h}$, $p$-anisaldehyde dimethylacetal $(208 \mu \mathrm{L}, 1.22 \mathrm{mmol})$ was further added. After stirring for further $17.5 \mathrm{~h}, \mathrm{NEt}_{3}$ was added to neutralize the reaction system, and then the mixture was concentrated under reduced pressure. tertButyldimethylchlorosilane $(221 \mathrm{mg}, 1.46 \mathrm{mmol})$ was added to a solution of the residue in dry pyridine (15 $\mathrm{mL})$, followed by stirring at $\mathrm{rt}$ under dry atmosphere. After $6 \mathrm{~h}$, tert-butyldimethylchlorosilane (37 mg, $0.24 \mathrm{mmol})$ was further added. After $17 \mathrm{~h}$, acetic anhydride $(1.38 \mathrm{~mL}, 14.6 \mathrm{mmol})$ was added to the mixture, and the mixture was stirred at $\mathrm{rt}$ under dry atmosphere overnight. Excess amount of MeOH was added to terminate the reaction, followed by concentration of the mixture under diminished pressure. The residue was extracted with $\mathrm{CHCl}_{3}$, washed successively aq $4 \% \mathrm{KHSO}_{4}$, satd aq $\mathrm{NaHCO}_{3}$, and brine. The organic layer was dried over $\mathrm{MgSO}_{4}$, filtered through filter paper, and concentrated under reduced pressure. The residue was subjected to silica gel column chromatography by Rf-75 system eluting with $\mathrm{CHCl}_{3}: \mathrm{MeOH}(0-16 \%$, linear gradient) to afford pure 17 (447 mg, $0.474 \mathrm{mmol}, 39 \%)$ as amorphous.

$$
[\alpha]_{\mathrm{D}}^{27}+14.4\left(c 1.0, \mathrm{CHCl}_{3}\right) ; R_{\mathrm{f}} 0.65\left(\mathrm{CHCl}_{3}: \mathrm{MeOH} 10: 1\right) ;{ }^{1} \mathrm{H} \mathrm{NMR}\left(\mathrm{CDCl}_{3}, 400 \mathrm{MHz}, \mathrm{TMS}\right): \delta(\mathrm{ppm})
$$

$7.38\left(\mathrm{~d}, 2 \mathrm{H}, J=9.0 \mathrm{~Hz}\right.$, aromatic), $6.90\left(\mathrm{~d}, 2 \mathrm{H}, J=8.5 \mathrm{~Hz}\right.$, aromatic), $6.43\left(\mathrm{~d}, 1 \mathrm{H}, J_{2, \mathrm{NH}}=9.5 \mathrm{~Hz}, \mathrm{NH}\right)$, $5.41(\mathrm{~s}, 1 \mathrm{H}, \mathrm{PhCH}), 5.23\left(\mathrm{dd}, 1 \mathrm{H}, J_{1^{\prime} 2^{\prime}}=8.0 \mathrm{~Hz}, J_{2^{\prime}, 3^{\prime}}=10.5 \mathrm{~Hz}, \mathrm{H}-2^{\prime}\right), 4.94\left(\mathrm{dd}, 1 \mathrm{H}, J_{2,3}=10.0 \mathrm{~Hz}, J_{3,4}=\right.$ 
$9.0 \mathrm{~Hz}, \mathrm{H}-3), 4.83\left(\mathrm{dd}, 1 \mathrm{H}, J_{2^{\prime}, 3^{\prime}}=10.3 \mathrm{~Hz}, J_{3^{\prime}, 4^{\prime}}=3.8 \mathrm{~Hz}, \mathrm{H}-3^{\prime}\right), 4.64\left(\mathrm{~d}, 1 \mathrm{H}, J_{1^{\prime}, 2^{\prime}}=8.0 \mathrm{~Hz}, \mathrm{H}-1^{\prime}\right), 4.60(\mathrm{~d}$, $\left.1 \mathrm{H}, J_{1,2}=8.0 \mathrm{~Hz}, \mathrm{H}-1\right), 4.34-4.27$ (m, 2H, H-4', H-6b), 4.10-3.99 (m, 2H, H-2, H-6a), 3.90-3.54 (m, 20H, H-4, H-6'a, H-6'b, $\mathrm{OCH}_{3}, \mathrm{CH}_{2}$ of $\left.\mathrm{PEG} \times 14\right), 3.40-3.38$ (m, 3H, H-5', $\mathrm{CH}_{2}$ of $\left.\mathrm{PEG} \times 2\right), 3.33-3.28$ (m, 1H, $\mathrm{H}-5), 2.06-1.98\left(\mathrm{~m}, 12 \mathrm{H}, \mathrm{CH}_{3}\right.$ of $\left.\mathrm{Ac}\right), 0.92\left(\mathrm{~s}, 9 \mathrm{H}, \mathrm{CH}_{3}\right.$ of $\left.{ }^{t} \mathrm{Bu}\right), 0.10,0.09\left(\mathrm{~s} \times 2,3 \mathrm{H} \times 2, \mathrm{Si}\left(\mathrm{CH}_{3}\right)_{2}\right) ;{ }^{13} \mathrm{C}$ NMR $\left(\mathrm{CDCl}_{3}, 100 \mathrm{MHz}\right): \delta(\mathrm{ppm}) 171.36,170.87,170.58,168.98(C=\mathrm{O}), 160.23\left(\mathrm{CH}_{3} \mathrm{O}-\mathrm{C}\right.$ of methoxybenzylidene), $\quad 130.29 \quad(\mathrm{C}-\mathrm{CH}-\quad$ of methoxybenzylidene $), \quad 127.89, \quad 113.65 \quad(\mathrm{CH} \quad$ of methoxyphenyl×4), 102.09 (C1), 101.24 (C-CH of methoxybenzylidene), 100.55 (C1'), 75.52 (C5), 74.75 (C4), 73.55 (C3), $73.30\left(\mathrm{C4}^{\prime}\right), 72.41\left(\mathrm{C}^{\prime}\right), 71.64,70.95,70.76,70.67,70.63,69.97\left(\mathrm{CH}_{2}\right.$ of PEG), 69.19 (C2'), $68.65(\mathrm{C} 6), 68.18\left(\mathrm{C}^{\prime}\right), 66.29\left(\mathrm{C}^{\prime}\right), 61.21\left(\mathrm{CH}_{2}\right.$ of PEG), $55.39\left(\mathrm{CH}_{3} \mathrm{O}-\mathrm{C}\right.$ of methoxybenzylidene), $53.57(\mathrm{C} 2), 50.75\left(\mathrm{CH}_{2}\right.$ of $\left.\mathrm{PEG}\right), 26.00\left(\mathrm{CH}_{3}\right.$ of $\left.{ }^{t} \mathrm{Bu}\right), 23.16,21.00 \times 2,20.90\left(\mathrm{CH}_{3}\right.$ of $\left.\mathrm{Ac} \times 4\right), 18.41$ $\left(C\left(\mathrm{CH}_{3}\right)_{3}\right.$ of $\left.{ }^{t} \mathrm{Bu}\right),-4.85,-5.20\left(\mathrm{Si}\left(\mathrm{CH}_{3}\right)_{2}\right)$; HRMS (ESI) $m / z[\mathrm{M}+\mathrm{H}]^{+}$calcd for $\mathrm{C}_{42} \mathrm{H}_{67} \mathrm{~N}_{4} \mathrm{O}_{18} \mathrm{Si}, 943.4214$ found, 943.4210; $\left[\mathrm{M}+\mathrm{NH}_{4}\right]^{+}$calcd for $\mathrm{C}_{42} \mathrm{H}_{70} \mathrm{~N}_{5} \mathrm{O}_{18} \mathrm{Si}$, 960.4485; found, 960.4469; [M+Na $]^{+}$calcd for $\mathrm{C}_{42} \mathrm{H}_{66} \mathrm{~N}_{4} \mathrm{O}_{18} \mathrm{SiNa}, 965.4039$; found, 965.4007.

2.11. 1-Azido-3,6,9-trioxaundecanyl 2,3-di-O-acetyl - $\beta$-D-galactopyranosyl-(1-4)-2-acetamido-3-Oacetyl-2-deoxy-ß-D-glucopyranoside (18).

Compound 17 (429 mg, $0.455 \mathrm{mmol}$ ) was dissolved in anhydrous THF (25 mL) containing acetic acid $(52.5 \mu \mathrm{L})$, followed by the addition of $1 \mathrm{~mol} \cdot \mathrm{L}^{-1}$ tetra- $n$-butylammonium fluoride in THF solution $(1.34$ $\mathrm{mL}, 1.37 \mathrm{mmol}$ ). The mixture was stirred at $\mathrm{rt}$ under Ar atmosphere for $6.5 \mathrm{~h}$. The reaction mixture was concentrated under diminished pressure, diluted with $\mathrm{CHCl}_{3}$, washed successively with satd aq $\mathrm{NaHCO}_{3}$ and brine. The organic layer was dried over $\mathrm{MgSO}_{4}$, and then filtered through filter paper. The filtrate was concentrated under reduced pressure, and the residue was subjected to silica gel chromatography $\left(\mathrm{CHCl}_{3}-\right.$ $\mathrm{MeOH}$, linear gradient from 0 to $5 \%$ of $\mathrm{MeOH}$ ) to give pure 1-azido-3,6,9-trioxaundecanyl 2,3-di-Oacetyl-4,6- $O$ - $p$-methoxybenzylidene- $\beta$-D-galactopyranosyl-(1 $\rightarrow 4)$-2-acetamido-3- $O$-acetyl-2-deoxy- $\beta$ - 
D-glucopyranoside (0.243 $\mathrm{g}, 0.293 \mathrm{mmol}, 64 \%)$ as amorphous.

$[\alpha]_{\mathrm{D}}{ }^{26}+10.0\left(c\right.$ 1.0, $\left.\mathrm{CHCl}_{3}\right) ; R_{\mathrm{f}} 0.55\left(\mathrm{CHCl}_{3}: \mathrm{MeOH} 10: 1\right) ;{ }^{1} \mathrm{H} \mathrm{NMR}\left(\mathrm{CDCl}_{3}, 400 \mathrm{MHz}, \mathrm{TMS}\right): \delta(\mathrm{ppm})$ $7.38\left(\mathrm{~d}, 2 \mathrm{H}, J=8.5 \mathrm{~Hz}\right.$, aromatic), $6.89\left(\mathrm{~d}, 2 \mathrm{H}, J=9.0 \mathrm{~Hz}\right.$, aromatic), $6.78\left(\mathrm{~d}, 1 \mathrm{H}, J_{2, \mathrm{NH}}=10.0 \mathrm{~Hz}, \mathrm{NH}\right)$ $5.41(\mathrm{~s}, 1 \mathrm{H}, \mathrm{MeOPh}-\mathrm{CH}), 5.22\left(\mathrm{dd}, 1 \mathrm{H}, J_{1^{\prime}, 2^{\prime}}=8.0 \mathrm{~Hz}, J_{2^{\prime}, 3^{\prime}}=10.0 \mathrm{~Hz}, \mathrm{H}-2^{\prime}\right), 5.00(\mathrm{dd}, 1 \mathrm{H}, J=9.3$ and $10.3 \mathrm{~Hz}, \mathrm{H}-3), 4.92\left(\mathrm{dd}, 1 \mathrm{H}, J_{2^{\prime}, 3^{\prime}}=10.3 \mathrm{~Hz}, J_{3^{\prime}, 4^{\prime}}=3.8 \mathrm{~Hz}, \mathrm{H}-3^{\prime}\right), 4.72\left(\mathrm{~d}, 1 \mathrm{H}, J_{1,2}=8.5 \mathrm{~Hz}, \mathrm{H}-1\right), 4.62$ $\left(\mathrm{d}, 1 \mathrm{H}, J_{1^{\prime}, 2^{\prime}}=7.5 \mathrm{~Hz}, \mathrm{H}-1^{\prime}\right), 4.30\left(\mathrm{bd}, 1 \mathrm{H}, J_{3^{\prime}, 4^{\prime}}=3.5 \mathrm{~Hz}, \mathrm{H}-4^{\prime}\right), 4.26\left(\mathrm{bd}, 1 \mathrm{H}, J=11.5 \mathrm{~Hz}, \mathrm{H}-6^{\prime} \mathrm{a}\right), 4.10$ (m, 1H, H-2), 4.00 (bd, 1H, J=11.5 Hz, H-6'b), 3.93-3.54 (m, 19H, H-4, H-6a, H-6b, OCH $\mathrm{CH}_{2} \times 13$ ), $3.50\left(\mathrm{~m}, 1 \mathrm{H}, \mathrm{H}-5^{\prime}\right), 3.40-3.37\left(\mathrm{~m}, 3 \mathrm{H}, \mathrm{CH}_{2} \times 3\right), 2.56\left(\mathrm{dd}, 1 \mathrm{H}, J_{6 \mathrm{a}, \mathrm{OH}}=9.0 \mathrm{~Hz}, J_{6 \mathrm{~b}, \mathrm{OH}}=4.5 \mathrm{~Hz}, 6-\mathrm{OH}\right), 2.07$, 2.05, 2.03, $1.97(\mathrm{~s} \times 4,3 \mathrm{H} \times 4, \mathrm{Ac} \times 4) ;{ }^{13} \mathrm{C} \mathrm{NMR}\left(\mathrm{CDCl}_{3}, 100 \mathrm{MHz}\right): \delta(\mathrm{ppm}) 171.03,170.66,170.64,169.10$ $(C=\mathrm{O}$ of $\mathrm{Ac}), 160.12\left(\mathrm{CH}_{3} \mathrm{O}-\mathrm{C}\right.$ of aromatic), 130. 21, 127.77, 113.53 (aromatic), $102.26(\mathrm{C} 1), 101.08(\mathrm{CH}$ of methoxybenzylidene), 100.68 (C1'), 75.03 (C5), 74.86 (C4), 73.62 (C3), 73.24 (C4'), 72.03 (C3'), 71.68, 70.76, 70.63, 70.48, 70.45, $69.83\left(\mathrm{CH}_{2}\right.$ of PEG), $69.20\left(\mathrm{C}^{\prime}\right), 68.59\left(\mathrm{CH}_{2}\right.$ of PEG), $68.50\left(\mathrm{C}^{\prime}\right), 66.11$ (C5'), $60.41(\mathrm{C} 6), 55.28\left(\mathrm{OCH}_{3}\right), 53.54(\mathrm{C} 2) 50.62\left(\mathrm{CH}_{2}\right.$ of PEG), 22.98, 20.87, 20.85, $20.76\left(\mathrm{CH}_{3}\right.$ of $\left.\mathrm{Ac}\right)$ ; HRMS (ESI) $m / z$ : $\left[\mathrm{M}+\mathrm{NH}_{4}\right]^{+}$calcd for $\mathrm{C}_{36} \mathrm{H}_{56} \mathrm{~N}_{5} \mathrm{O}_{18}, 846.3620$; found, 846.3588; [M+Na] ${ }^{+}$calcd for $\mathrm{C}_{36} \mathrm{H}_{52} \mathrm{~N}_{4} \mathrm{NaO}_{18}, 851.3174$; found, 851.3142; [M+H] $]^{+}$calcd for $\mathrm{C}_{36} \mathrm{H}_{53} \mathrm{~N}_{4} \mathrm{O}_{18}, 829.3349$; found, 829.3330.

The purified compound obtained above (242 mg, $0.292 \mathrm{mmol})$ was dissolved in $80 \%$ aq AcOH (30 mL) and then stirred at $50{ }^{\circ} \mathrm{C}$ for $2.5 \mathrm{~h}$. The reaction mixture was concentrated under diminished pressure, coevaporated with toluene $(20 \mathrm{~mL})$ three times, and dried up by vacuum pump overnight. The residue was subjected to silica gel column chromatography $\left(\mathrm{CHCl}_{3}-\mathrm{MeOH}\right.$, linear gradient from 0 to $16 \%$ of $\left.\mathrm{MeOH}\right)$ to afford pure 18 (179 $\mathrm{mg}, 0.251 \mathrm{mmol}, 86 \%)$ as colorless amorphous.

$[\alpha]_{\mathrm{D}}{ }^{26}-19.4\left(c\right.$ 1.0, $\left.\mathrm{CHCl}_{3}\right) ; R_{\mathrm{f}} 0.49\left(\mathrm{CHCl}_{3}: \mathrm{MeOH} 5: 1\right) ;{ }^{1} \mathrm{H} \mathrm{NMR}\left(\mathrm{CDCl}_{3}, 400 \mathrm{MHz}, \mathrm{TMS}\right): \delta(\mathrm{ppm})$ $6.95\left(\mathrm{~d}, 1 \mathrm{H}, J_{2, \mathrm{NH}}=9.2 \mathrm{~Hz}, \mathrm{NH}\right), 5.21\left(\mathrm{dd}, 1 \mathrm{H}, J_{1^{\prime} 2^{\prime}}=8.0 \mathrm{~Hz}, J_{2^{\prime}, 3^{\prime}}=10.0 \mathrm{~Hz}, \mathrm{H}-2^{\prime}\right), 5.11\left(\mathrm{t}, 1 \mathrm{H}, J_{2,3}=J_{3,4}\right.$ $=9.5 \mathrm{~Hz}, \mathrm{H}-3), 4.90\left(\mathrm{dd}, 1 \mathrm{H}, J_{2^{\prime}, 3^{\prime}}=10.3 \mathrm{~Hz}, J_{3^{\prime}, 4^{\prime}}=2.8 \mathrm{~Hz}, \mathrm{H}-3^{\prime}\right), 4.72\left(\mathrm{~d}, 1 \mathrm{H}, J_{1,2}=8.5 \mathrm{~Hz}, \mathrm{H}-1\right), 4.66$ 
(d, $\left.1 \mathrm{H}, J_{1^{\prime}, 2^{\prime}}=7.5 \mathrm{~Hz}, \mathrm{H}-1^{\prime}\right), 4.12-3.55$ (m, 24H, H-4', H-2, H-4, H-6'a, H-6b, H-6'b, H-6a, OCH ${ }_{3}, \mathrm{CH}_{2}$ of $\left.\mathrm{PEG} \times 14, \mathrm{H}-5^{\prime}, 6^{\prime}-\mathrm{OH}, 4^{\prime}-\mathrm{OH}\right), 3.50-3.44(\mathrm{~m}, 1 \mathrm{H}, \mathrm{H}-5), 3.41-3.36\left(\mathrm{~m}, 2 \mathrm{H}, \mathrm{CH}_{2}\right.$ of $\left.\mathrm{PEG} \times 2\right), 2.83-2.76(\mathrm{~m}$, 1H, 6-OH), 2.11-2.04 (m, 9H, $\mathrm{CH}_{3}$ of $\left.\mathrm{Ac} \times 3\right), 1.94\left(\mathrm{~s}, 3 \mathrm{H}, \mathrm{CH}_{3}\right.$ of $\left.\mathrm{Ac}\right) ;{ }^{13} \mathrm{C} \mathrm{NMR}\left(\mathrm{CDCl}_{3}, 100 \mathrm{MHz}\right): \delta$ (ppm) 171.38, 170.95, 170.41, $170.13(\mathrm{C}=\mathrm{O}), 101.62(\mathrm{C} 1), 101.18\left(\mathrm{C}^{\prime}\right), 75.45(\mathrm{C} 4), 74.88\left(\mathrm{C5}^{\prime}\right), 74.81$ (C5), 74.78 (C3), $73.76\left(\mathrm{C3}^{\prime}\right), 71.15,70.77,70.65,70.53,70.47\left(\mathrm{CH}_{2}\right.$ of PEG), 70.17 (C2'), 69.93, 68.99 $\left(\mathrm{CH}_{2}\right.$ of PEG), $67.36\left(\mathrm{C}^{\prime}\right), 61.73\left(\mathrm{C}^{\prime}\right), 60.62(\mathrm{C} 6), 53.89(\mathrm{C} 2), 50.65\left(\mathrm{CH}_{2}\right.$ of PEG), 22.93, 21.29, 20.87, $20.82\left(\mathrm{CH}_{3}\right.$ of $\left.\mathrm{Ac} \times 4\right)$; HRMS (ESI) $m / z[\mathrm{M}+\mathrm{H}]^{+}$calcd for $\mathrm{C}_{28} \mathrm{H}_{47} \mathrm{~N}_{4} \mathrm{O}_{7}, 711.2936$; found, 711.2917; $\left[\mathrm{M}+\mathrm{NH}_{4}\right]^{+}$calcd for $\mathrm{C}_{28} \mathrm{H}_{50} \mathrm{~N}_{5} \mathrm{O}_{17}, 728.3202$; found, 728.3183; $[\mathrm{M}+\mathrm{Na}]^{+}$calcd for $\mathrm{C}_{28} \mathrm{H}_{46} \mathrm{~N}_{4} \mathrm{O}_{17} \mathrm{Na}$, 733.2756; found, 733.2734; [M+K $]^{+}$calcd for $\mathrm{C}_{28} \mathrm{H}_{46} \mathrm{~N}_{4} \mathrm{O}_{17} \mathrm{~K}, 749.2495$; found, 749.2473.

\subsection{Di-triethylammonium 1-azido-3,6,9-trioxaundecanyl $\quad 2,3-$ di-O-acetyl $\quad 6-\mathrm{O}-$-sulfo- $\beta$-D-} galactopyranosyl-(1 $\rightarrow 4)$-2-acetamido-3-O-acetyl-2-deoxy-6-O-sulfo- $\beta$-D-glucopyranoside (19).

Sulfur trioxide trimethylamine complex $(65 \mathrm{mg}, 0.467 \mathrm{mmol})$ was added to a solution of compound 18 (167 mg, $0.235 \mathrm{mmol})$ in dry DMF $(10 \mathrm{~mL})$ at $0{ }^{\circ} \mathrm{C}$ under Ar atmosphere. The reaction mixture was stirred at $0{ }^{\circ} \mathrm{C}$ under $\mathrm{Ar}$ atmosphere for $1 \mathrm{~h}$, followed by addition of $\mathrm{MeOH}(1 \mathrm{~mL})$ and $\mathrm{NEt}_{3}(1 \mathrm{~mL})$ to quench excess reagents. The mixture was concentrated under reduced pressure and then subjected to silica gel column chromatography $\left(\mathrm{CHCl}_{3}-\mathrm{MeOH}\right.$ containing $0.5 \%(\mathrm{v} / \mathrm{v}) \mathrm{NEt}_{3}$, linear gradient from 0 to $16 \%$ of $\mathrm{MeOH})$ and LH-20 size exclusion chromatography $(\mathrm{MeOH})$ to afford pure 19 (157 mg, $0.146 \mathrm{mmol}, 62 \%)$ as colorless amorphous.

$[\alpha]_{\mathrm{D}}{ }^{26}-6.4(c$ 1.0, $\mathrm{MeOH}) ; R_{\mathrm{f}} 0.26\left(\mathrm{CHCl}_{3}: \mathrm{MeOH} 3: 1\right) ;{ }^{1} \mathrm{H} \mathrm{NMR}\left(\mathrm{CDCl}_{3}, 400 \mathrm{MHz}, \mathrm{TMS}\right): \delta(\mathrm{ppm}) 8.87$ $\left(\mathrm{s}, 2 \mathrm{H}, \mathrm{SO}_{3} \mathrm{H} \times 2\right), 6.91\left(\mathrm{~d}, 1 \mathrm{H}, J_{2, \mathrm{NH}}=9.6 \mathrm{~Hz}, \mathrm{~N} H\right), 5.10\left(\mathrm{dd}, 1 \mathrm{H}, J_{1^{\prime} 2^{\prime}}=8.0 \mathrm{~Hz}, J_{2^{\prime}, 3^{\prime}}=9.6 \mathrm{~Hz}, \mathrm{H}-2^{\prime}\right), 4.97$ $\left(\mathrm{t}, 1 \mathrm{H}, J_{2,3}=J_{3,4}=9.2 \mathrm{~Hz}, \mathrm{H}-3\right), 4.83\left(\mathrm{dd}, 1 \mathrm{H}, J_{2^{\prime}, 3^{\prime}}=10.8 \mathrm{~Hz}, J_{3^{\prime}, 4^{\prime}}=2.0 \mathrm{~Hz}, \mathrm{H}-3^{\prime}\right), 4.74\left(\mathrm{~d}, 1 \mathrm{H}, J_{1^{\prime}, 2^{\prime}}=7.6\right.$ Hz, H-1'), 4.68 (d, 1H, $J_{1,2}=8.0$ Hz, H-1), 4.31-4.05 (m, 5H, H-6a, H-6b, H-6'a, H-6'b, H-4'), 3.94 (q, $\left.1 \mathrm{H}, J_{1,2}=J_{2,3}=J_{2, \mathrm{NH}}=9.2 \mathrm{~Hz}, \mathrm{H}-2\right), 3.86-3.53\left(\mathrm{~m}, 18 \mathrm{H}, \mathrm{H}-4, \mathrm{CH}_{2}\right.$ of PEG $\left.\times 14, \mathrm{H}-5^{\prime}, \mathrm{H}-5,4^{\prime}-\mathrm{OH}\right), 3.42-$ 
$3.38\left(\mathrm{~m}, 2 \mathrm{H}, \mathrm{CH}_{2}\right.$ of $\left.\mathrm{PEG} \times 2\right), 3.22\left(\mathrm{q} 12 \mathrm{H}, J=7.2 \mathrm{~Hz},\left(\mathrm{CH}_{3} \mathrm{CH}_{2}\right)_{3} \mathrm{~N} \times 2\right), 2.07,2.05,2.03,1.95(\mathrm{~s} \times 4,3 \mathrm{H} \times 4$, $\mathrm{CH}_{3}$ of $\left.\mathrm{Ac} \times 4\right), 1.38\left(\mathrm{t}, 18 \mathrm{H}, J=7.2 \mathrm{~Hz},\left(\mathrm{CH}_{3} \mathrm{CH}_{2}\right)_{3} \mathrm{~N} \times 2\right) ;{ }^{13} \mathrm{C} \mathrm{NMR}\left(\mathrm{CDCl}_{3}, 100 \mathrm{MHz}\right): \delta(\mathrm{ppm}) 171.26$, 170.59, 170.29, $169.87(\mathrm{C}=\mathrm{O}), 101.38(\mathrm{C} 1), 100.24\left(\mathrm{C}^{\prime}\right), 74.81(\mathrm{C} 4), 73.40\left(\mathrm{C} 3^{\prime}\right), 73.24(\mathrm{C} 3, \mathrm{C} 5), 72.61$ (C5'), 70.98, 70.64, 70.54, 70.43, 70.37, $69.85\left(\mathrm{CH}_{2}\right.$ of PEG), $69.47\left(\mathrm{C}^{\prime}\right), 68.67\left(\mathrm{CH}_{2}\right.$ of PEG), 65.82 (C4'), 64.97, $64.83\left(\mathrm{C} 6, \mathrm{C}^{\prime}\right), 58.09\left(\mathrm{CH}_{2}\right.$ of PEG), $53.37(\mathrm{C} 2), 50.64\left(\mathrm{CH}_{2}\right.$ of PEG), $46.70\left(\left(\mathrm{CH}_{3} \mathrm{CH}_{2}\right)_{3} \mathrm{~N}\right)$, 22.82, 21.08, $20.88\left(\mathrm{CH}_{3}\right.$ of $\left.\mathrm{Ac} \times 4\right), 18.25\left(\left(\mathrm{CH}_{3} \mathrm{CH}_{2}\right)_{3} \mathrm{~N}\right)$; HRMS (ESI) $m / z[\mathrm{M}-2 \mathrm{H}]^{2-}$ calcd for $\left(\mathrm{C}_{28} \mathrm{H}_{44} \mathrm{~N}_{4} \mathrm{O}_{23} \mathrm{~S}_{2}\right) / 2$, 434.0919; found, 434.0925; [M-H] $]^{-}$calcd for $\mathrm{C}_{28} \mathrm{H}_{45} \mathrm{~N}_{4} \mathrm{O}_{23} \mathrm{~S}_{2}^{-}$, 869.1921; found, 869.1928.

2.13. Di-sodium 1-azido-3,6,9-trioxaundecanyl $\quad 6$-O-sulfonato- $\beta$-D-galactopyranosyl-(1 $\rightarrow 4)$-2acetamido-2-deoxy-6-O-sulfonato- $\beta$-D-glucopyranoside (5).

Compound 19 (157 mg, $0.146 \mathrm{mmol})$ was dissolved in $\mathrm{MeOH}(4 \mathrm{~mL})$, followed by stirring at $0{ }^{\circ} \mathrm{C} .1$ $\mathrm{mol} \cdot \mathrm{L}^{-1}$ aq $\mathrm{NaOH}(876 \mu \mathrm{L})$ was added to a solution of the mixture, and then stirred at $0{ }^{\circ} \mathrm{C}$ overnight. The reaction mixture was directly subjected to size exclusion chromatography (BioGel P2) eluting with distilled water to give pure 5 (100 $\mathrm{mg}, 0.127 \mathrm{mmol}, 87 \%)$ as a white solid.

$[\alpha]_{\mathrm{D}}{ }^{19}-9.5\left(c\right.$ 0.1, $\left.\mathrm{H}_{2} \mathrm{O}\right) ; R_{\mathrm{f}} 0.33\left(\mathrm{CHCl}_{3}: \mathrm{MeOH}: \mathrm{H}_{2} \mathrm{O}\right.$ 5:4:1); ${ }^{1} \mathrm{H}$ NMR $\left(\mathrm{D}_{2} \mathrm{O}, 400 \mathrm{MHz}, \mathrm{HOD}\right): \delta(\mathrm{ppm})$ $4.60\left(\mathrm{~d}, 1 \mathrm{H}, J_{1,2}=7.6 \mathrm{~Hz}, \mathrm{H}-1\right), 4.54\left(\mathrm{~d}, 1 \mathrm{H}, J_{1^{\prime}, 2^{\prime}}=7.6 \mathrm{~Hz}, \mathrm{H}-1^{\prime}\right), 4.41\left(\mathrm{dd}, 1 \mathrm{H}, J_{5,6 \mathrm{~b}}=1.6 \mathrm{~Hz}, J_{6 \mathrm{a}, 6 \mathrm{~b}}=11.2\right.$ Hz, H-6b), 4.30 (dd, 1H, $\left.J_{5,6 \mathrm{a}}=4.6 \mathrm{~Hz}, J_{6 \mathrm{a}, 6 \mathrm{~b}}=11.2 \mathrm{~Hz}, \mathrm{H}-6 \mathrm{a}\right), 4.21-4.17$ (m, 2H, H-6'a, H-6'b), 4.023.65 (m, 21H, H-2, H-3, H-3', H-4', H-4, H-5, H-5', CH $H_{2}$ of PEG×14), 3.56-3.48 (m, 3H, H-2', $\mathrm{CH}_{2}$ of $\mathrm{PEG} \times 2), 2.03\left(\mathrm{~s}, 3 \mathrm{H}, \mathrm{CH} \mathrm{H}_{3}\right.$ of $\left.\mathrm{Ac}\right) ;{ }^{13} \mathrm{C} \mathrm{NMR}\left(\mathrm{D}_{2} \mathrm{O}, 100 \mathrm{MHz}\right): \delta(\mathrm{ppm}) 175.11(\mathrm{C}=\mathrm{O}), 103.32\left(\mathrm{C} 1^{\prime}\right), 101.73$ (C1), 79.17 (C4), 73.34 (C5), 73.14 (C3), 72.87 (C3', C5'), $71.42\left(\mathrm{C} 2{ }^{\prime}\right), 70.24,70.17,70.12,69.80\left(\mathrm{CH}_{2}\right.$ of PEG), 68.85 (C4'), 68.85 (C4'), $67.64\left(\mathrm{C6}^{\prime}\right), 67.08$ (C6), 58.09 (C2), 55.60 (C2), 50.76 (CH $\mathrm{H}_{2}$ of PEG), $47.28\left(\mathrm{CH}_{2}\right.$ of PEG), $22.85\left(\mathrm{CH}_{3}\right.$ of Ac $\left.\times 4\right)$; HRMS (ESI) $m / z[\mathrm{M}-2 \mathrm{H}]^{2-}$ calcd for $\left(\mathrm{C}_{22} \mathrm{H}_{38} \mathrm{~N}_{4} \mathrm{O}_{20} \mathrm{~S}_{2}\right) / 2$, 371.0760; found, 371.0767; [M-H] $]^{-}$calcd for $\mathrm{C}_{22} \mathrm{H}_{39} \mathrm{~N}_{4} \mathrm{O}_{20} \mathrm{~S}_{2}, 743.1599$; found, 743.1615. 
2.14. Tetra-sodium 1-azido-3,6,9-trioxaundecanyl (5-acetamido-3,5-dideoxy-D-glycero- $\alpha$-D-galactonon-2-uropyranosyl)onate-(2 $\rightarrow 3)-6-\mathrm{O}-$ sulfonato- $\beta$-D-galactopyranosyl-( $(\rightarrow 4)$-2-acetamido-2-deoxy-6O-sulfonato- $\beta$-D-glucopyranosyl-( $(1 \rightarrow 3)-\beta$-D-galactopyranosyl-( $(1 \rightarrow 4)$-[ $\alpha$-L-fucopyranosyl-( $(1 \rightarrow 3)] 2$ acetamido-2-deoxy-6-O-sulfonato- $\beta$-D-glucopyranoside (1)

A mixture of compounds 3,6 and $\mathrm{K}_{3} \mathrm{PO}_{4}$ (total $20 \mathrm{mg}$, content of the oxazoline donor 3 was $48 \%$, therefore, $1.06 \mu \mathrm{mol}$ calculated according to the method shown in Table S1; for the start of the reaction, the amount of $\mathbf{3}$ was roughly calculated by using the total recovery after the oxazoline formation and the total amount of $\mathbf{6}$ and $\mathrm{K}_{3} \mathrm{PO}_{4}$ used, and the purity of $\mathbf{3}$ determined by ${ }^{1} \mathrm{H}$ NMR) and the glycosyl acceptor $4(1.3 \mathrm{mg}, 1.54 \mu \mathrm{mol})$ in phosphate buffered $\mathrm{D}_{2} \mathrm{O}\left(50 \mathrm{mmol} \cdot \mathrm{L}^{-1}\right)$ was added to the medium containing KSaseII $(0.1 \mathrm{U})$ as the total volume was $52 \mu \mathrm{L}$, and the $\mathrm{pH}$ value of the mixture was finely adjusted to 7.3 by using $20 \%(\mathrm{w} / \mathrm{w})$ deuterium chloride in $\mathrm{D}_{2} \mathrm{O}$ (Cambridge Isotope Laboratories, Inc.). The reaction mixture was kept standing at $40^{\circ} \mathrm{C}$ for $6 \mathrm{~h}$. The reaction mixture was heated at $90^{\circ} \mathrm{C}$ for $1 \mathrm{~min}$ to inactivate the enzyme and centrifuged to remove insoluble precipitates. The supernatant was then subjected to GPC/SEC eluting with $100 \mathrm{mmol} \cdot \mathrm{L}^{-1} \mathrm{NaNO}_{3}$ aq. (flow rate; $0.7 \mathrm{~mL} \cdot \mathrm{min}^{-1}$ ). The yield of 1 was $86 \%$, which was calculated by measuring the area ratio of the SEC chromatogram of the reaction mixture. Compound $\mathbf{1}$ was then isolated by GPC/SEC system collecting and concentrating the eluent corresponding to the peak at 18.8-20.1 min. on the chromatogram, followed by Sephadex G-10 eluting with distilled water and lyophilization $(0.36 \mathrm{mg}, 0.210 \mu \mathrm{mol}, 14 \%)$.

ESI-MS $m / z:[\mathrm{M}]^{4-}$ calcd.: 405.5952, found: 405.5964: $[\mathrm{M}+\mathrm{H}]^{3-}$ calcd.: 541.1289, found: 541.1313: [M+H+Na $]^{2-}$ calcd: 823.1882 , found: $823.1896:[\mathrm{M}+3 \mathrm{Na}]^{-}$calcd: 1691.3481 , found: 1691.3684 .

2.15. Penta-sodium 1-azido-3,6,9-trioxaundecanyl (5-acetamido-3,5-dideoxy-D-glycero- $\alpha$-D-galacto-

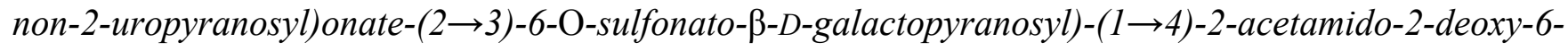


O-sulfonato- $\beta$-D-glucopyranosyl-( $(1 \rightarrow 3)-6$-O-sulfonato- $\beta$-D-galactopyranosyl-( $(1 \rightarrow 4)$-2-acetamido-2deoxy-6-O-sulfonato- $\beta$-D-glucopyranoside (2)

A mixture containing 3,6 and $\mathrm{K}_{3} \mathrm{PO}_{4}(17 \mathrm{mg}$, content of the oxazoline donor 3 was $55 \%$, therefore, $1.65 \mu \mathrm{mol}$ according to calculations) and the glycosyl acceptor $5(3.2 \mathrm{mg}, 4.36 \mu \mathrm{mol})$ in phosphate buffered $\mathrm{D}_{2} \mathrm{O}\left(50 \mathrm{mmol} \cdot \mathrm{L}^{-1}\right)$ was added to the medium containing KSase II $(0.1 \mathrm{U})$ as the total volume was $44 \mu \mathrm{L}$, and the $\mathrm{pH}$ value of the mixture was finely adjusted to 7.3 as described above. The reaction mixture was kept standing at $40{ }^{\circ} \mathrm{C}$ for $7 \mathrm{~h}$, heated at $90{ }^{\circ} \mathrm{C}$ for $1 \mathrm{~min}$ to inactivate the enzyme and centrifuged to remove insoluble precipitates. The yield of $\mathbf{2}$ was $95 \%$, which was calculated by measuring the area ratio of the $\mathrm{GPC} / \mathrm{SEC}$ chromatogram of the reaction mixture (elution; $100 \mathrm{mM}$ aq. $\mathrm{NaNO}_{3}$, flow rate; $\left.0.7 \mathrm{~mL} \cdot \mathrm{min}^{-1}\right)$. The reaction mixture was then subjected to BioGel P-4 size exclusion chromatography eluting with distilled water. The product fractions were collected and combined, followed by lyophilization to give pure $2(1.0 \mathrm{mg}, 0.643 \mu \mathrm{mol}, 15 \%)$.

ESI-MS $m / z:[\mathrm{M}+\mathrm{Na}]^{4-}$ calcd: 394.5649 , found: $394.5662:[\mathrm{M}+2 \mathrm{Na}]^{3-}$ calcd: 533.7498 , found: 533.7524: $[\mathrm{M}+3 \mathrm{Na}]^{2-}$ calcd: 812.1196 , found:812.1232: $[\mathrm{M}+4 \mathrm{Na}]^{-}$calcd: 1647.2289 , found: 1647.2468 .

2.16. Tri-sodium 1-azido-3,6,9-trioxaundecanyl (5-acetamido-3,5-dideoxy-D-glycero- $\alpha$-D-galacto-non-2uropyranosyl)onate-(2 $\rightarrow 3)$-6-O-sulfonato- $\beta$-D-galactopyranosyl-( $(1 \rightarrow 4)$-2-acetamido-2-deoxy-6-Osulfonato-D-glucopyranoside (21)

As the positive control compound for the QCM measurements, we synthesized the 6,6'-di-su-SLacNAc derivative (21). Compounds 5 (10 mg, $13.5 \mu \mathrm{mol})$ and CMP-sialic acid (10 mg, $15.8 \mu \mathrm{mol})$ were dissolved in Tris-HCl buffer $\left(300 \mu \mathrm{L}, 100 \mathrm{mmol} \cdot \mathrm{L}^{-1}, \mathrm{pH} 8.5\right)$ containing $\mathrm{MgCl}_{2}\left(20 \mathrm{mmol} \cdot \mathrm{L}^{-1}\right)$. PmST1 $(83 \mathrm{mU})$ and alkaline phosphatase from calf intestine $(9 \mathrm{U})$ were added to the mixture, and kept standing at $37{ }^{\circ} \mathrm{C}$ for $18 \mathrm{~h}$. The reaction mixture was heated at $90{ }^{\circ} \mathrm{C}$ for $5 \mathrm{~min}$, then centrifuged to remove insoluble precipitates, and the supernatant was subjected to BioGel P-4 size exclusion chromatography eluting with 
distilled water. The product containing fractions were collected and subjected to GPC/SEC eluting with $100 \mathrm{mmol} \cdot \mathrm{L}^{-1}$ aq. $\mathrm{NaNO}_{3}\left(\right.$ flow rate; $0.7 \mathrm{~mL} \cdot \mathrm{min}^{-1}$ ). The product fractions were collected and subjected to Sephadex G10 gel filtration chromatography eluting with distilled water to remove inorganic salts. The product fractions were collected and combined, followed by lyophilization to give $\mathbf{2 1}$ (1.6 $\mathrm{mg}, 1.52 \mu \mathrm{mol}$, $11 \%)$.

ESI-MS $m / z$ : $[\mathrm{M}+\mathrm{Na}]^{2-}$ calcd.: 527.6147, found: 527.6153; $[\mathrm{M}+2 \mathrm{Na}]^{-}$calcd.: 1078.2192, found: 1078.2192 .

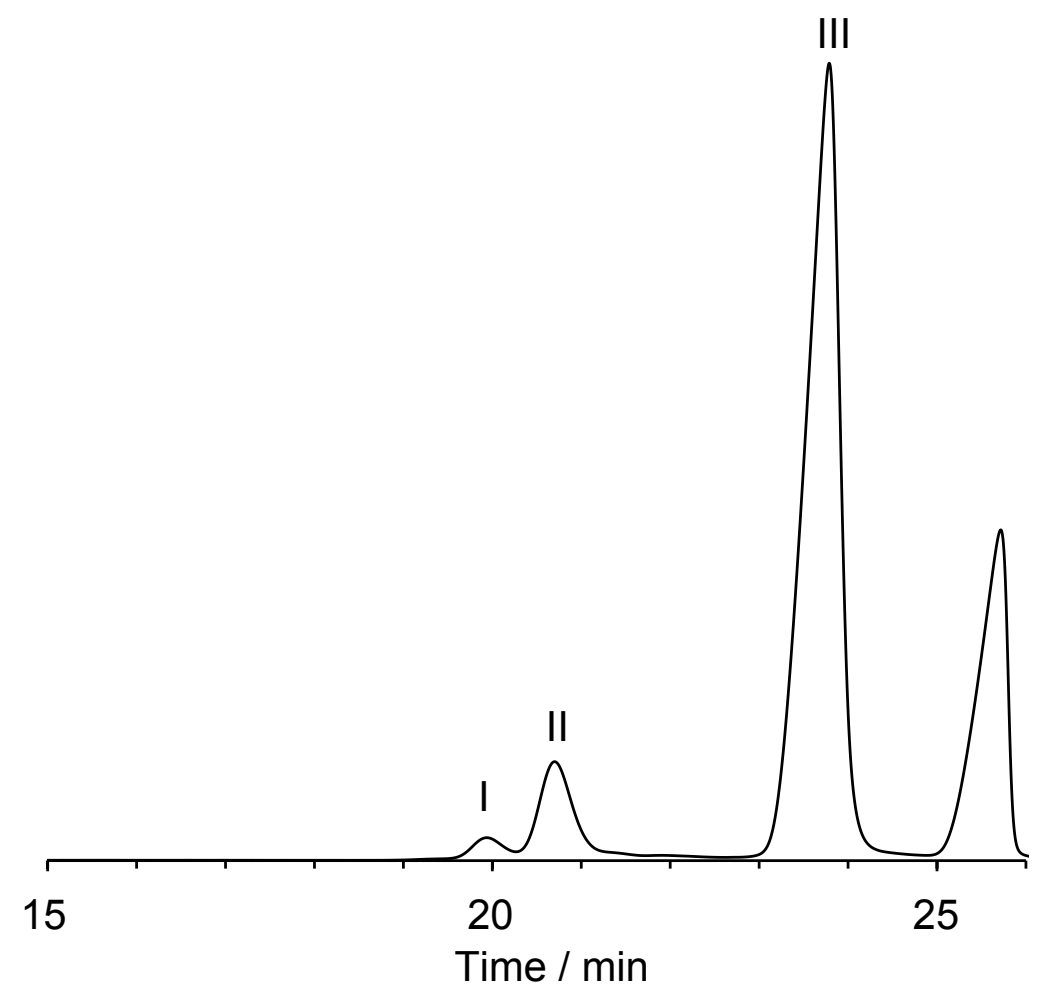

Figure S1. The SEC chart of the mixtures after the KSase II-catalyzed reaction of $\mathbf{3}$ with $\mathbf{4}$ under the conditions of entry 2 in Table 1. The peaks under the Roman numbers correspond to $\mathbf{1}$ (I), 6 (II, containing decomposed, hydrolyzed form from 3), and 4 (III; overlapped with a buffer peak).

Table S1. The peaks and their area values on the SEC in Figure 2. 


\begin{tabular}{c|ccc||ccc}
\hline Peak No. & I & II & III & IV & V & VI \\
\hline Area $/ \mathrm{mV} \cdot \mathrm{sec}$ & 1345.406 & 1915.245 & 937.954 & 580.479 & 526.316 & 1024.552 \\
\hline
\end{tabular}

Calculation of the amount of $\mathbf{3}$ in entry 1 of Table 1 was carried out as follows:

Calculate the molar ratio of the acceptor 4 and the donor $\mathbf{3}+$ the precursor 6 by using the peak area values of the SEC chart. That is,

Compounds $\mathbf{3}+\mathbf{6}=$ peaks I $+\mathrm{II}=3260.651 \mathrm{mV} \cdot \mathrm{sec}$

Compound $\mathbf{4}=$ peaks I $+\mathrm{III}=2283.36 \mathrm{mV} \cdot \mathrm{sec}$

Purity of $\mathbf{3}$ was calculated as $48 \%$ from ${ }^{1} \mathrm{H}$ NMR, therefore, the area of $\mathbf{3}$ is calculated by $3260.651 \times 0.48$ $=1565.112 \mathrm{mV} \cdot \mathrm{sec}$. The molar amount of 4 was $1.54 \mu \mathrm{mol}$ (calculated by the weight), therefore, the molar amount of $\mathbf{3}$ is calculated by:

$1565.112 \mathrm{mV} \cdot \mathrm{sec} \times 1.54 \mu \mathrm{mol} / 2283.36 \mathrm{mV} \cdot \mathrm{sec}=1.056 \mu \mathrm{mol}$

\section{The QCM measurements}

Waiting after stabilization of the Siglec-8 Fc chimera-immobilized sensor, each glycan sample was added to the sensor cell according to the time schedule as shown in Table S2. After measurements, baseline-drift correction was carried out on each sensorgram. In the cases of the ligands $\mathbf{1}$ and $\mathbf{2}$, the frequency change $\Delta F$ was plotted as a function of the concentration of the ligand. Curve fitting of the plot was carried out according to the equation (1) to determine the $K_{\mathrm{D}}{ }^{[3]}$ in which [L] means the concentration of the glycan ligand.

$\Delta F=\frac{[\mathrm{L}] \Delta F_{\max }}{K_{\mathrm{D}}+[\mathrm{L}]}$

Table S2. Details of the injected glycan samples in the QCM measurements.

\begin{tabular}{lllll}
\hline Glycan & Ch. $^{[a]}$ & Conc. $^{[b]}$ & Volume & Time/min. ${ }^{[\mathrm{d}]}$ \\
\hline
\end{tabular}




\begin{tabular}{|c|c|c|c|c|c|c|c|c|}
\hline & & $/ \mathrm{mmol} \cdot \mathrm{L}^{-1}$ & $/ \mu \mathrm{L}^{[\mathrm{c}]}$ & 1 & 2 & 3 & 4 & 5 \\
\hline \multirow{2}{*}{1} & 1 & 1.94 & 5 & 44 & 55 & $66^{[\mathrm{e}]}$ & 71 & 102 \\
\hline & 2 & 2.91 & 5 & 59 & 70 & 102 & 113 & 123 \\
\hline 2 & 4 & 0.598 & 5 & 1 & 12 & 19 & 28 & - \\
\hline \multirow{2}{*}{20} & & 6.10 & 5 & 6 & 11 & & & \\
\hline & & 12.2 & 5 & & & 16 & 21 & 55 \\
\hline \multirow[b]{2}{*}{21} & & 0.906 & 5 & 5 & & & & \\
\hline & $4^{[\mathrm{f}]}$ & 4.53 & 5 & & 7 & 17 & 30 & _ \\
\hline
\end{tabular}

[a] The channel used for the measurement on the Affinix Q4. [b] Concentration of the sample glycan solution. [c] The sample volume for each injection. [d] Indicating the time and the number of the sample injection. [e] At this time the sample concentration was $2.91 \mathrm{mmol} \cdot \mathrm{L}^{-1}$. [f] The measurements were sequentially carried out in the same cells. 

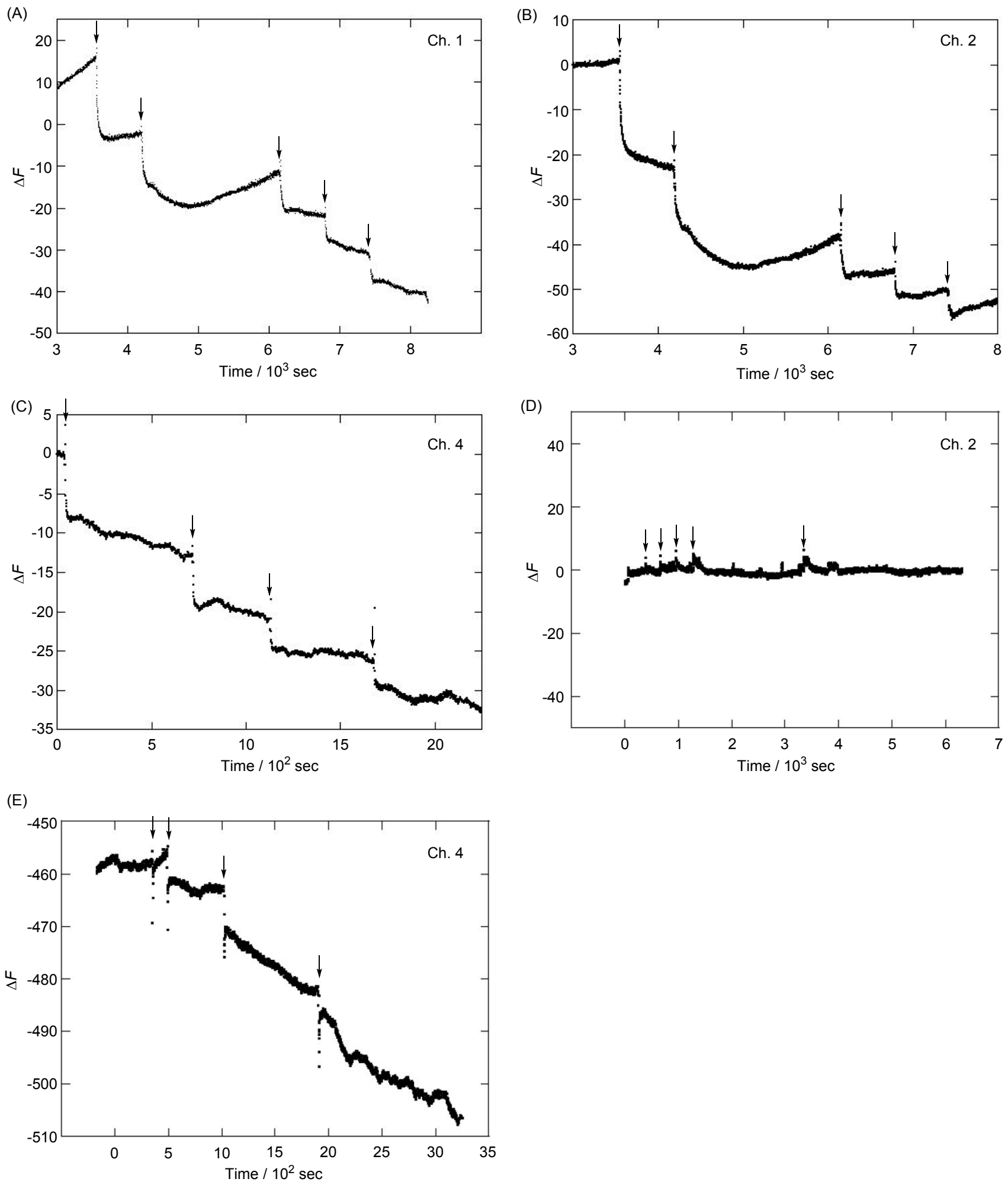

Figure S2. The QCM sensorgrams using (A) 1 in Ch.1, (B) 1 in $\mathrm{Ch} 2$, (C) 2, (D) Neu5Ac $\alpha(2 \rightarrow 3) \mathrm{Gal} \beta(1 \rightarrow 4) \mathrm{Glc}-\mathrm{OH}$ $(\mathbf{2 0}$ negative control), and Neu5Ac $\alpha(2 \rightarrow 3) \mathrm{Gal} 6 \mathrm{~S} \beta(1 \rightarrow 4)$ GlcNAc6S $\beta-O-\left(\mathrm{C}_{2} \mathrm{H}_{4} \mathrm{O}\right)_{3} \mathrm{C}_{2} \mathrm{H}_{4} \mathrm{~N}_{3}$ (21; positive control). Arrows show the 
time for the addition of each glycan sample shown in Table S2.
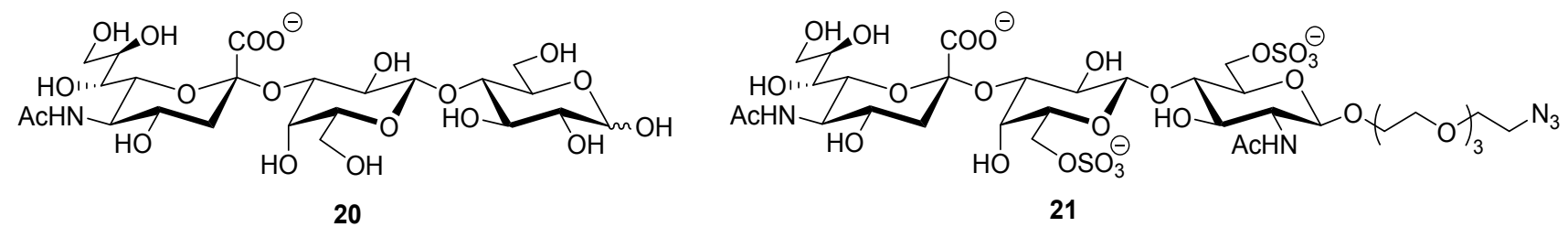

Chart S1. Chemical structures of compounds 20 and 21.

\section{References}

1. R.U. Lemieux, S.Z. Abbas, M.H. Burzynska, R.M. Ratcliffe, Can. J. Chem. 1982, 60, 63-67.

2. M. Ohmae, K. Sakaguchi, T. Kaneto, S. Fujikawa, S. Kobayashi, ChemBioChem 2007, 8, 1710-1720.

3. Y. Ebara, Y. Okahata, J. Am. Chem. Soc. 1994, 116, 11209-11212. 

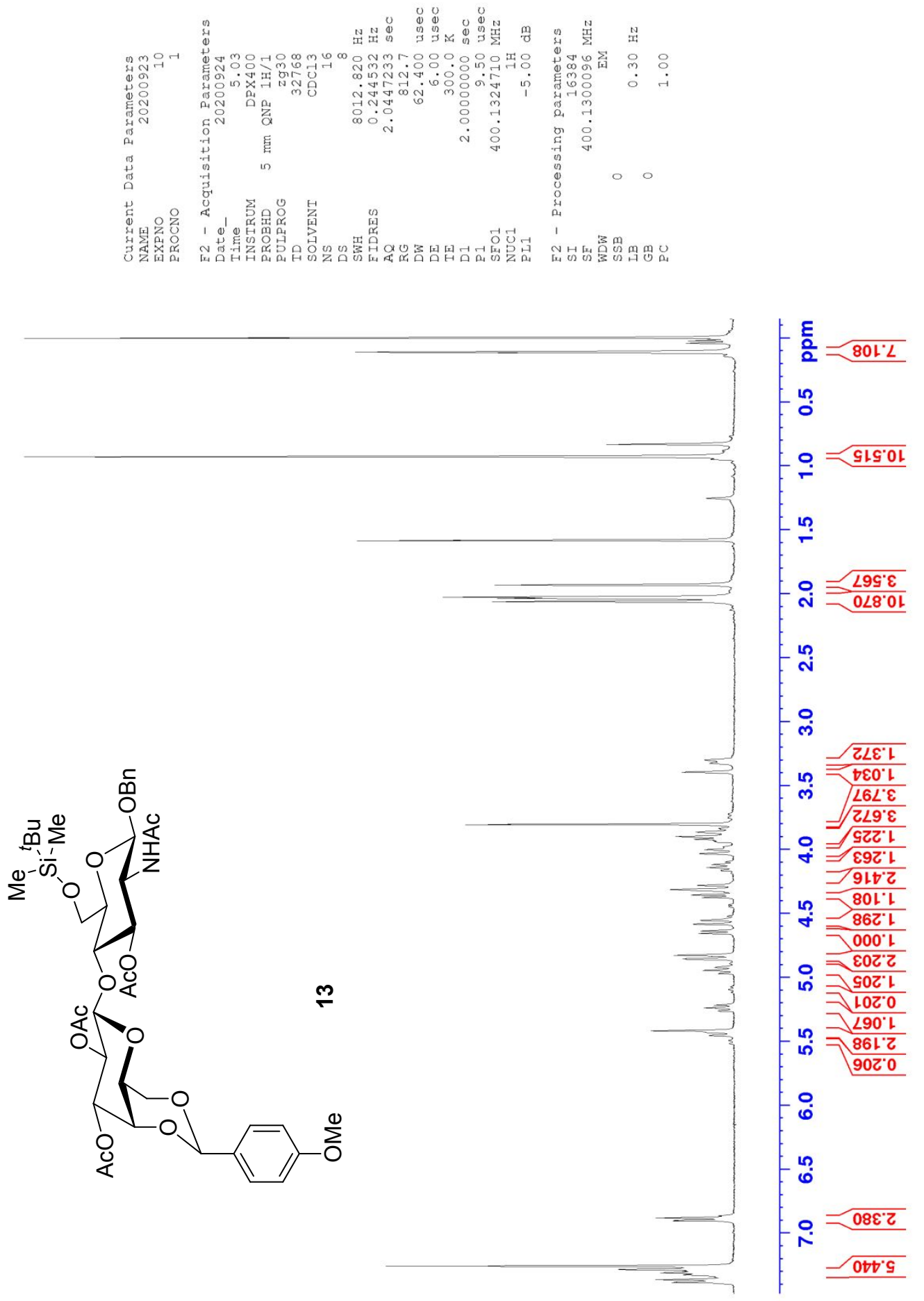

Figure S3. The ${ }^{1} \mathrm{H}$ NMR spectrum of compound 13. 


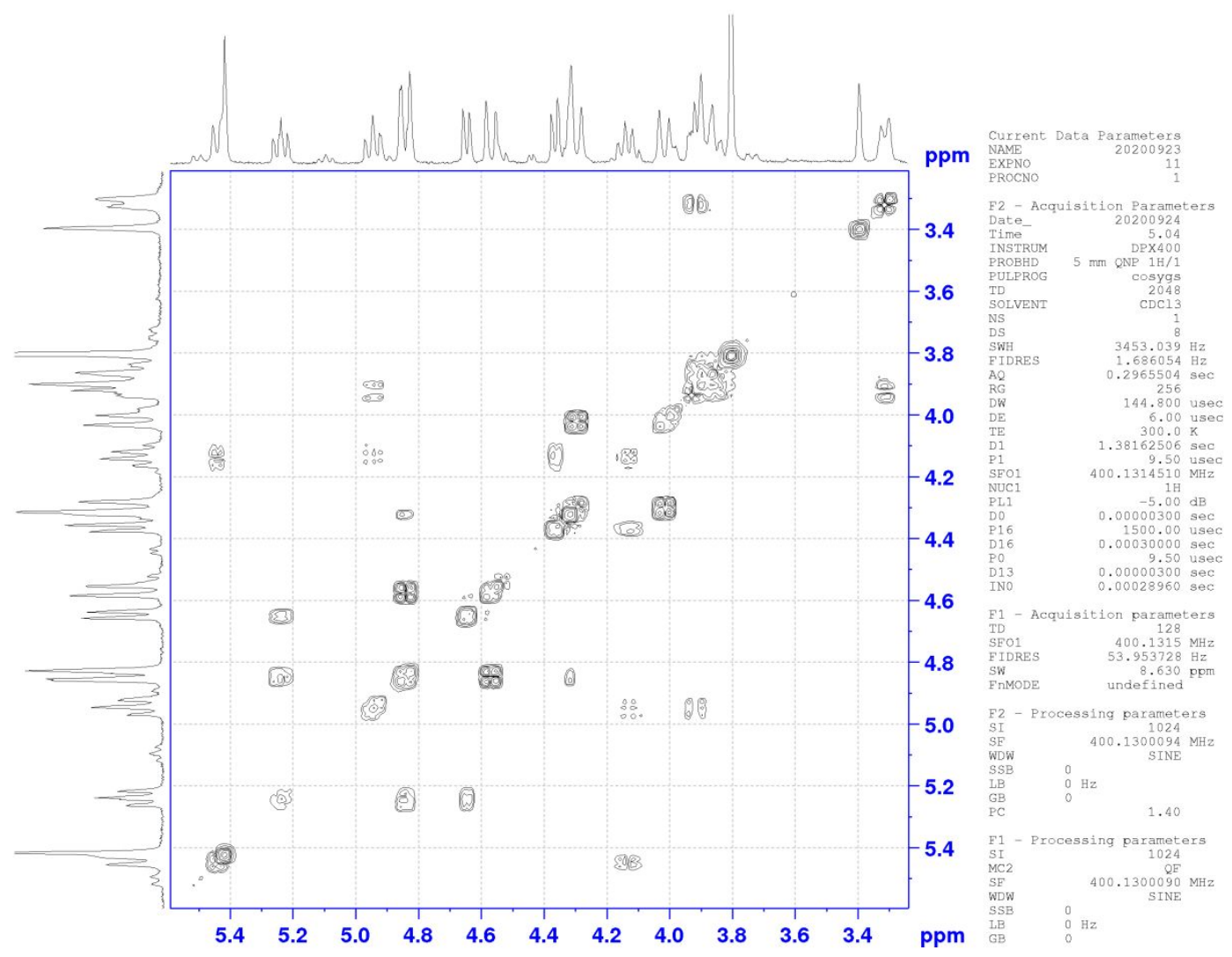

Figure S4. The magnified H-H COSY NMR spectrum of compound 13. 


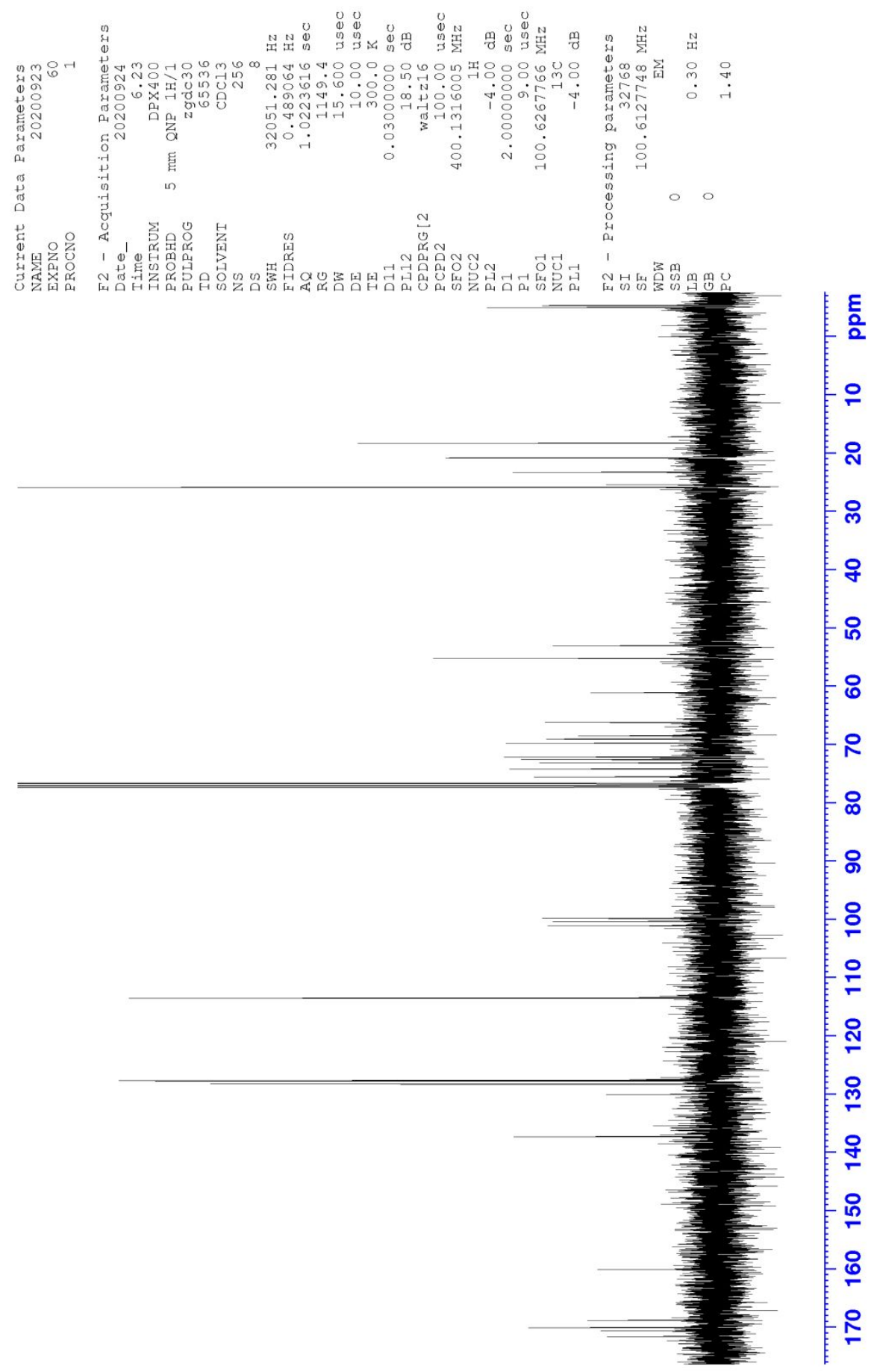

Figure S5. The ${ }^{13} \mathrm{C}$ NMR spectrum of compound $\mathbf{1 3}$. 


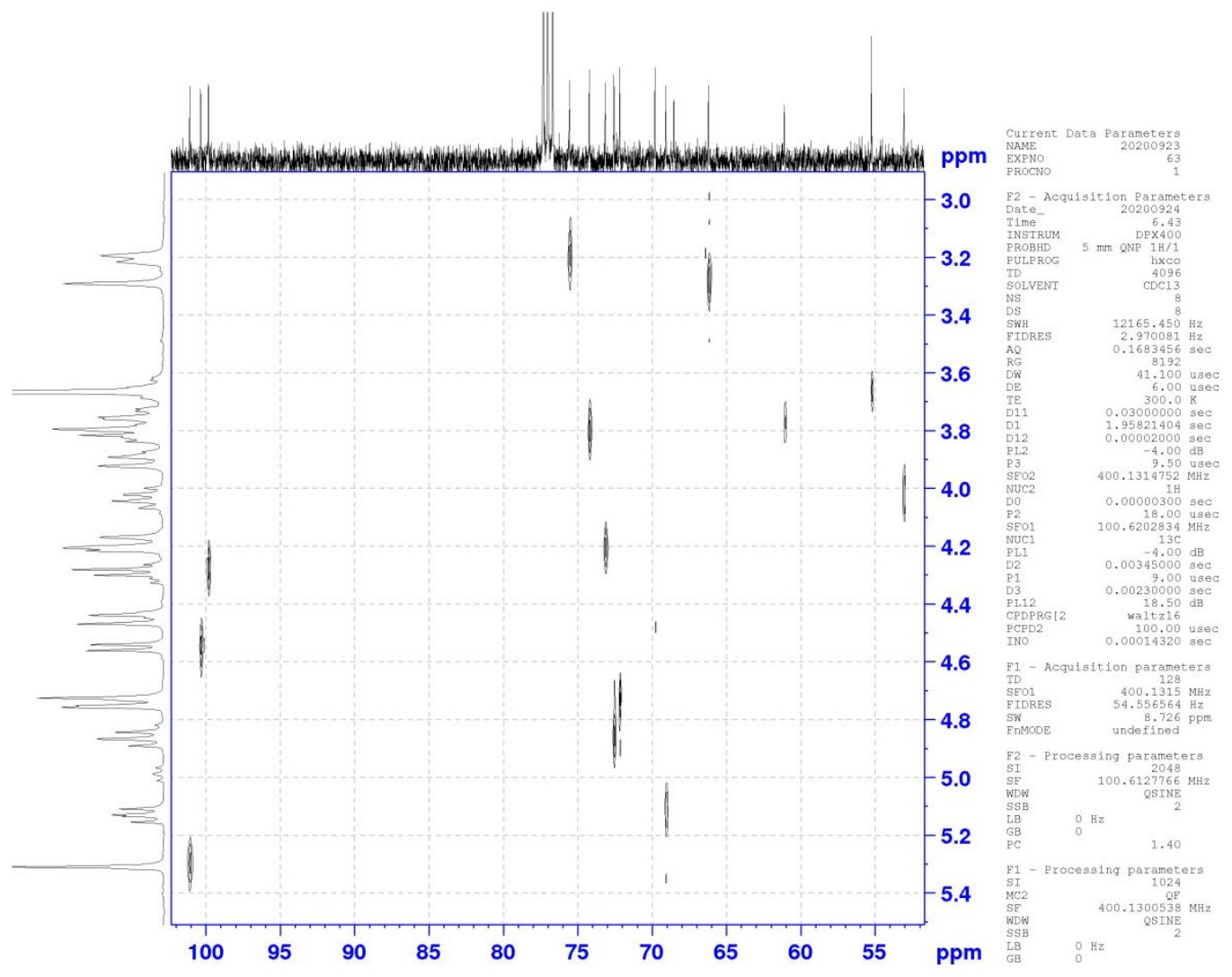

Figure S6. The C-H COSY NMR spectrum of compound 13. 

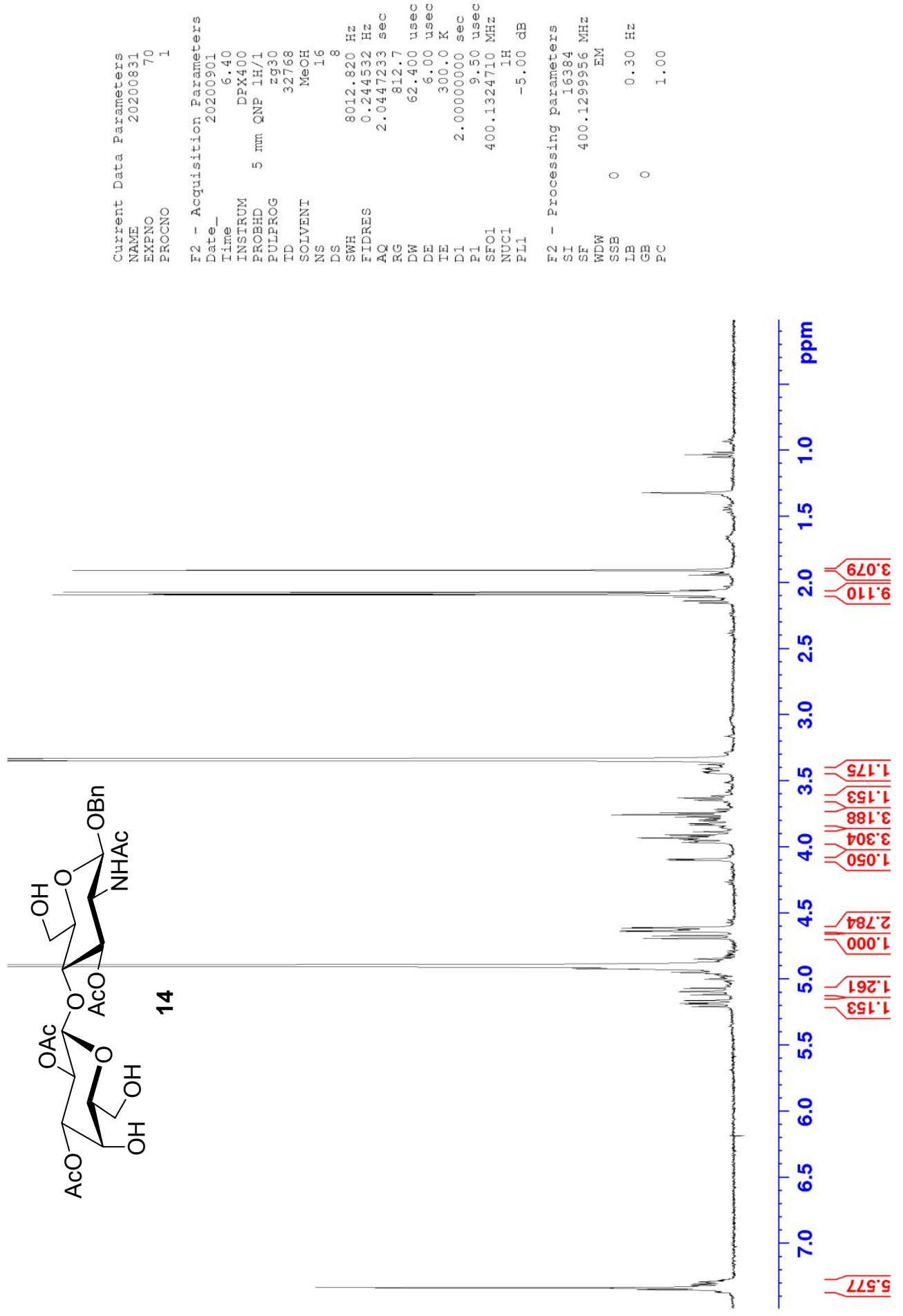

Figure S7. The ${ }^{1} \mathrm{H}$ NMR spectrum of compound 14. 


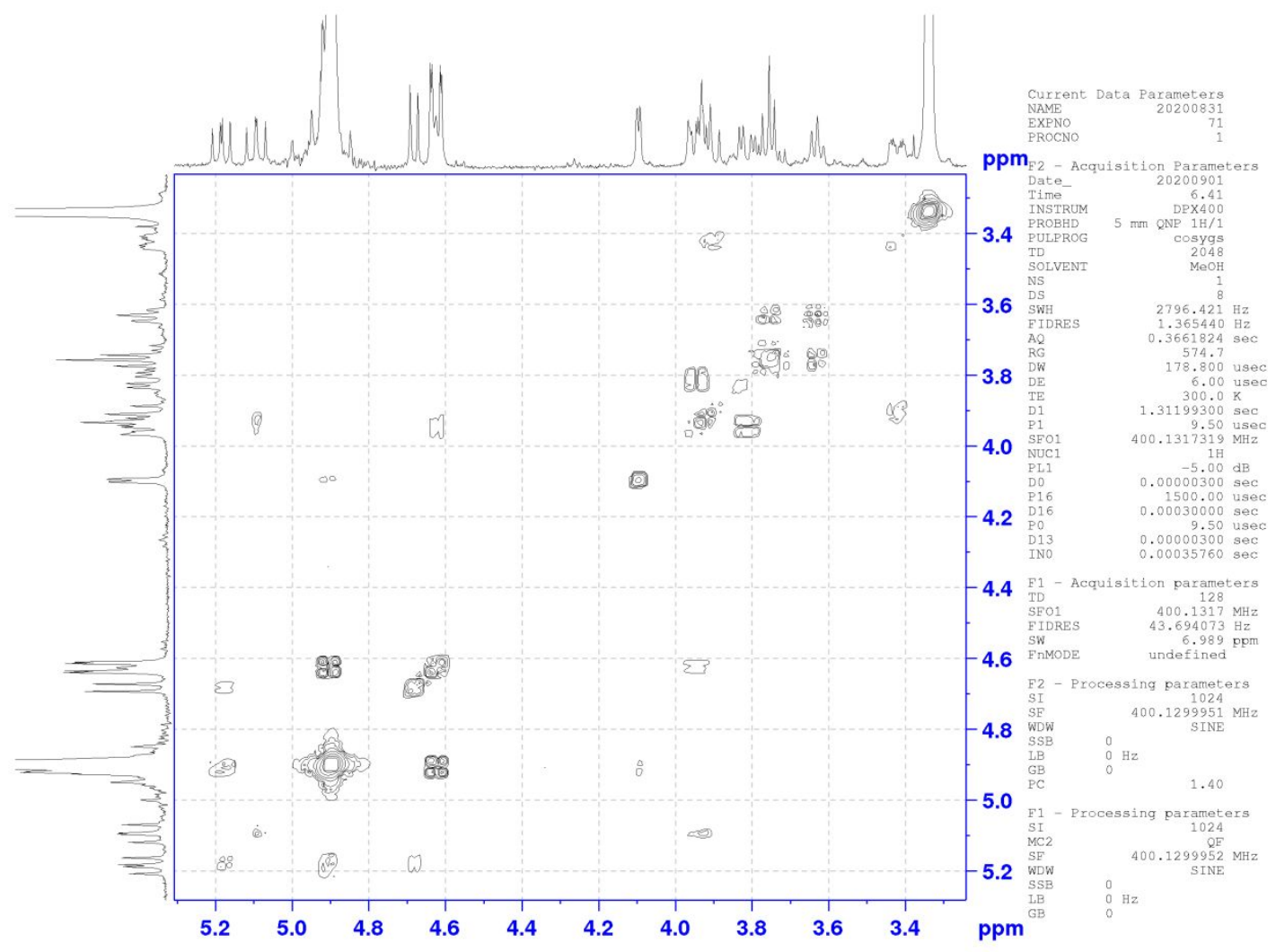

Figure S8. The magnified H-H COSY NMR spectrum of compound 14. 


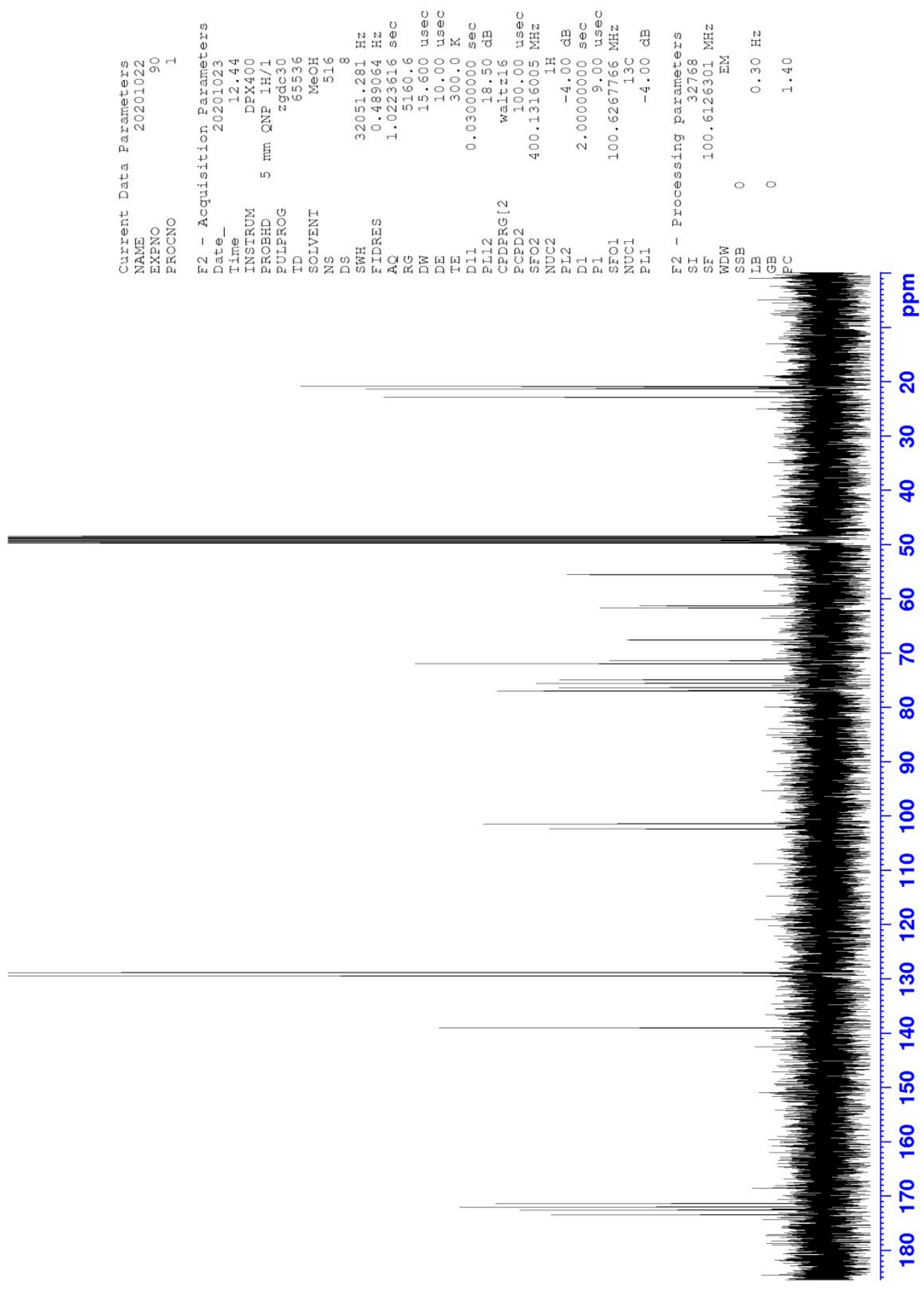

Figure S9. The ${ }^{13} \mathrm{C}$ NMR spectrum of compound 14 . 


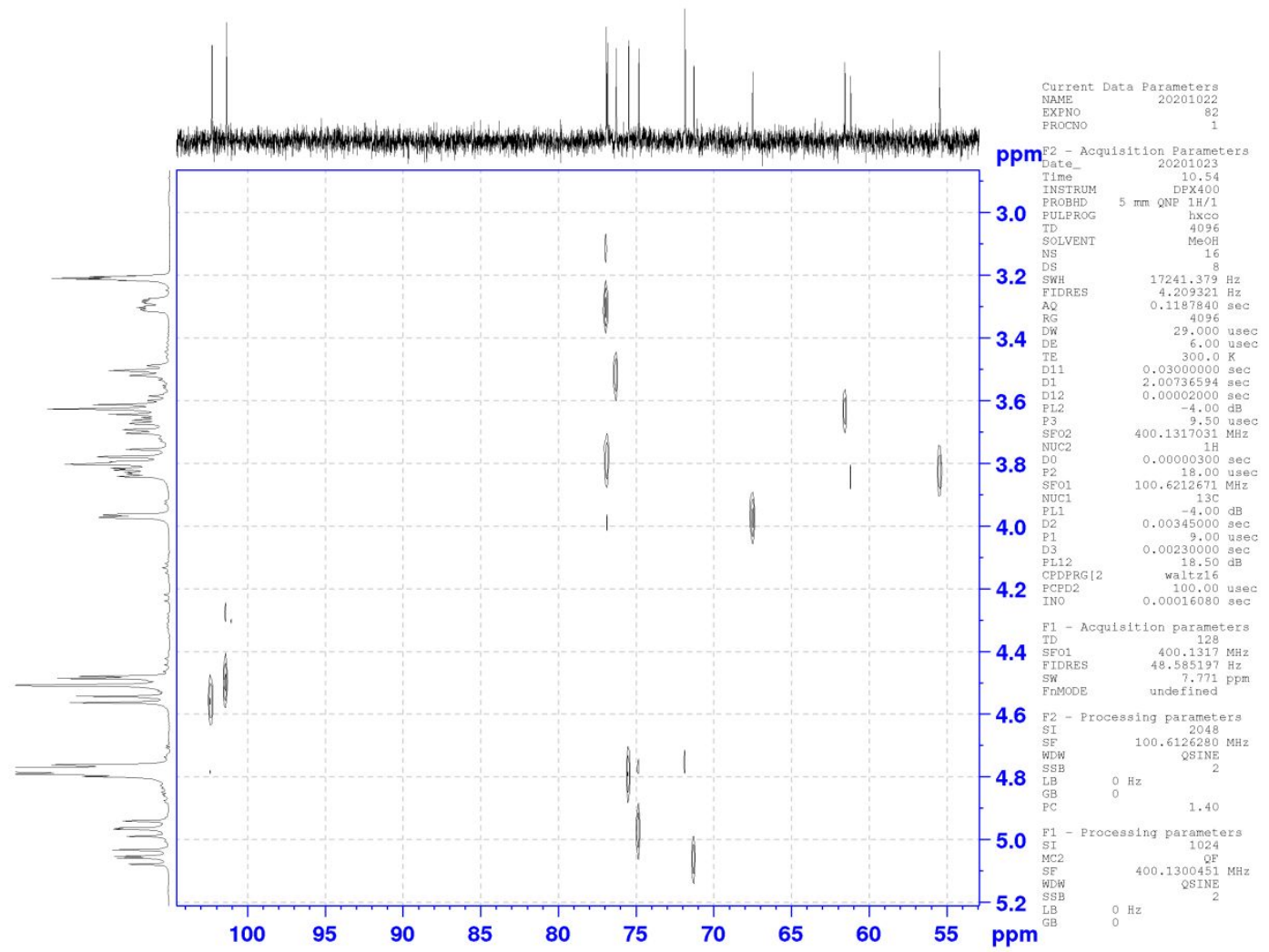

Figure S10. The magnified C-H COSY NMR spectrum of compound 14. 

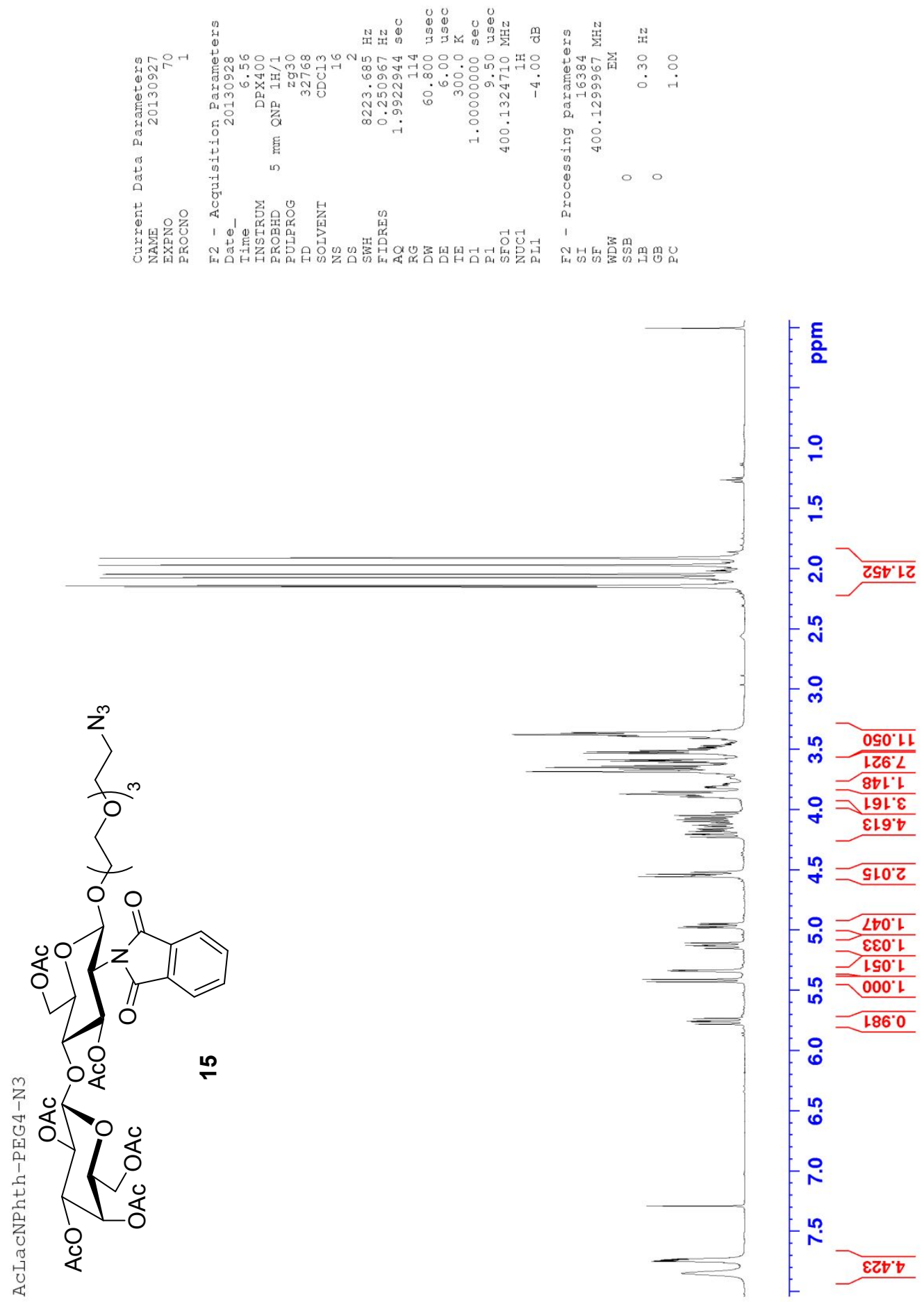

Figure S11. The ${ }^{1} \mathrm{H}$ NMR spectrum of compound $\mathbf{1 5}$. 


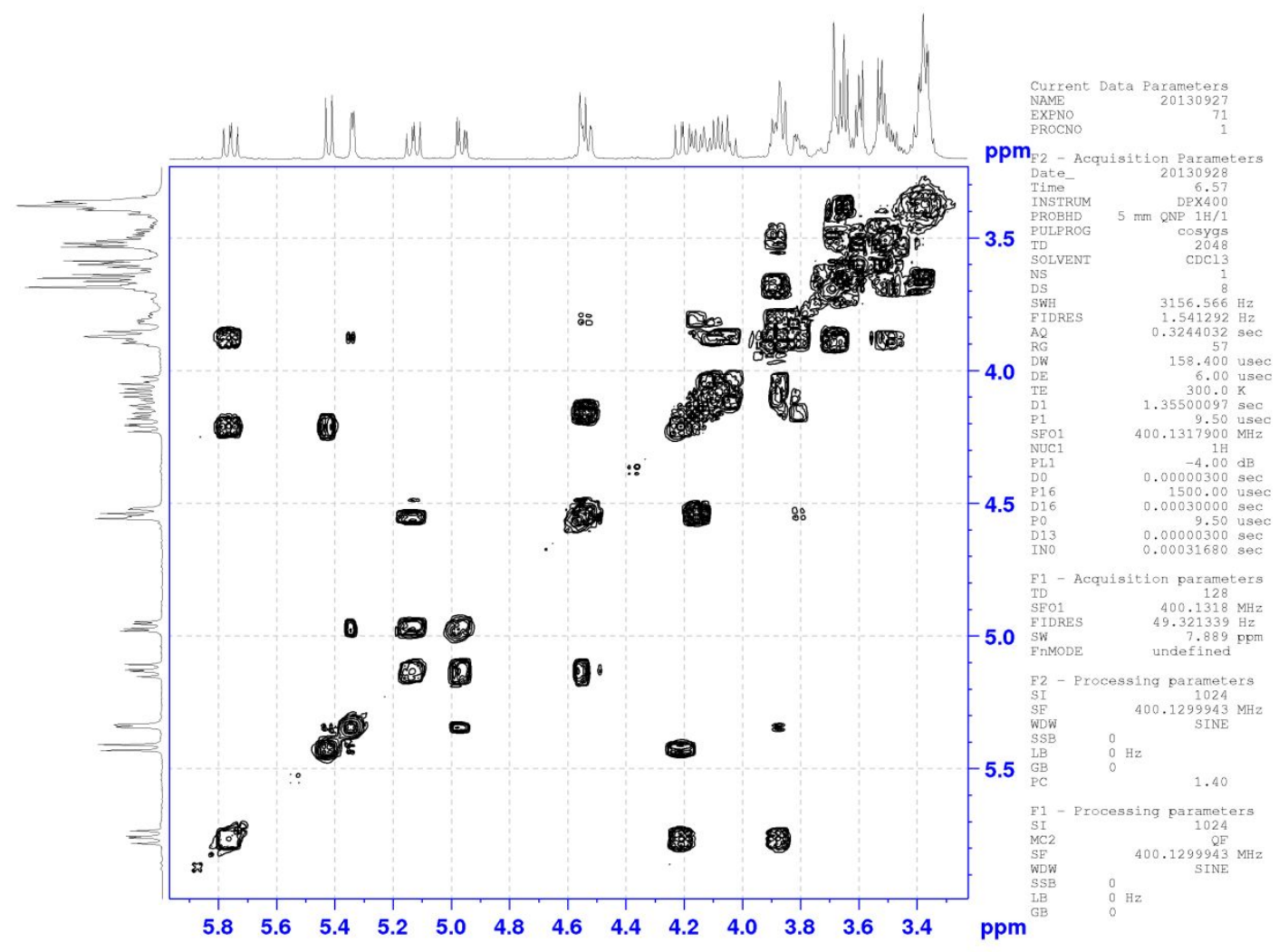

Figure S12. The magnified H-H COSY NMR spectrum of compound 15. 


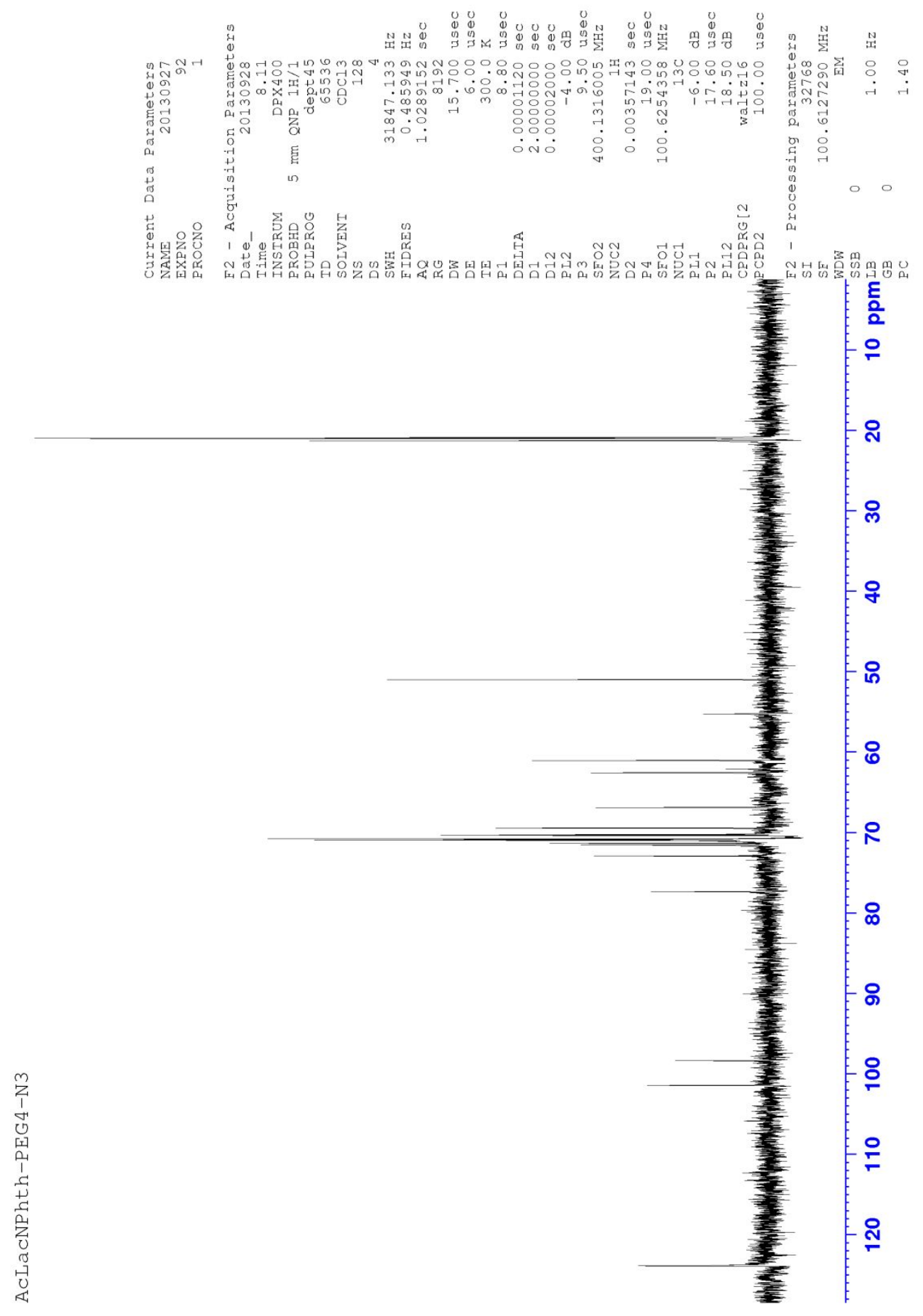

Figure S13. The ${ }^{13} \mathrm{C}$ NMR spectrum of compound 15. 


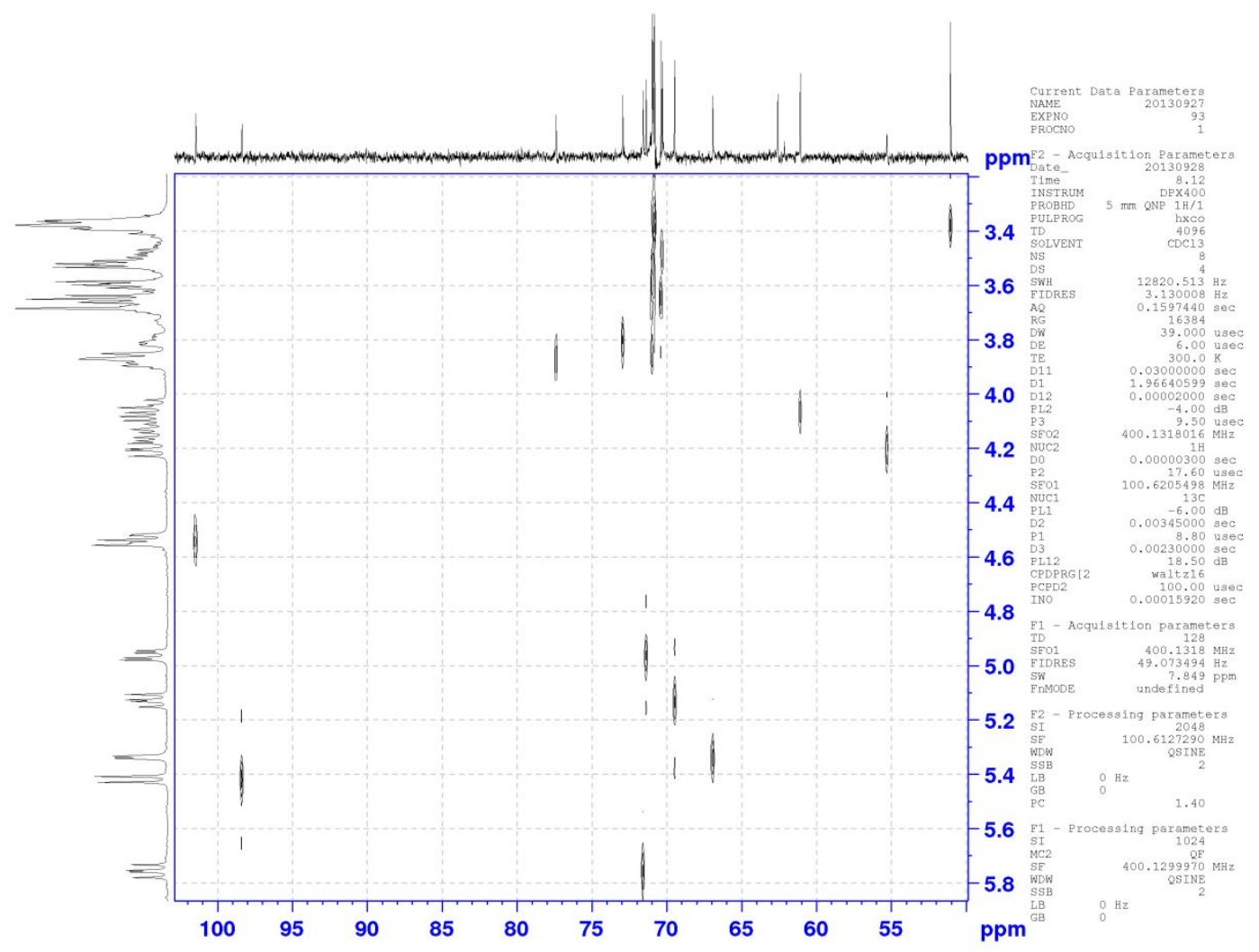

Figure S14. The magnified C-H COSY NMR spectrum of compound 15. 

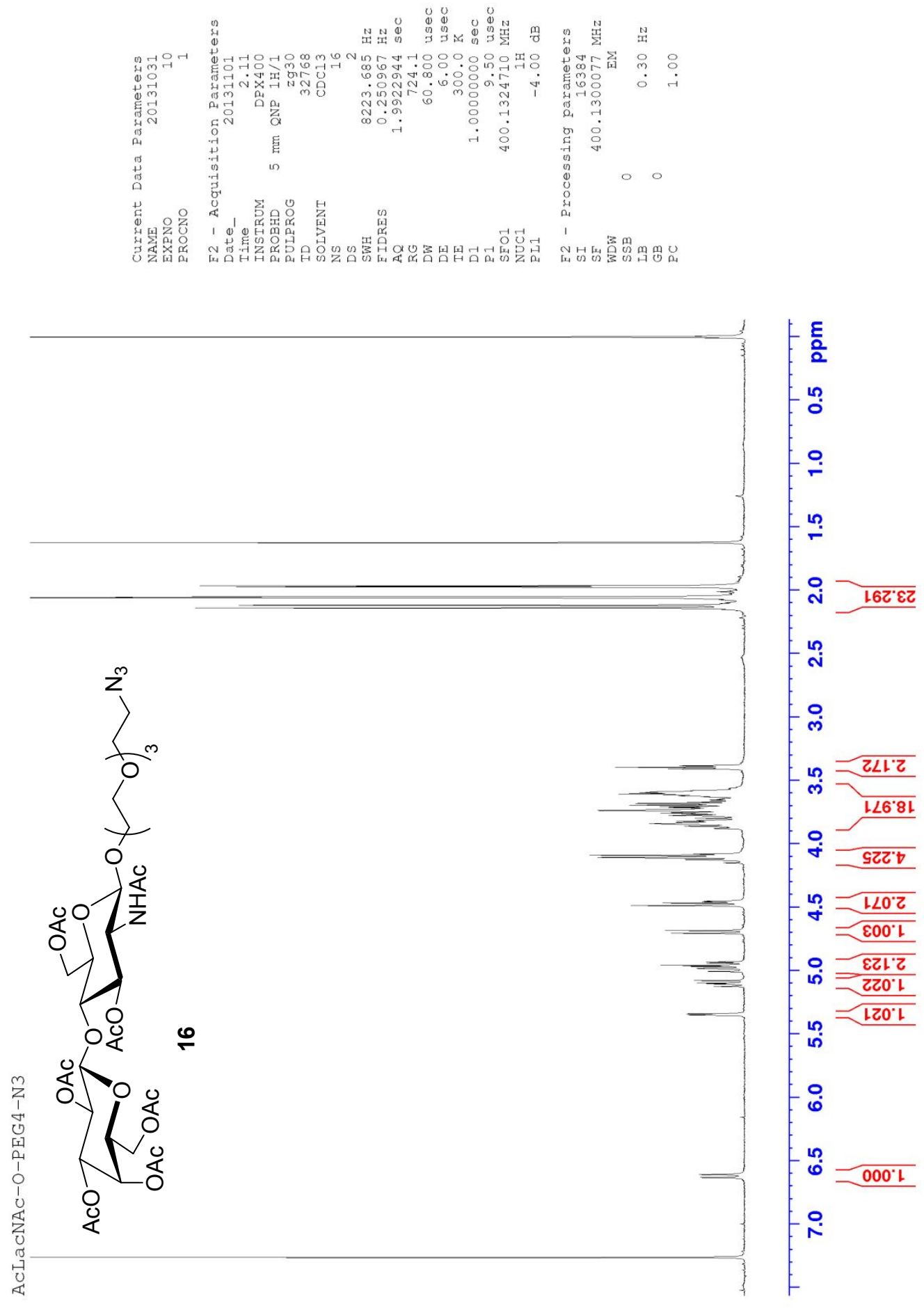

Figure S15. The ${ }^{1} \mathrm{H}$ NMR spectrum of compound $\mathbf{1 6}$. 


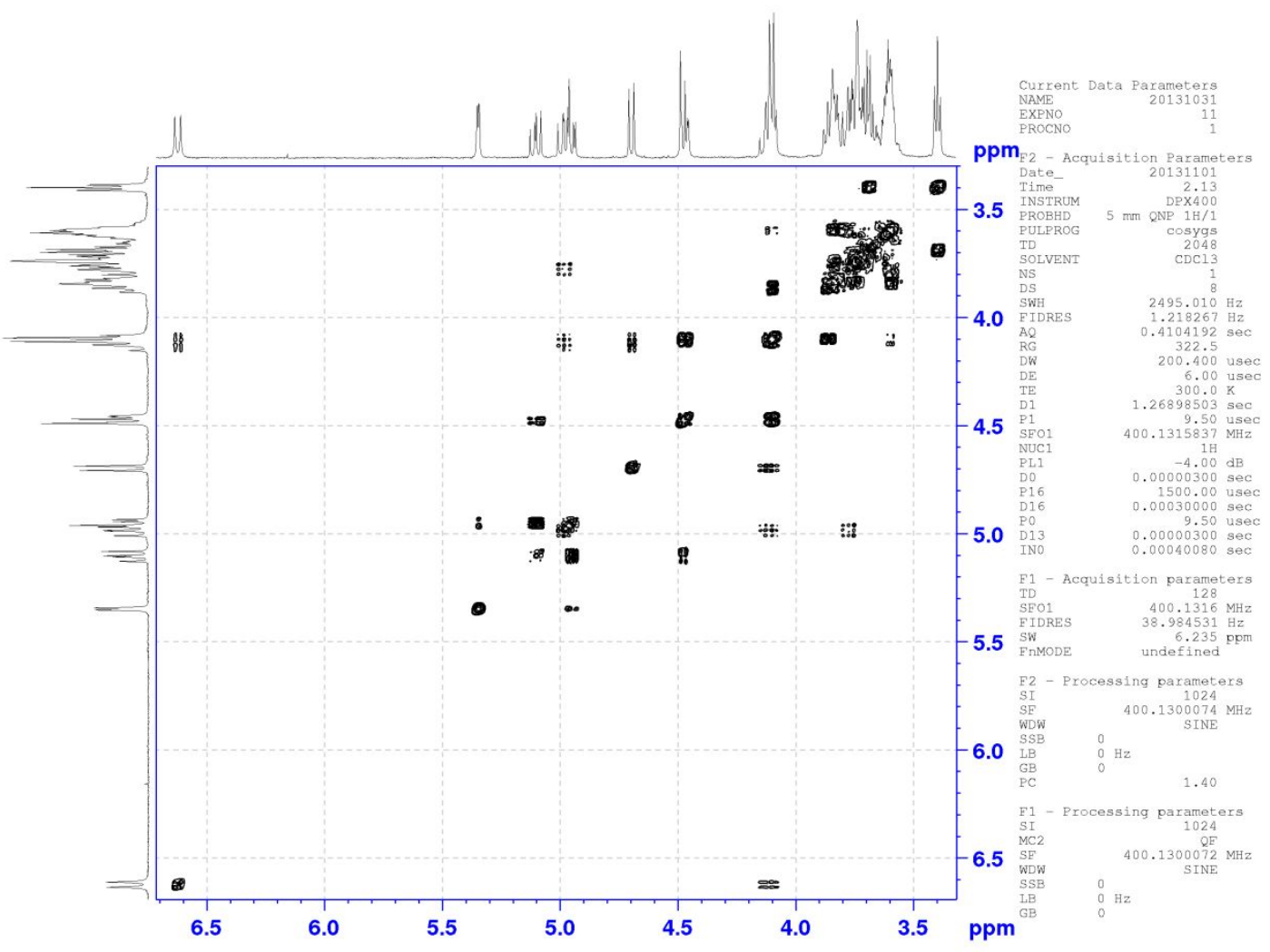

Figure S16. The magnified H-H COSY NMR spectrum of compound 16. 


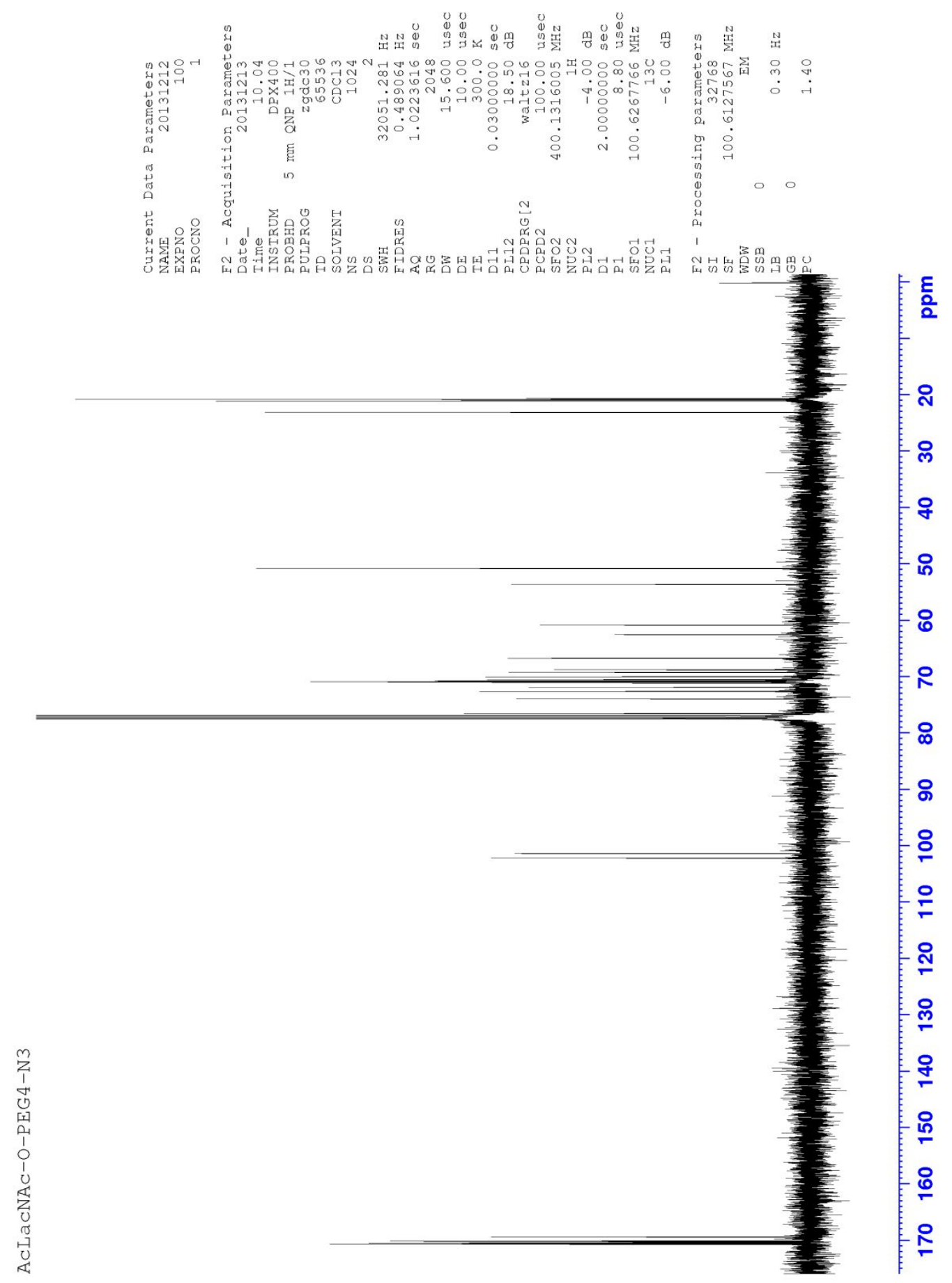

Figure S17. The ${ }^{13} \mathrm{C}$ NMR spectrum of compound $\mathbf{1 6}$. 


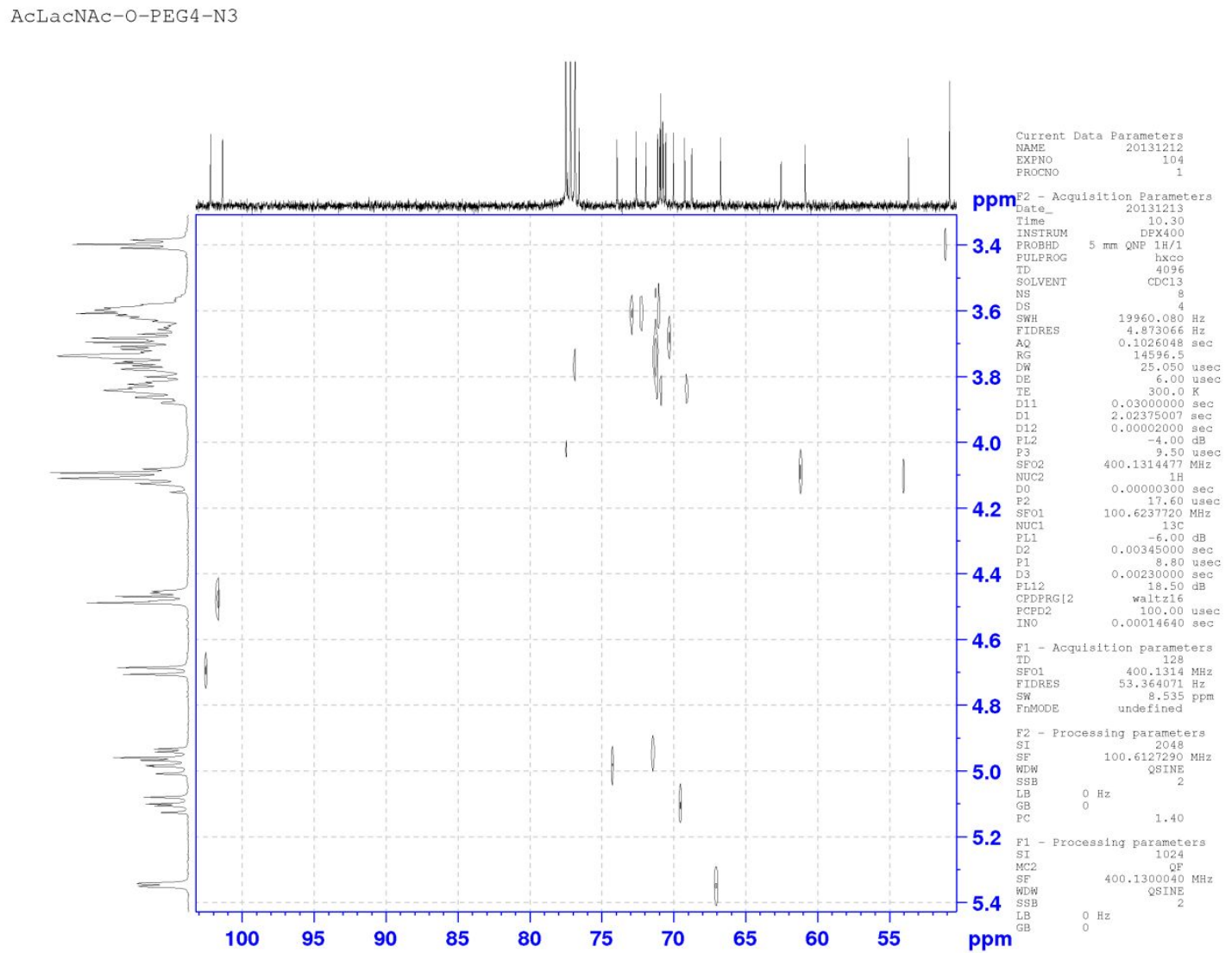

Figure S18. The magnified C-H COSY NMR spectrum of compound 16. 

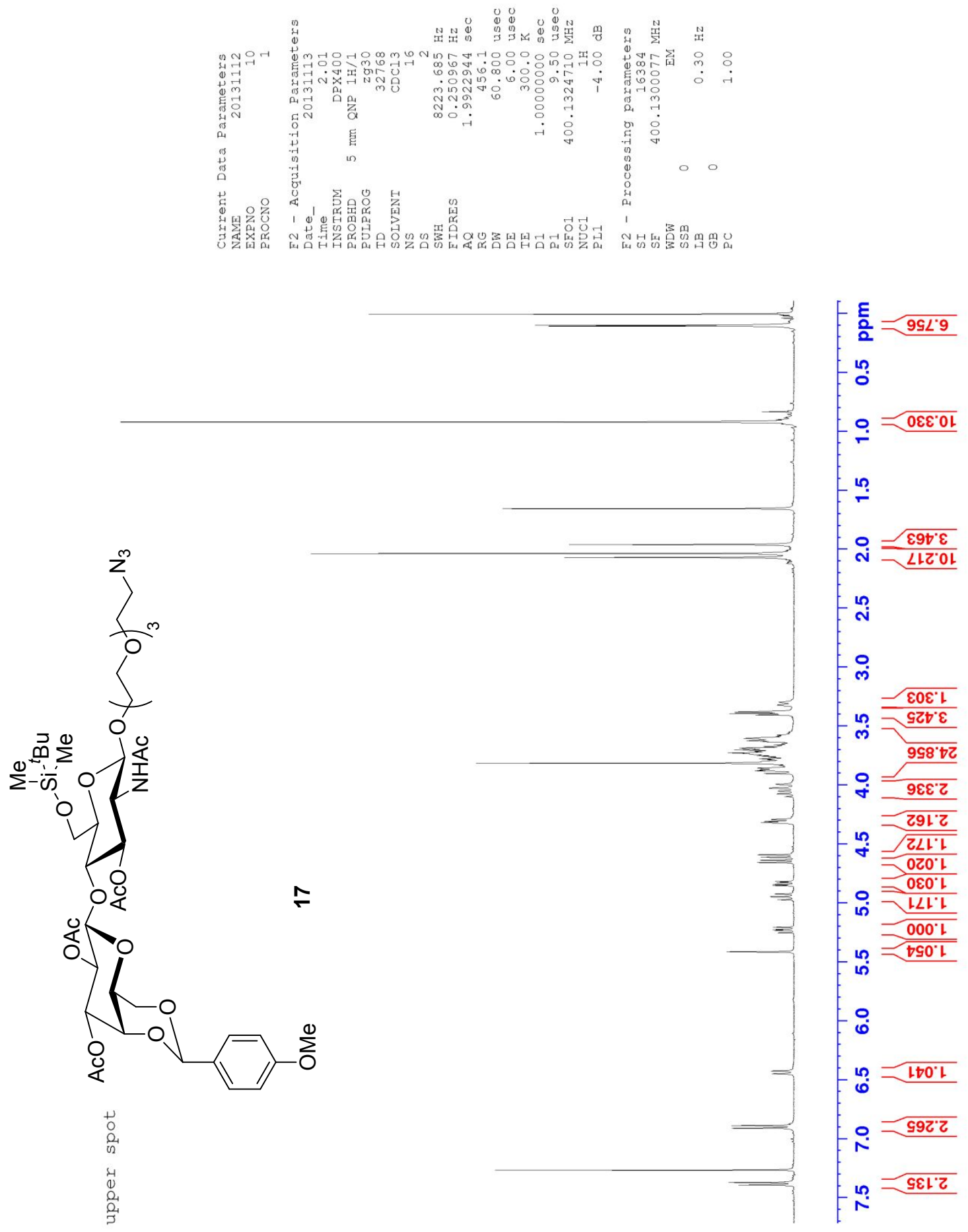

Figure S19. The ${ }^{1} \mathrm{H}$ NMR spectrum of compound 17. 


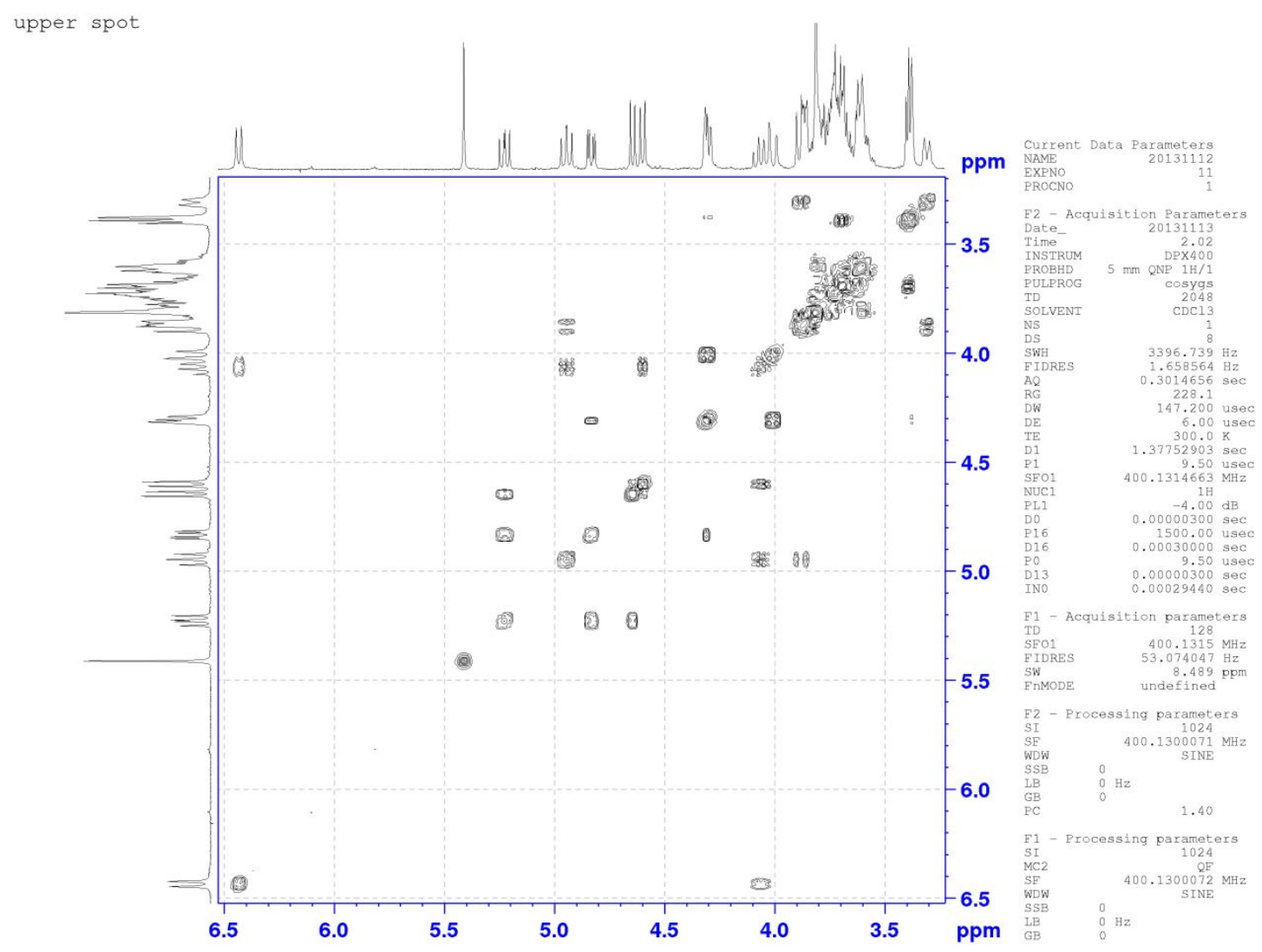

Figure S20. The magnified H-H COSY NMR spectrum of compound 17. 


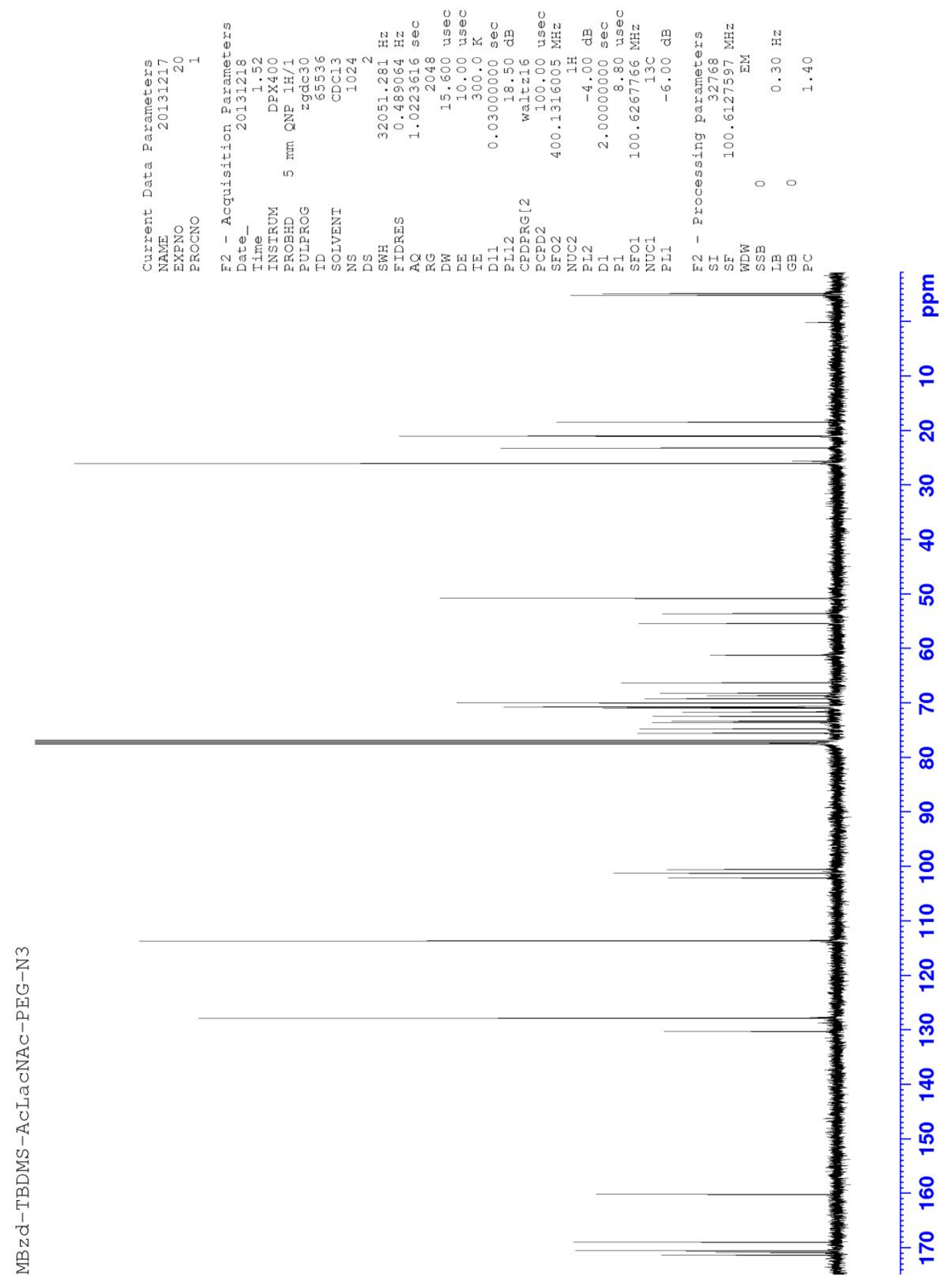

Figure S21. The ${ }^{13} \mathrm{C}$ NMR spectrum of compound 17. 


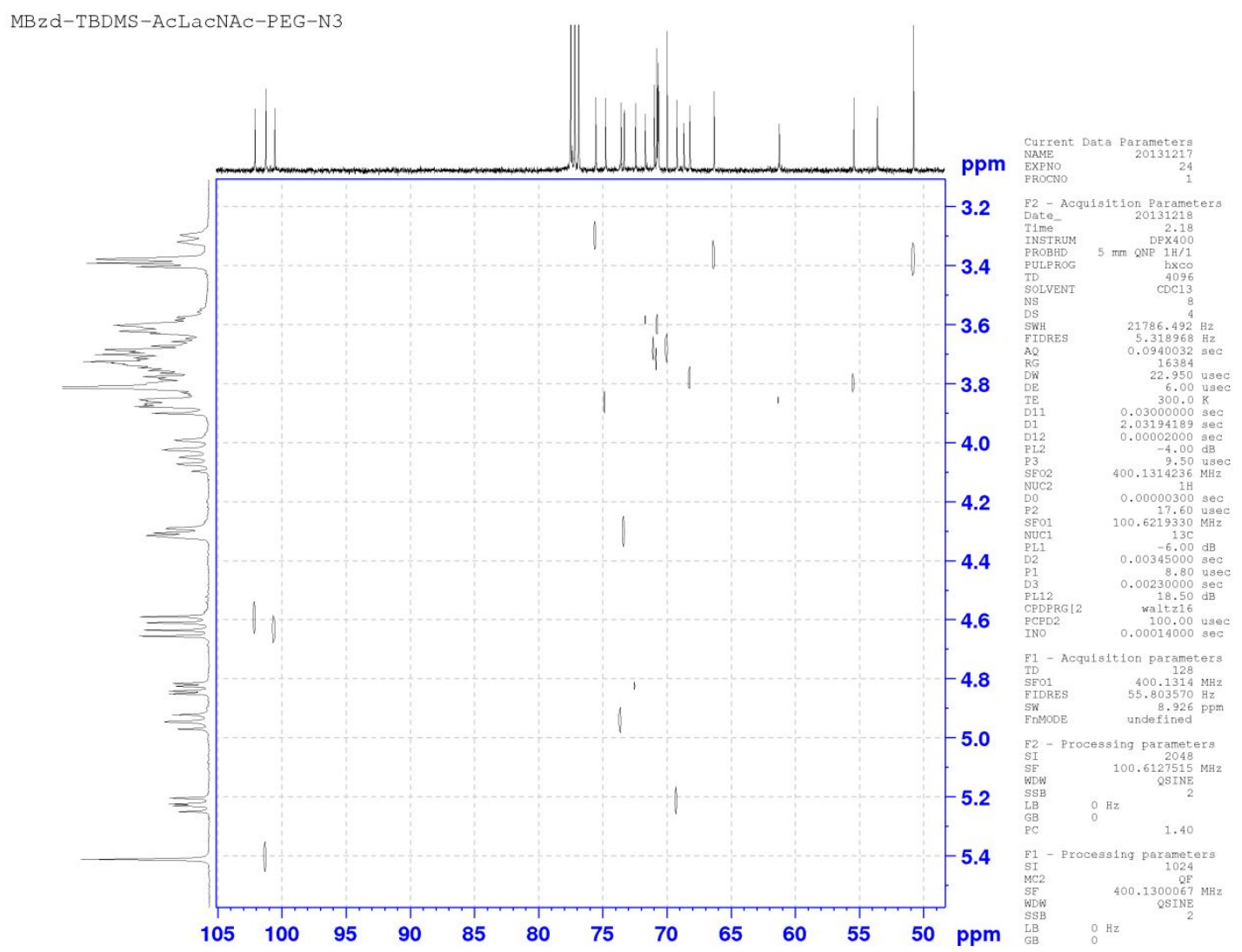

Figure S22. The magnified C-H COSY NMR spectrum of compound 17. 

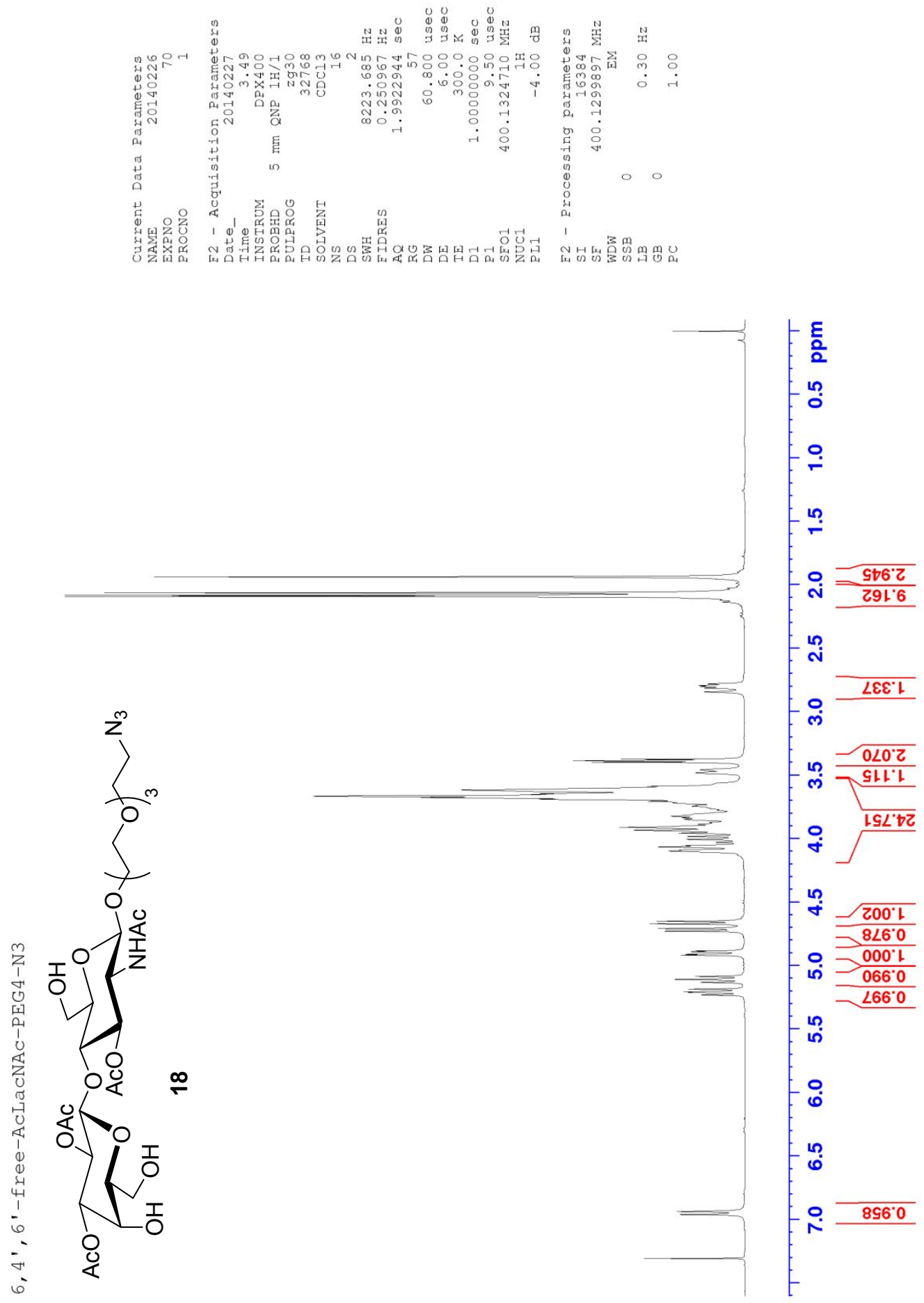

Figure S23. The ${ }^{1} \mathrm{H}$ NMR spectrum of compound 18. 


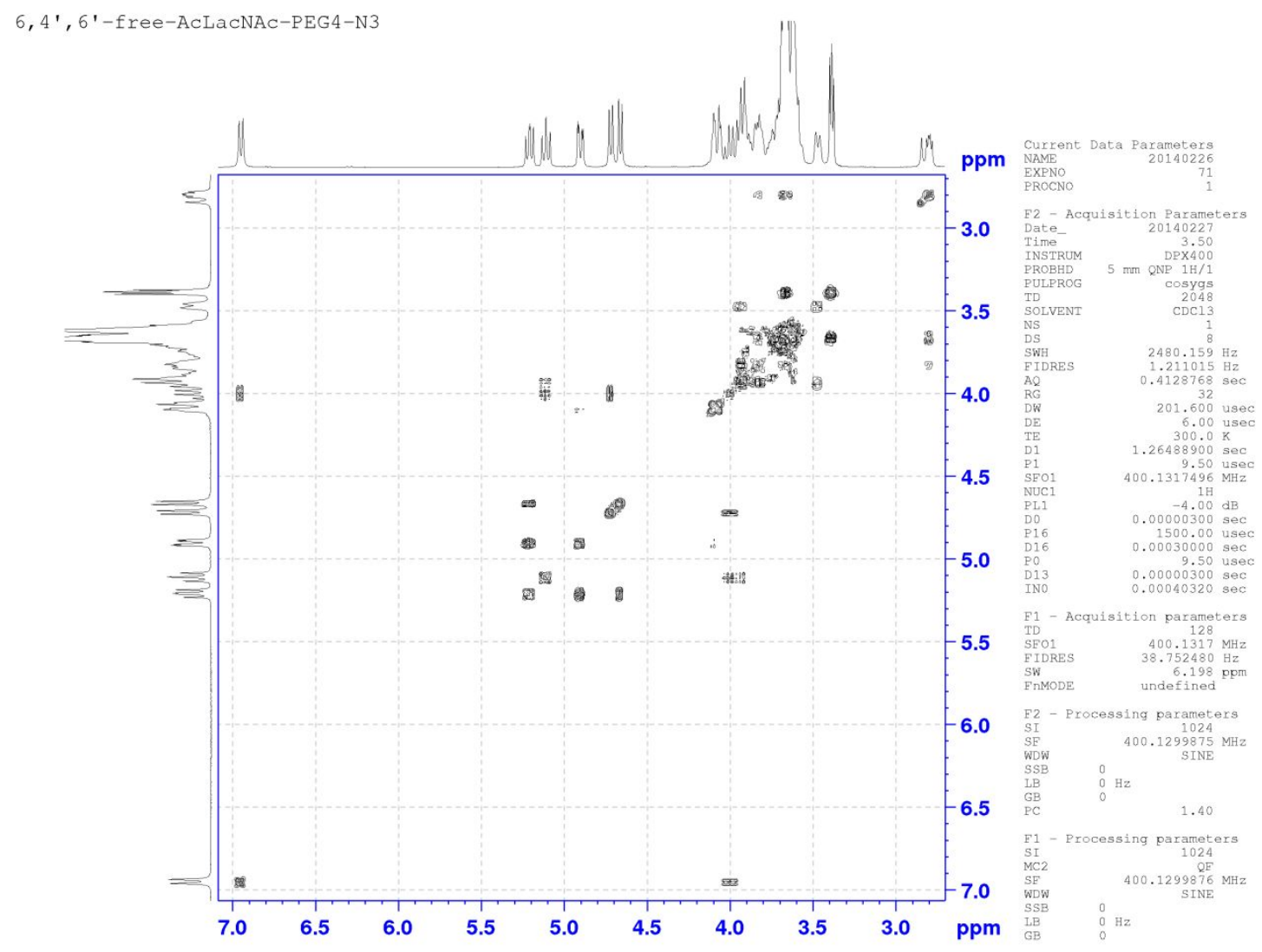

Figure S24. The magnified H-H COSY NMR spectrum of compound 18. 


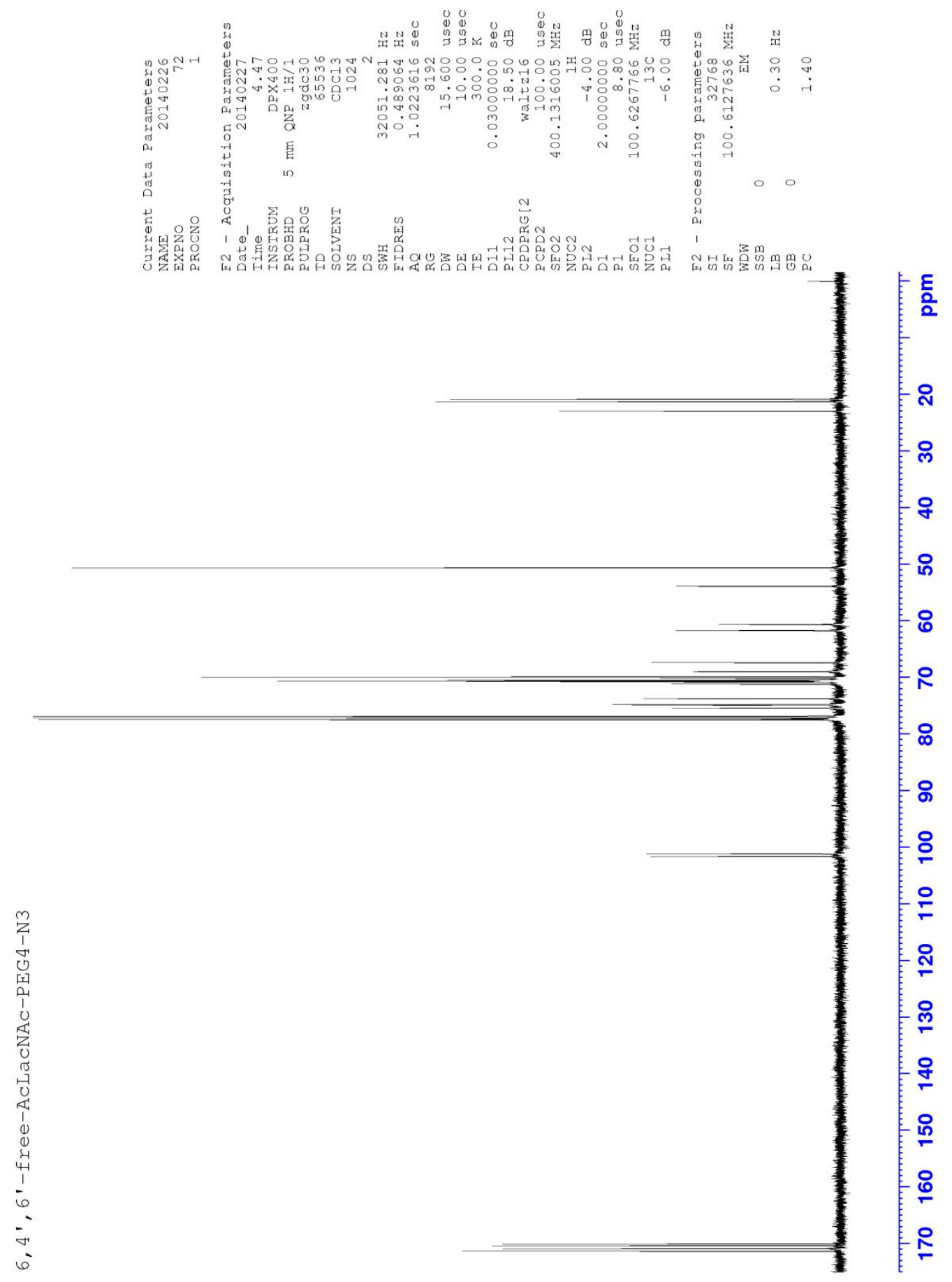

Figure S25. The ${ }^{13} \mathrm{C}$ NMR spectrum of compound $\mathbf{1 8}$. 


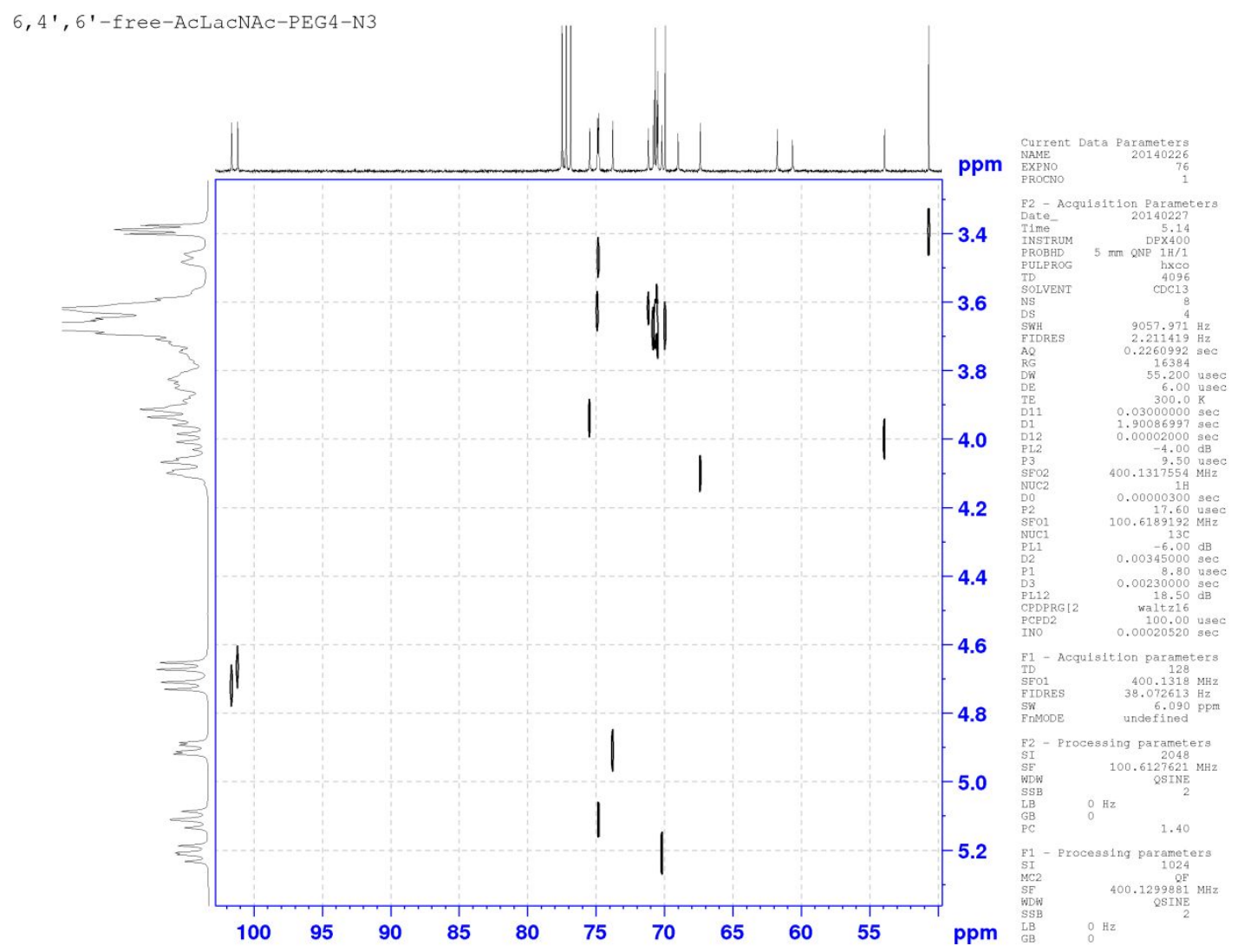

Figure S26. The magnified C-H COSY NMR spectrum of compound 18. 

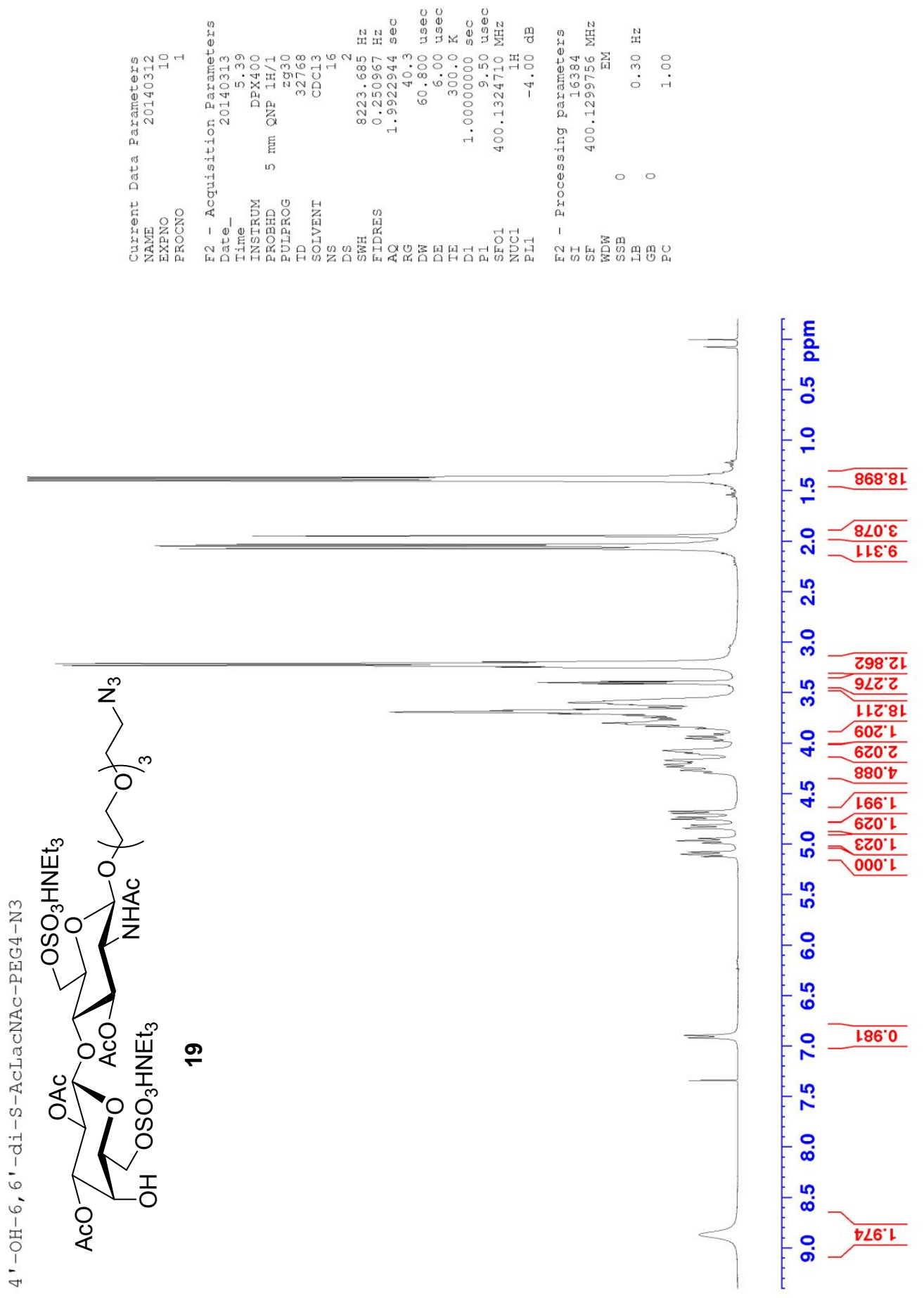

Figure S27. The ${ }^{1} \mathrm{H}$ NMR spectrum of compound 19. 


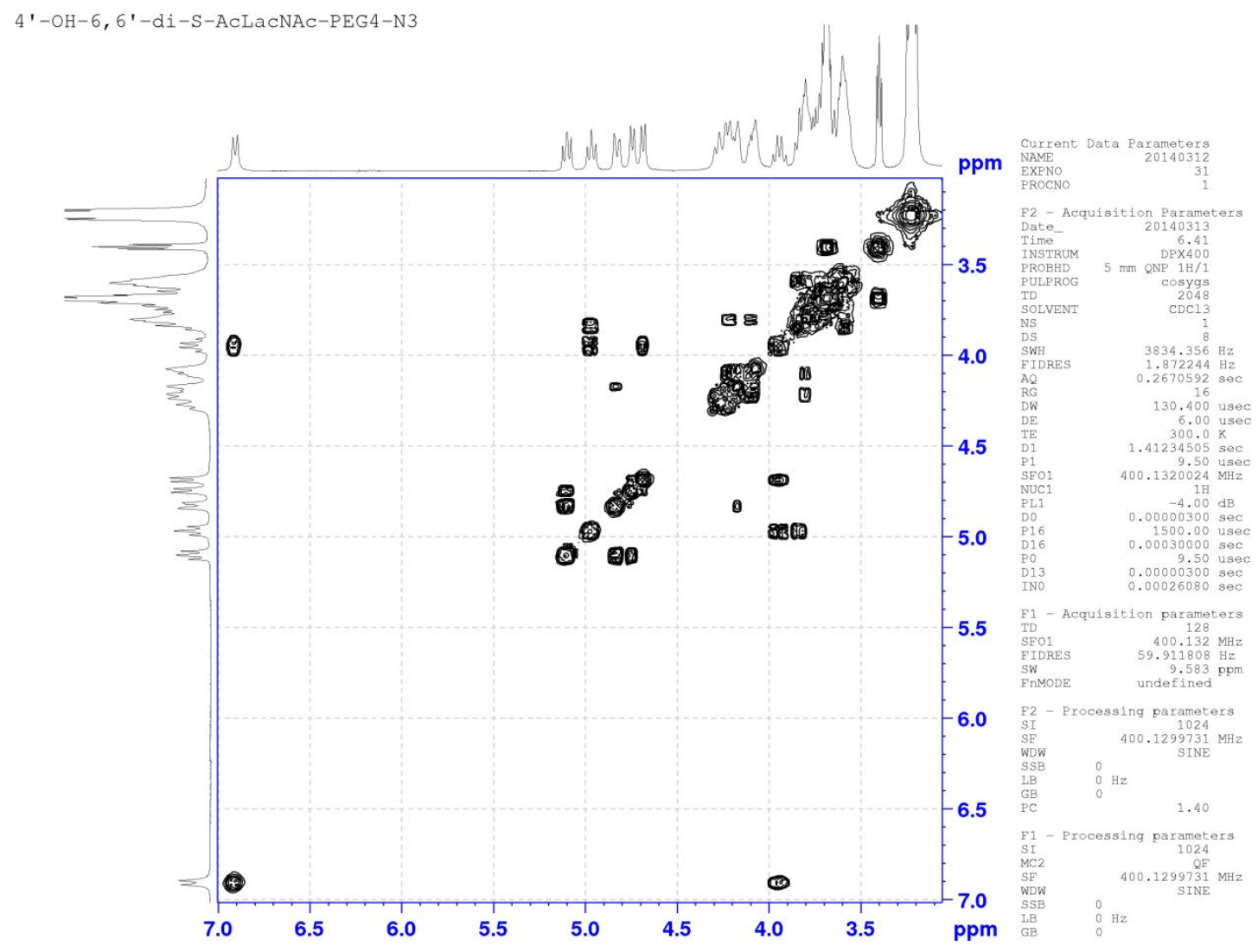

Figure S28. The magnified H-H COSY NMR spectrum of compound 19. 


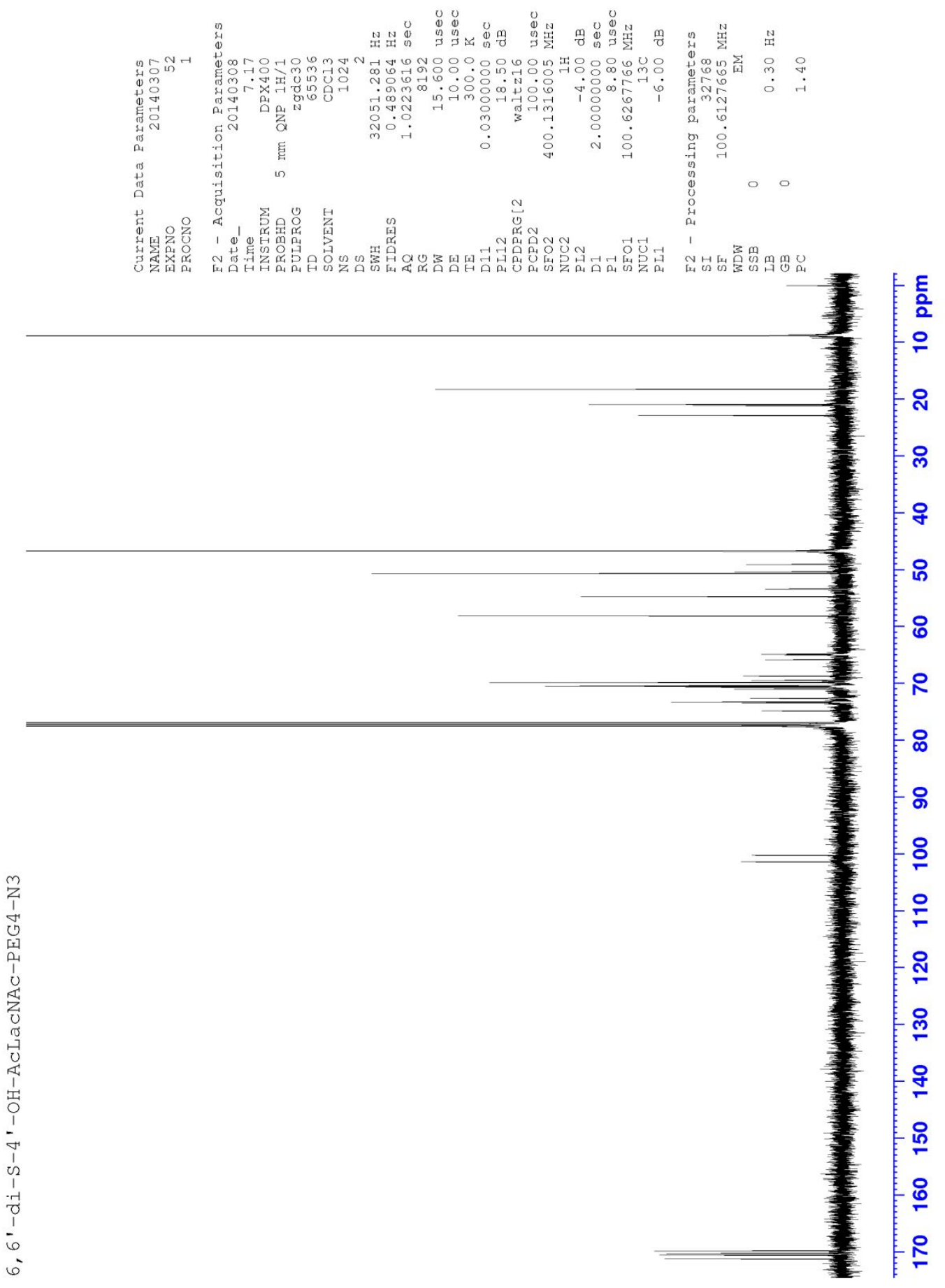

Figure S29. The ${ }^{13} \mathrm{C}$ NMR spectrum of compound 19. 


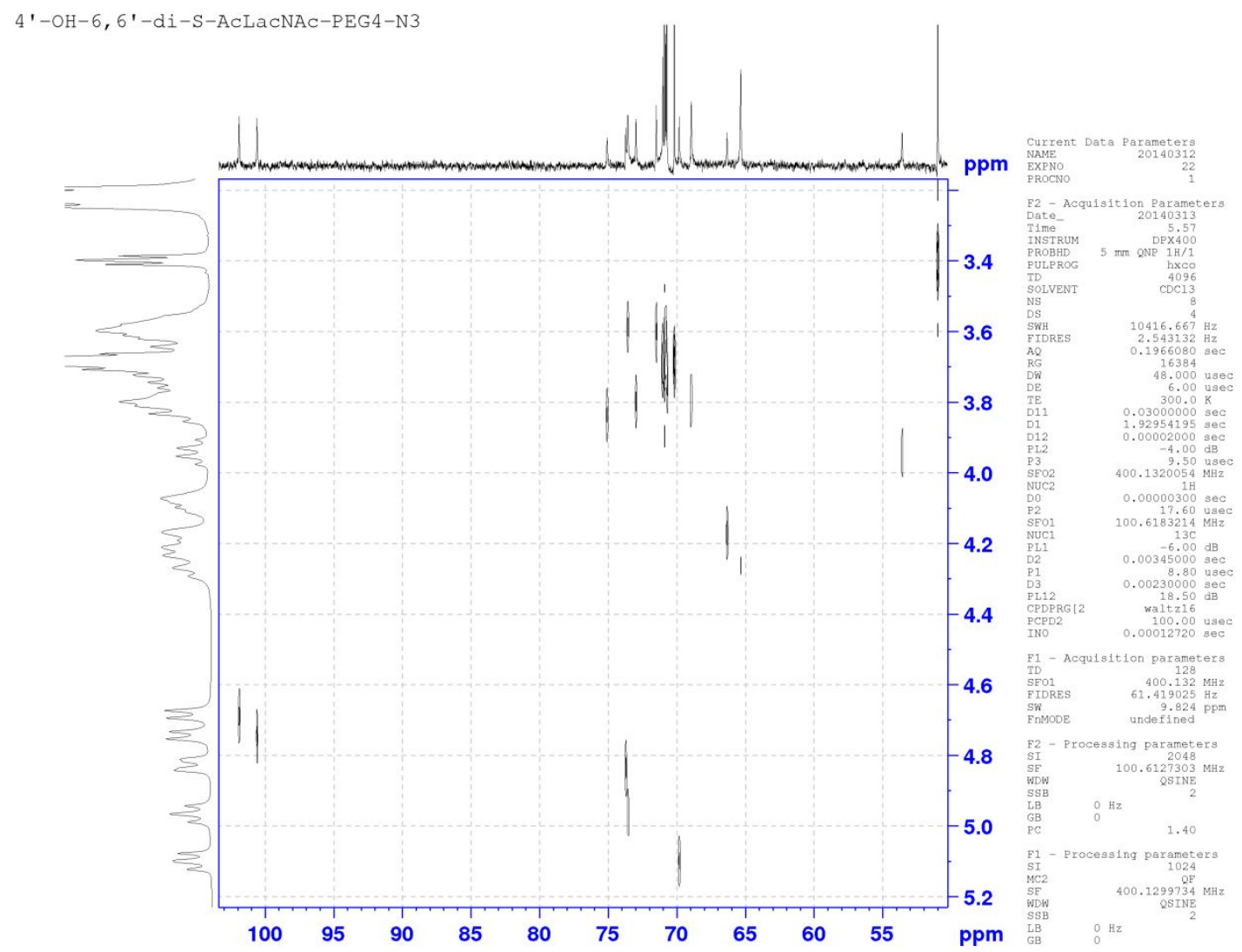

Figure S30. The magnified C-H COSY NMR spectrum of compound 19. 

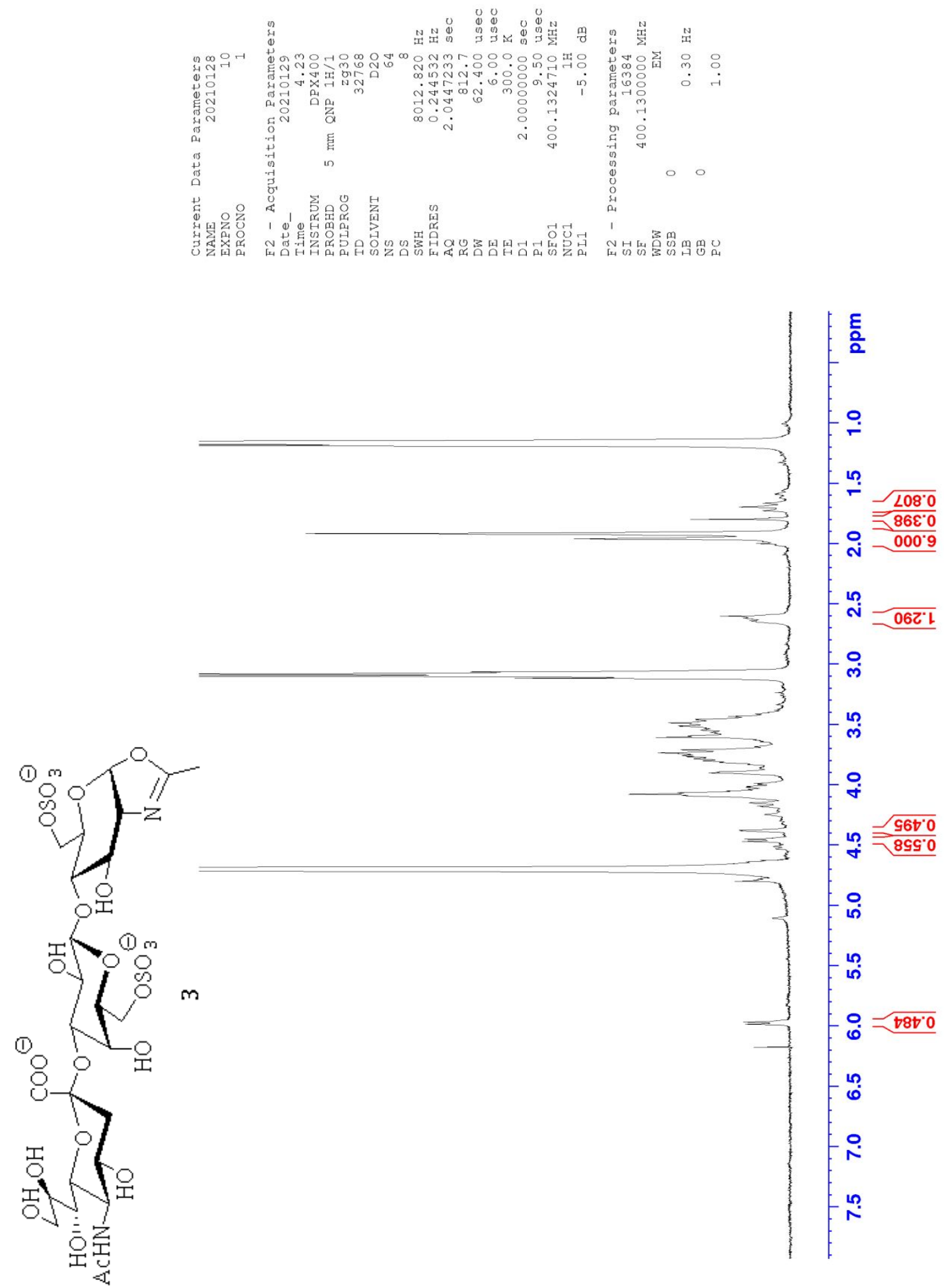

Figure S31. The ${ }^{1} \mathrm{H}$ NMR spectrum of the mixture containing the oxazoline donor 3 . 


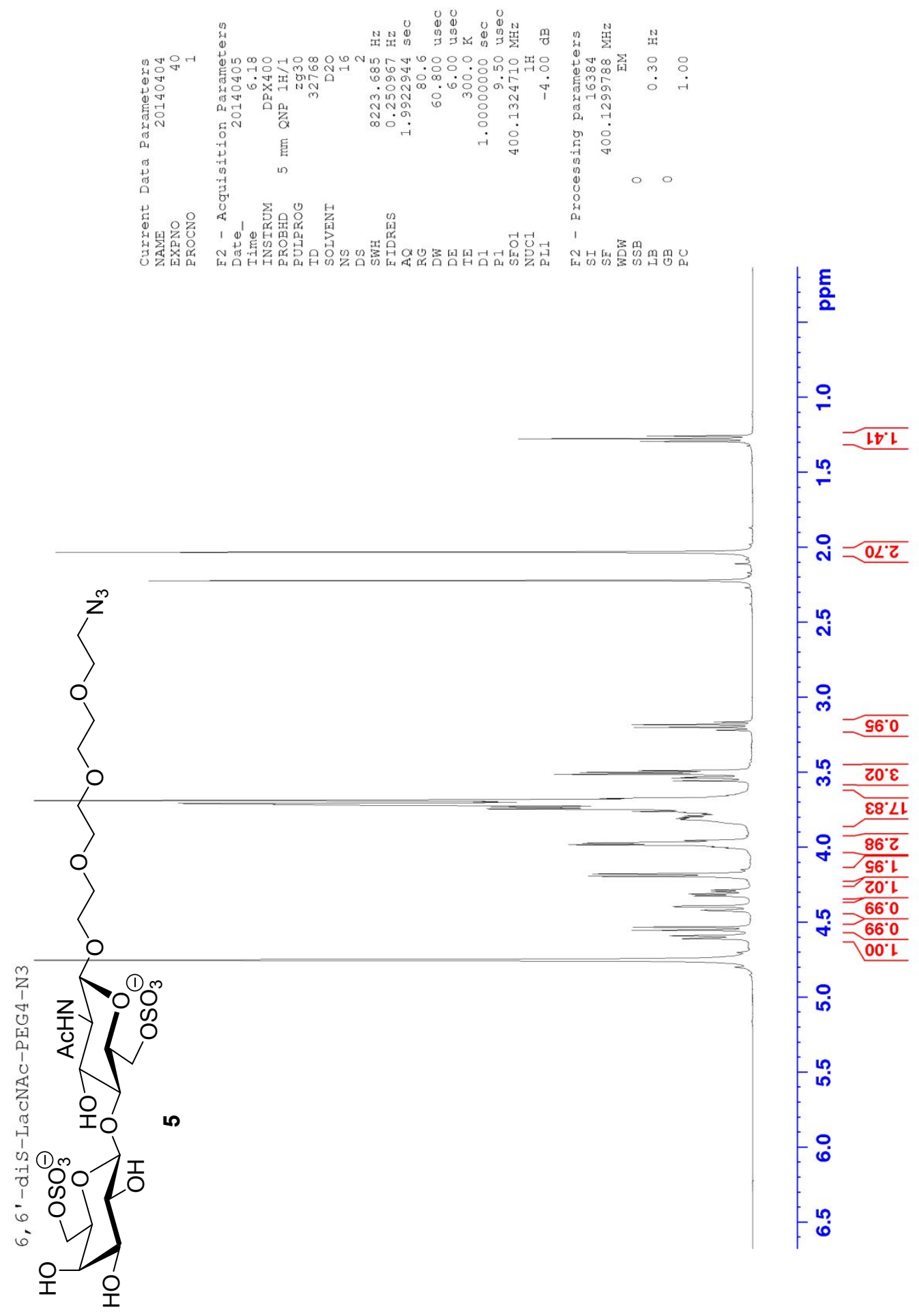

Figure S32. The ${ }^{1} \mathrm{H}$ NMR spectrum of compound 5 (acetone at $2.22 \mathrm{ppm}$ as the internal standard). 


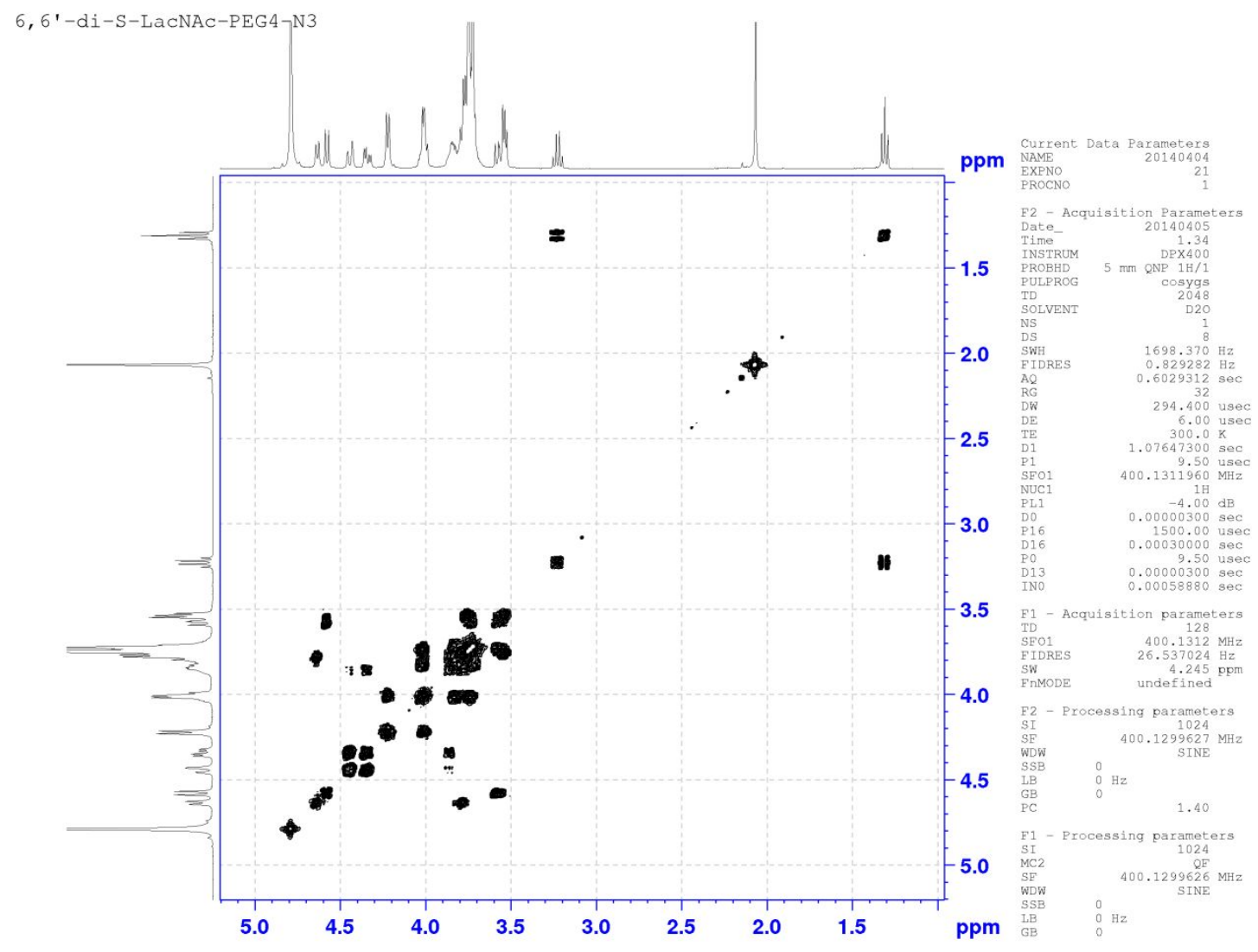

Figure S33. The H-H COSY NMR spectrum of compound 5. 

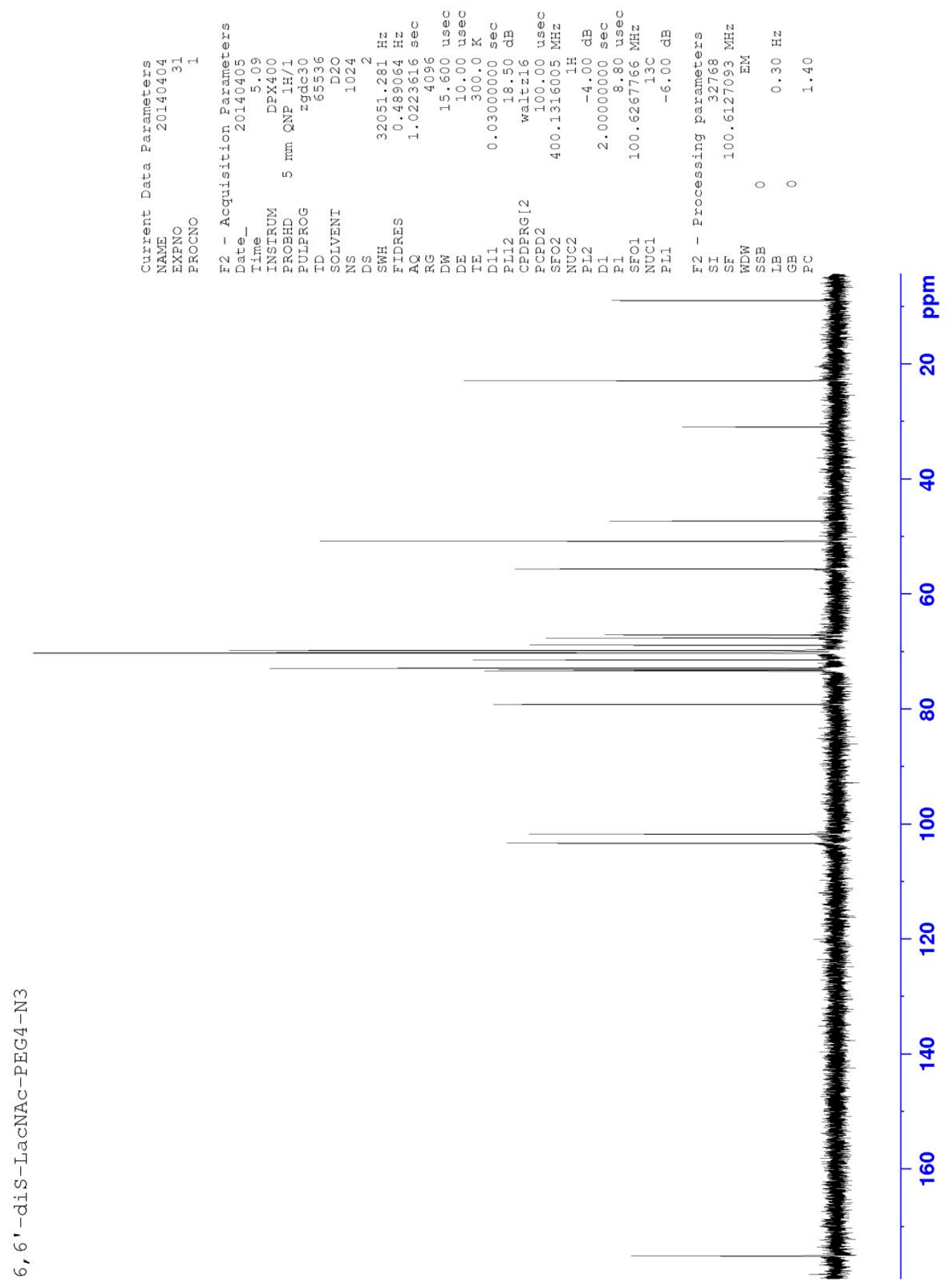

Figure S34. The ${ }^{13} \mathrm{C}$ NMR spectrum of compound $\mathbf{5}$. 


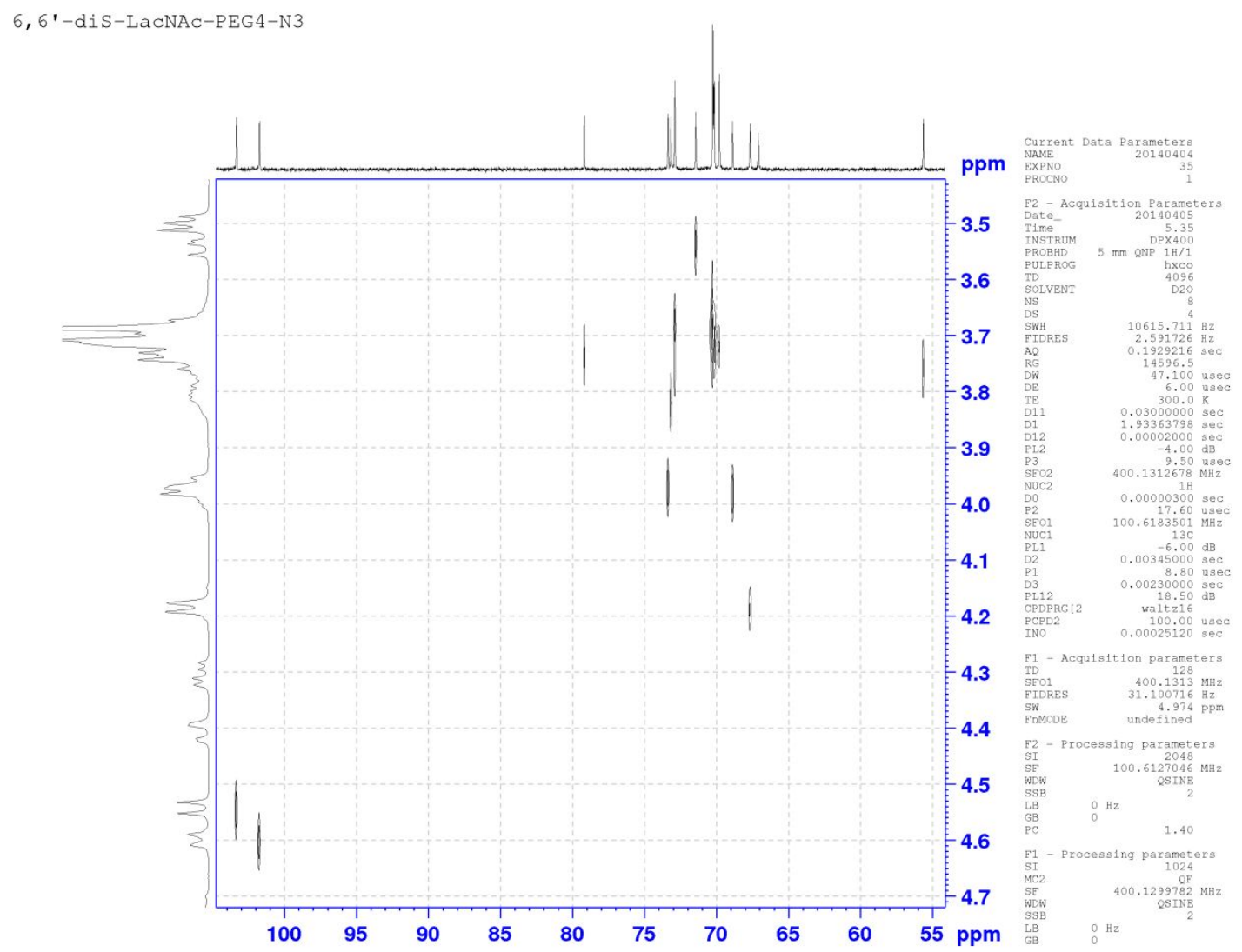

Figure S35. The magnified C-H COSY NMR spectrum of compound 5. 

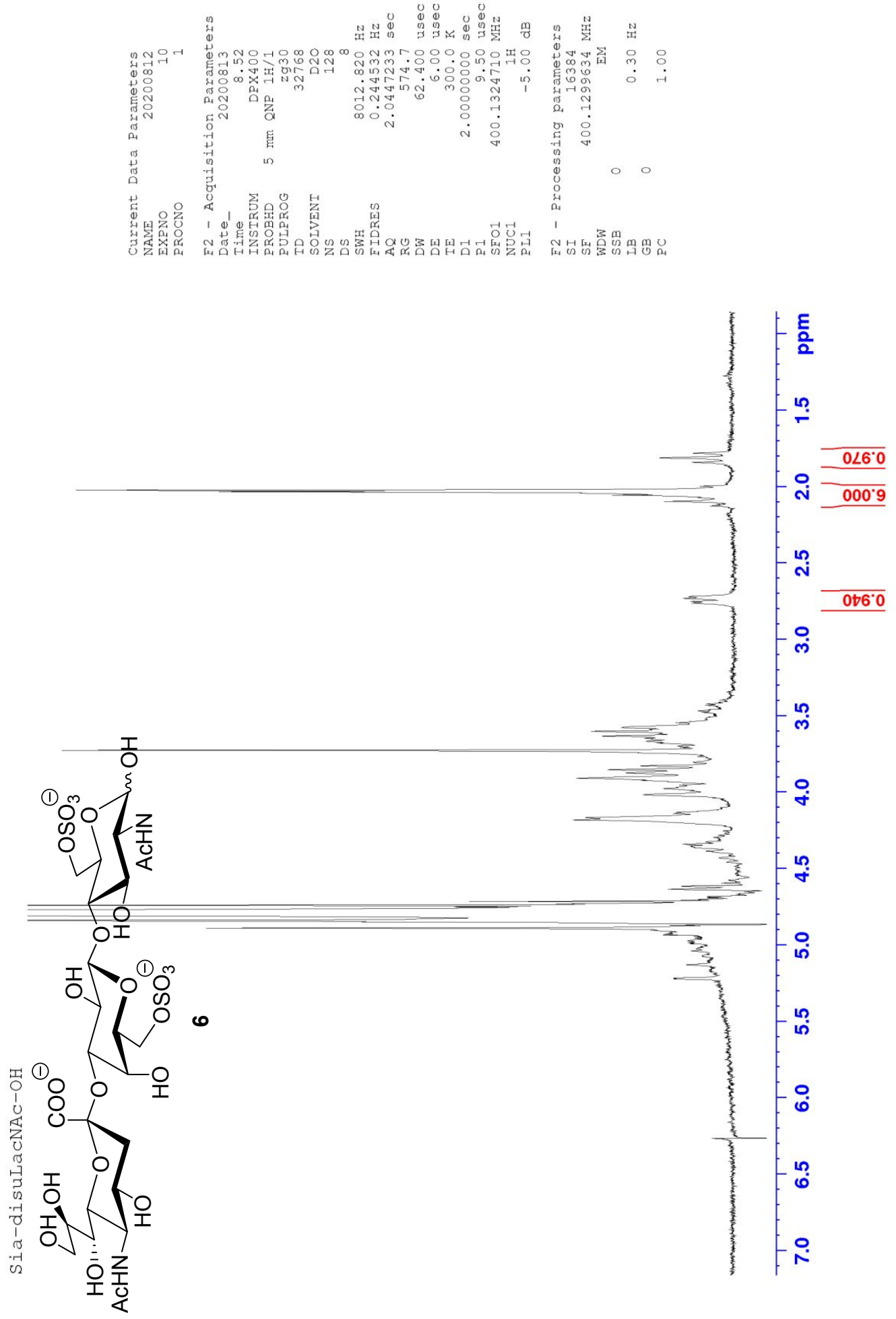

Figure S36. The ${ }^{1} \mathrm{H}$ NMR spectrum of compound $\mathbf{6}$. 


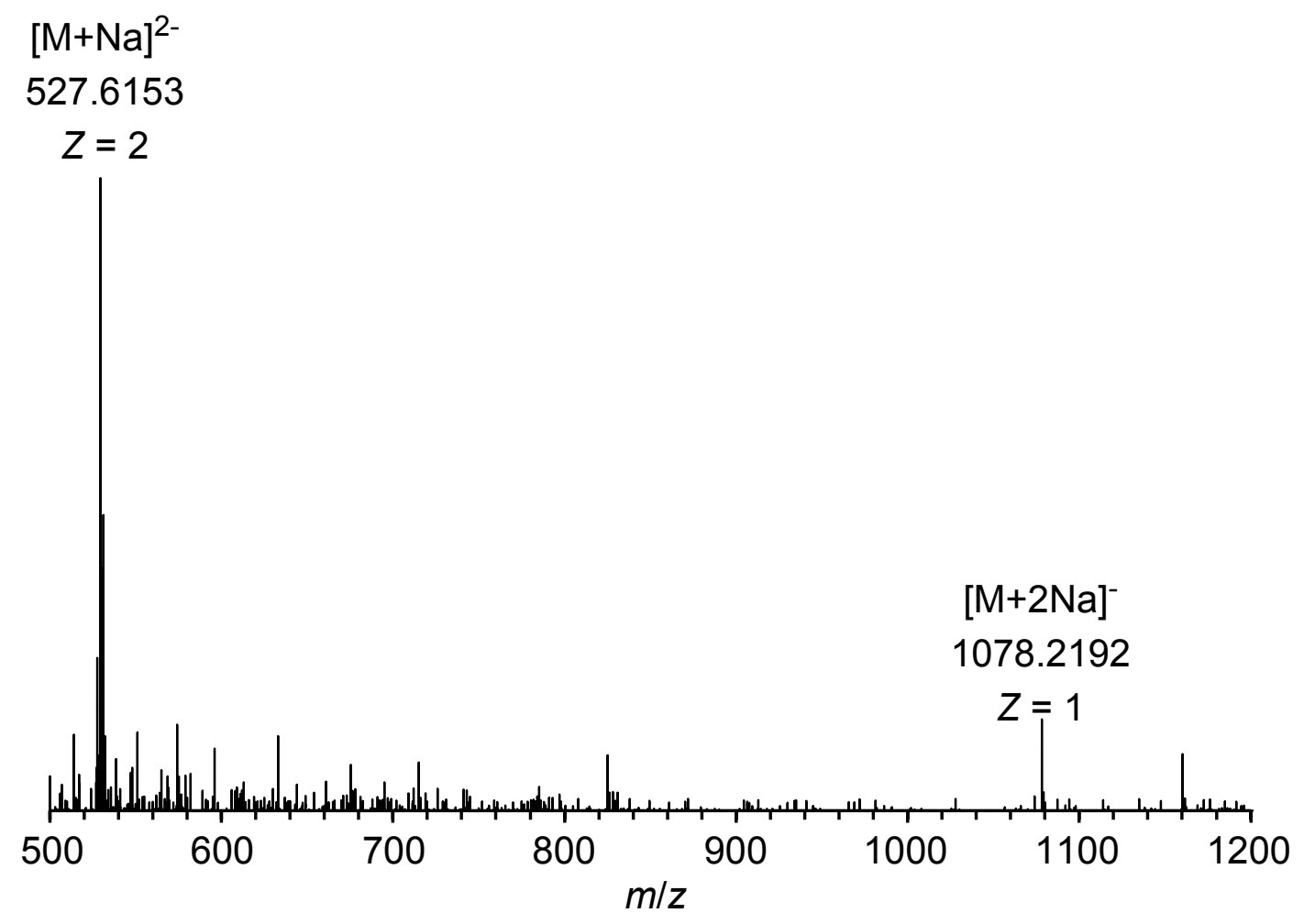

Figure S37. The high resolution ESI mass spectrum of 21 under negative ion mode. 